Supporting Information for

\title{
Imaging and profiling of proteins under oxidative conditions in cells and tissues by hydrogen-peroxide-responsive labeling
}

Hao Zhu, ${ }^{1}$ Tomonori Tamura, ${ }^{1}$ Alma Fujisawa, ${ }^{1}$ Yuki Nishikawa,,${ }^{1}$ Rong Cheng,,${ }^{1}$ Mikiko Takato, ${ }^{1}$ and Itaru Hamachi*1,2

${ }^{1}$ Department of Synthetic Chemistry and Biological Chemistry, Graduate School of Engineering, Kyoto University, Katsura, Nishikyo-ku, Kyoto 615-8510, Japan

${ }^{2}$ ERATO, Japan Science and Technology Agency (JST), 5 Sanbancho, Chiyoda-ku, Tokyo 1020075, Japan

Correspondence should be addressed to I.H. (ihamachi@sbchem.kyoto-u.ac.jp) 


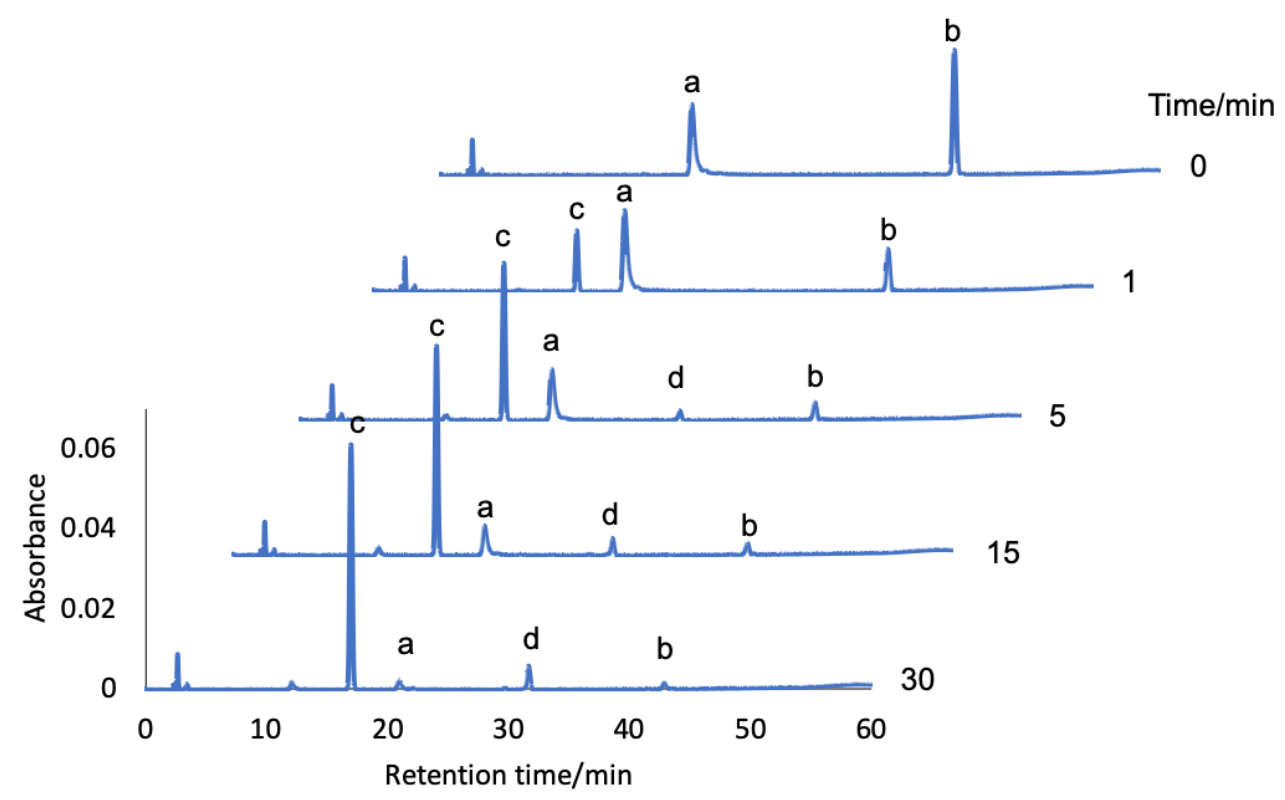

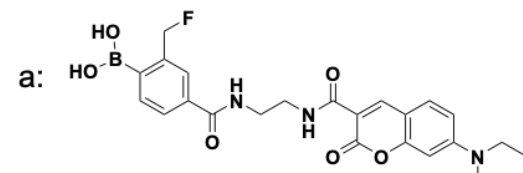

BA form of Hyp-L-1

$[\mathrm{M}+\mathrm{H}]^{+}: 484.536$ cal. 484.206

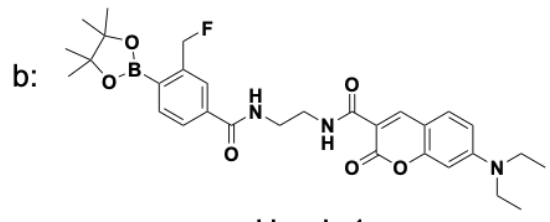

Hyp-L-1

$[\mathrm{M}+\mathrm{H}]^{+}: 566.705$ cal. 566.284

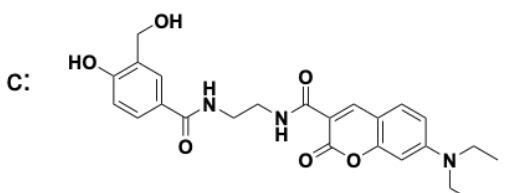

Hydrolyzed QM

$[\mathrm{M}+\mathrm{H}]^{+}: 454.548$ cal. 454.198

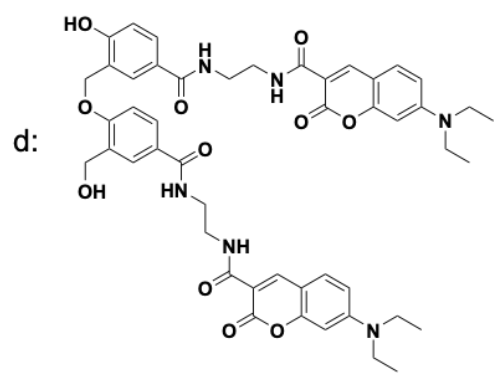

Dimer of hydrolyzed QM

$[\mathrm{M}+\mathrm{Na}]^{+}: 912.012$ cal. 911.359

Supplementary Fig. 1 Time course of hydrolysis in the presence of $\mathbf{H}_{2} \mathbf{O}_{2} .50 \mu \mathrm{M}$ of Hyp-L-1 was incubated with $500 \mu \mathrm{M}$ of $\mathrm{H}_{2} \mathrm{O}_{2}$ in PBS (-) at $37^{\circ} \mathrm{C}$ for varied time $(0,1,5,15$, and $30 \mathrm{~min})$. The pinacolboronate group in Hyp-L-1 (peak b) was partially hydrolyzed to the corresponding BA compound (peak a) during HPLC. In addition to the hydrolyzed QM (peak c), the dimer of hydrolyzed QM (peak d), formed by the reaction of QM with hydrolyzed QM, was also detected. Compounds a-d were identified by MALDI-TOF-MS. BA: boronic acid; QM: quinone methide. 


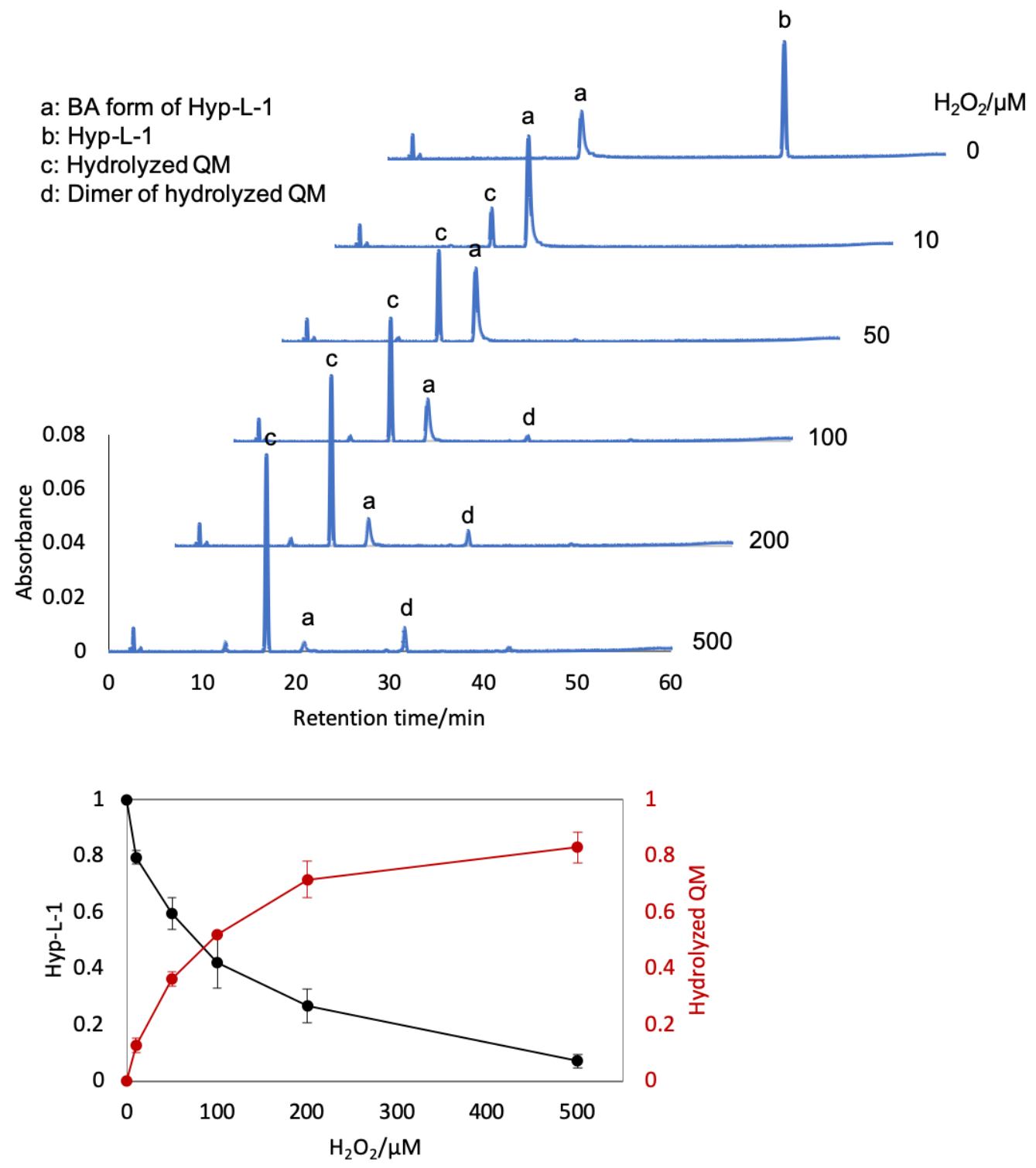

Supplementary Fig. $2 \mathbf{H}_{2} \mathrm{O}_{2}$-concentration-dependent hydrolysis. $50 \mu \mathrm{M}$ of Hyp-L-1 was incubated with various concentrations $(0,10,50,100,200$, and $500 \mu \mathrm{M})$ of $\mathrm{H}_{2} \mathrm{O}_{2}$ in PBS (-) at 37 ${ }^{\circ} \mathrm{C}$ for $30 \mathrm{~min}$. The percentages of Hyp-L-1 and hydrolyzed QM in the plot (lower) were calculated according to the HPLC peak areas (upper). Error bars indicate s.d., $n=3$. 
a)
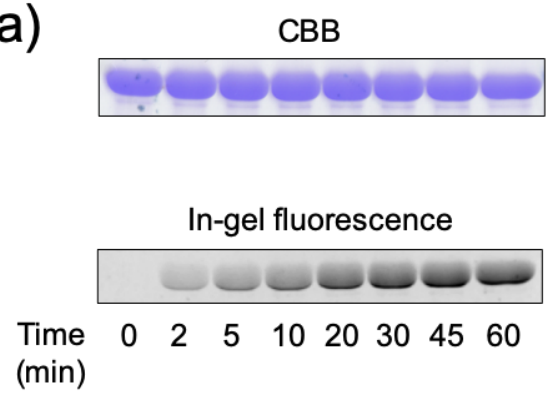

b)

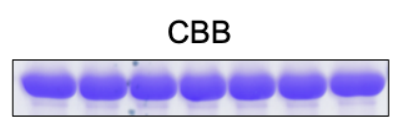

In-gel fluorescence

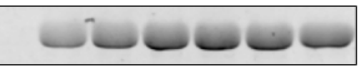

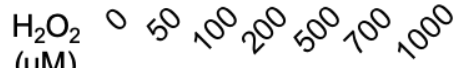
$(\mu \mathrm{M})$

c)
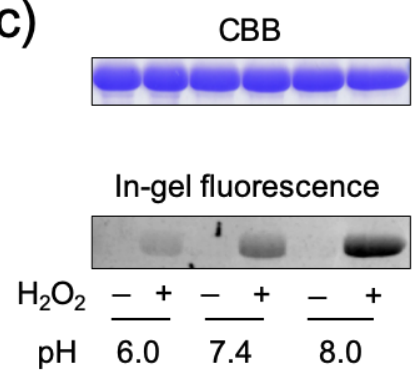
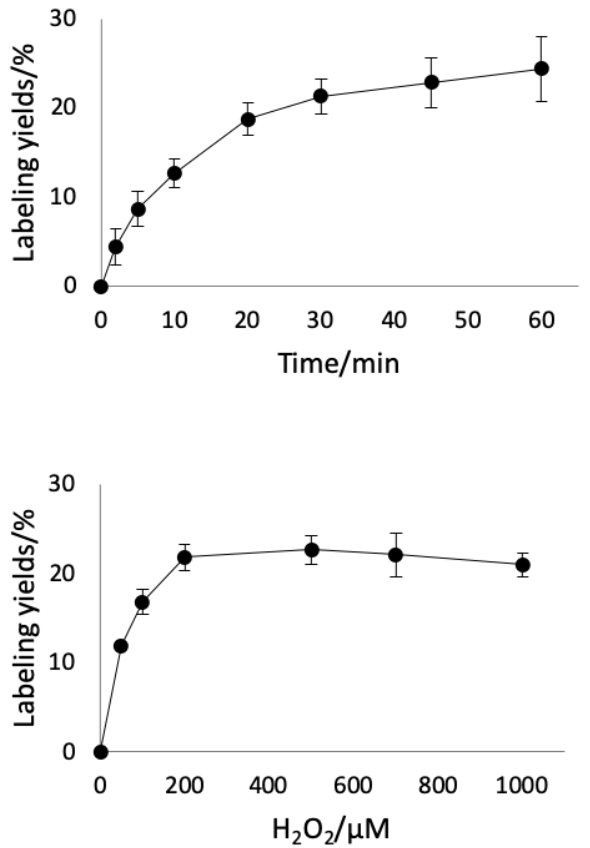

Supplementary Fig. $3 \mathrm{H}_{2} \mathrm{O}_{2}$-modulated BSA labeling. $\mathrm{H}_{2} \mathrm{O}_{2}$ was added to a PBS (-) solution of BSA $(10 \mu \mathrm{M})$ containing $50 \mu \mathrm{M}$ of Hyp-L-1, and the mixture was incubated at $37^{\circ} \mathrm{C}$. a) Time course in the presence of $200 \mu \mathrm{M}$ of $\mathrm{H}_{2} \mathrm{O}_{2}$. b) $\mathrm{H}_{2} \mathrm{O}_{2}$-concentration dependency after incubation for 30 min. c) $\mathrm{pH}$ dependency of the $\mathrm{H}_{2} \mathrm{O}_{2}$-responsive labeling. $200 \mu \mathrm{M}$ of $\mathrm{H}_{2} \mathrm{O}_{2}$ was added and the mixture was incubated for $30 \mathrm{~min}$. Error bars in the intensity plots ( $\mathrm{a}$ and $\mathrm{b}$ ) indicate s. d., $n=3$. 


$\begin{array}{rllllll}\text { BSA } & \text { sequence } & & & & \\ 1 & \text { MKWVTFISLL } & \text { LLFSSAYSRG } & \text { VFRRDTHKSE } & \text { IAHRFKDLGE } & \text { EHFKGLVLIA } & \text { FSQYLQQCPF } \\ 61 & \text { DEHVKLVNEL } & \text { TEFAKTCVAD } & \text { ES AGCEKSL } & \text { HTLFGDELCK } & \text { VASLRETYGD } & \text { MADCCEKQEP } \\ 121 & \text { ERNECFLSHK } & \text { DDSPDLPKLK } & \text { PDPNTLCDEF } & \text { KADEKKFWGK } & \text { YLYEIARRHP } & \text { YFYAPELLYY } \\ 181 & \text { ANKYNGVFQE } & \text { CCQAE KGAC } & \text { LLPKIETMRE } & \text { KVLASSARQR } & \text { LRCASIQKFG } & \text { ERALKAWSVA } \\ 241 & \text { RLSQKFPKAE } & \text { FVEVTKLVTD } & \text { LTKVHKECCH } & \text { GDLLECADDR } & \text { ADLAKYICDN } & \text { QDTISSKLKE } \\ 301 & \text { CCDKPLLEKS } & \text { HCIAEVEKDA } & \text { IPENLPPLTA } & \text { DFAEDKDVCK } & \text { NYQEAKDAFL } & \text { GSFLYEYSRR } \\ 361 & \text { HPEYAVSVLL } & \text { RLAKEYEATL } & \text { EECCAKDDP } & \text { ACYSTVFDKL } & \text { KHLVDEPQNL } & \text { IKQNCDQFEK } \\ 421 & \text { LGEYGFQNAL } & \text { IVRYTRKVPQ } & \text { VSTPTLVEVS } & \text { RSLGKVGTRC } & \text { CTKPESERMP } & \text { CTEDYLSLIL } \\ 481 & \text { NRLCVLHEKT } & \text { PVSEKVTKCC } & \text { TESLVNRRPC } & \text { FSALTPDETY } & \text { VPKAFDEKLF } & \text { TFHADICTLP } \\ 541 & \text { DTEKQIKKQT } & \text { ALVELLKHKP } & \text { KATEEQLKTV } & \text { MENFVAFVDK } & \text { CCAADDKEAC } & \text { FAVEGPKLVV } \\ 601 & \text { STQTALA } & & & & & \end{array}$
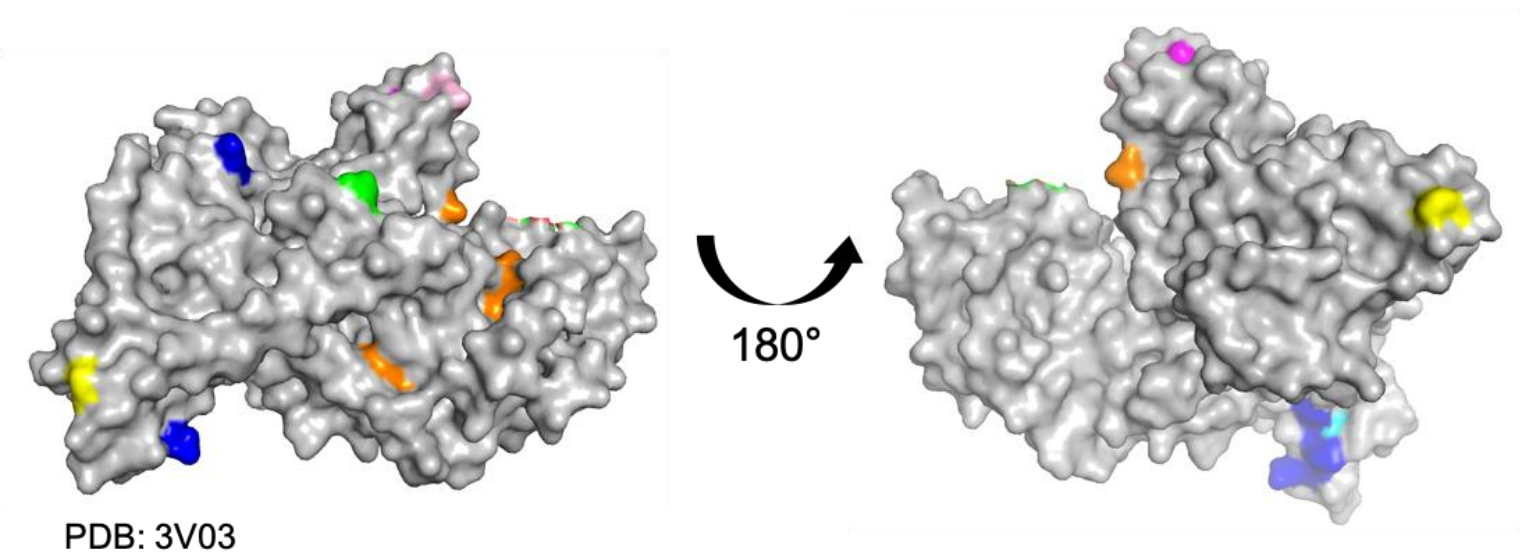

PDB: 3V03

Supplementary Fig. 4 Labeled residues on BSA. Top: BSA sequence, Hyp-L-1-modified residues were labeled in colors, $\mathrm{H}$ (yellow), $\mathrm{S}$ (bold black). Bottom: crystal structure of BSA visualized by PyMOL. 
T7, T17, and Y20

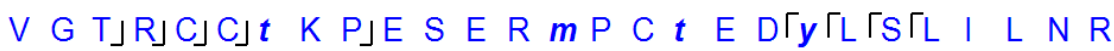

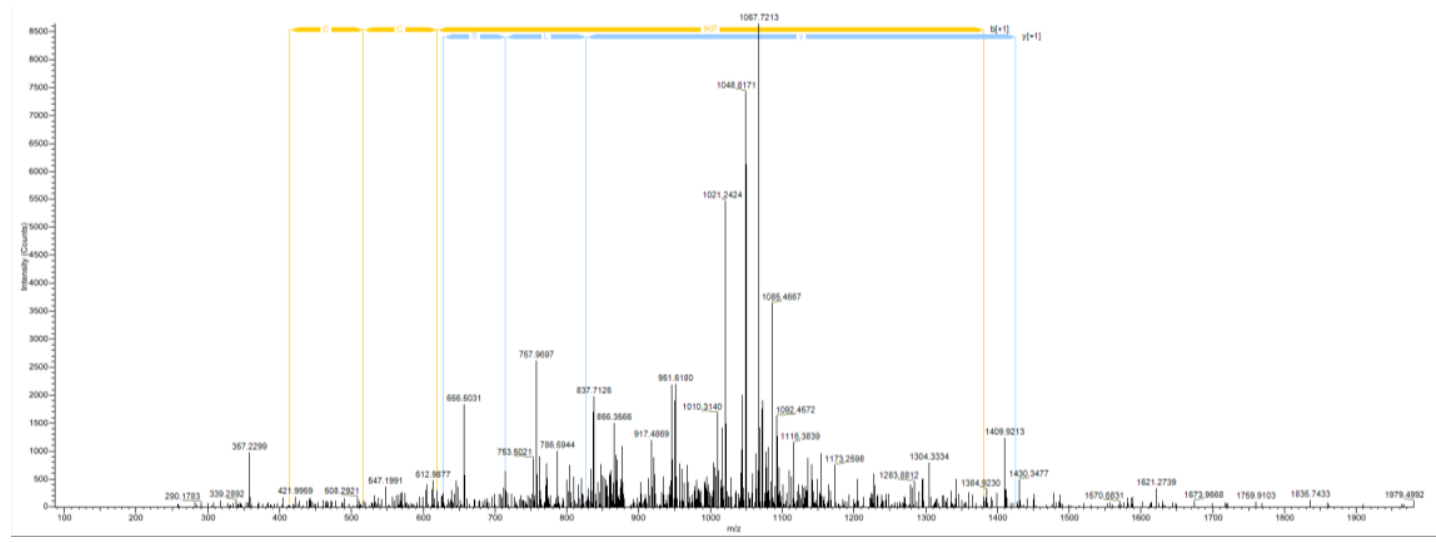

E10, E11, and H19

$L A K J E J Y J E J A J T J L J$ e e C C A K D D P $\boldsymbol{h}\lceil A\lceil C \Gamma Y \Gamma S\lceil T \Gamma V F \Gamma D K$

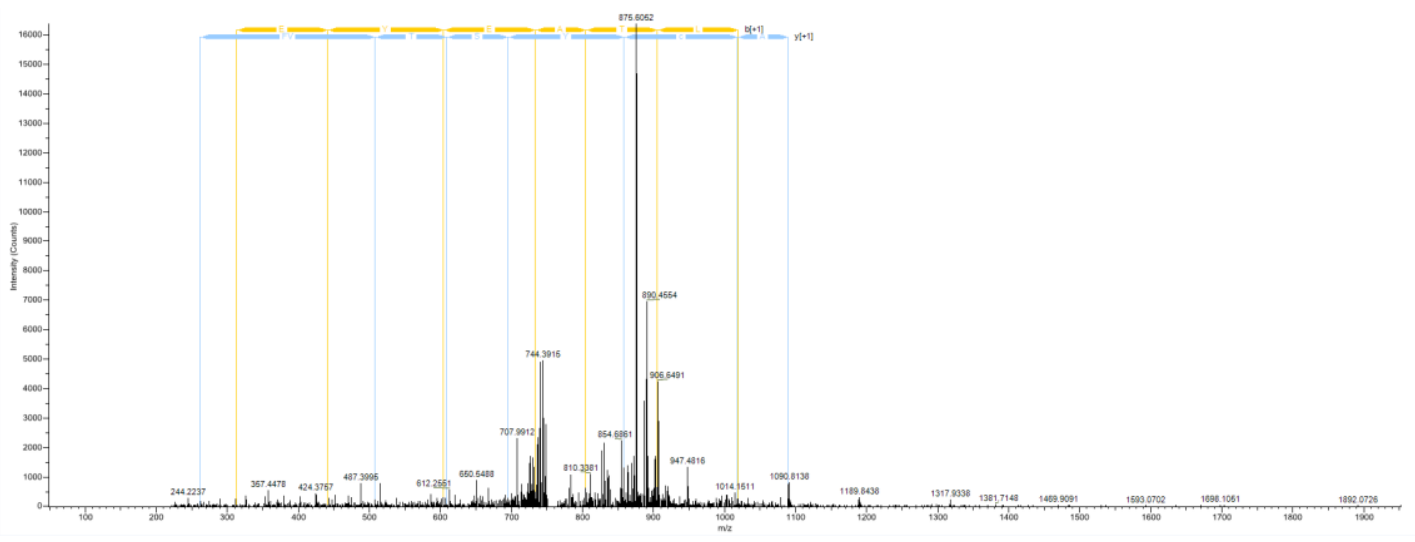

H8

$T c\lrcorner V\lrcorner A\lrcorner D J E\lrcorner S \int h\lceil A\lceil G\lceil c\lceil E K$

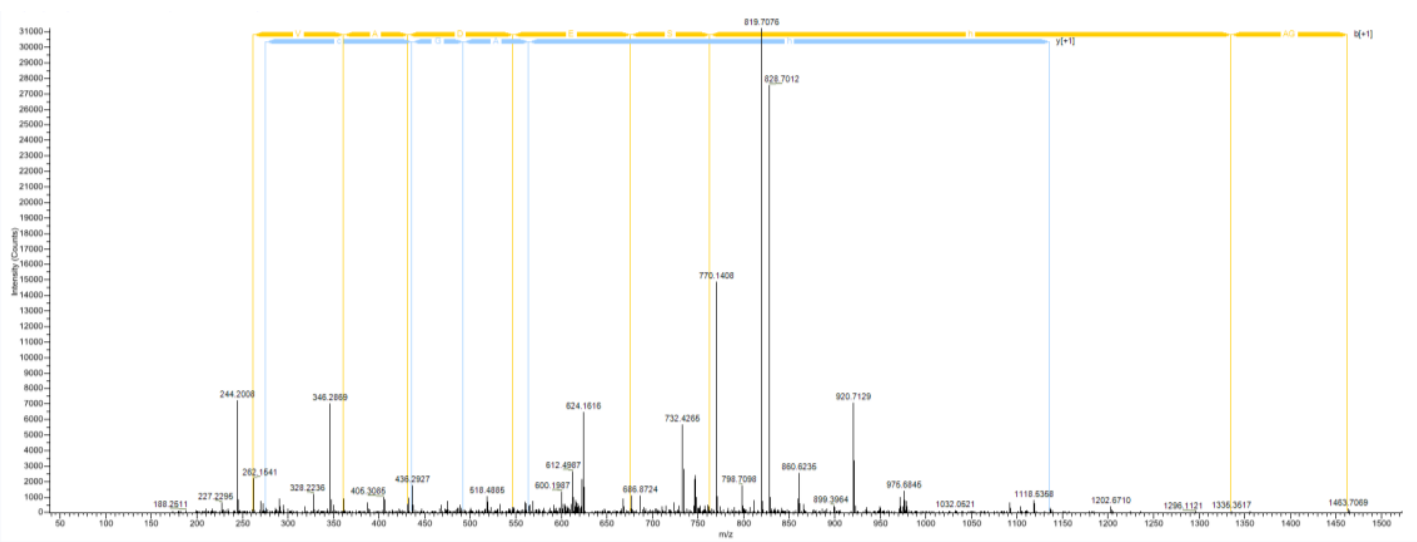




\section{$\mathrm{K} 2$}

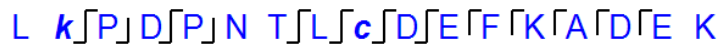

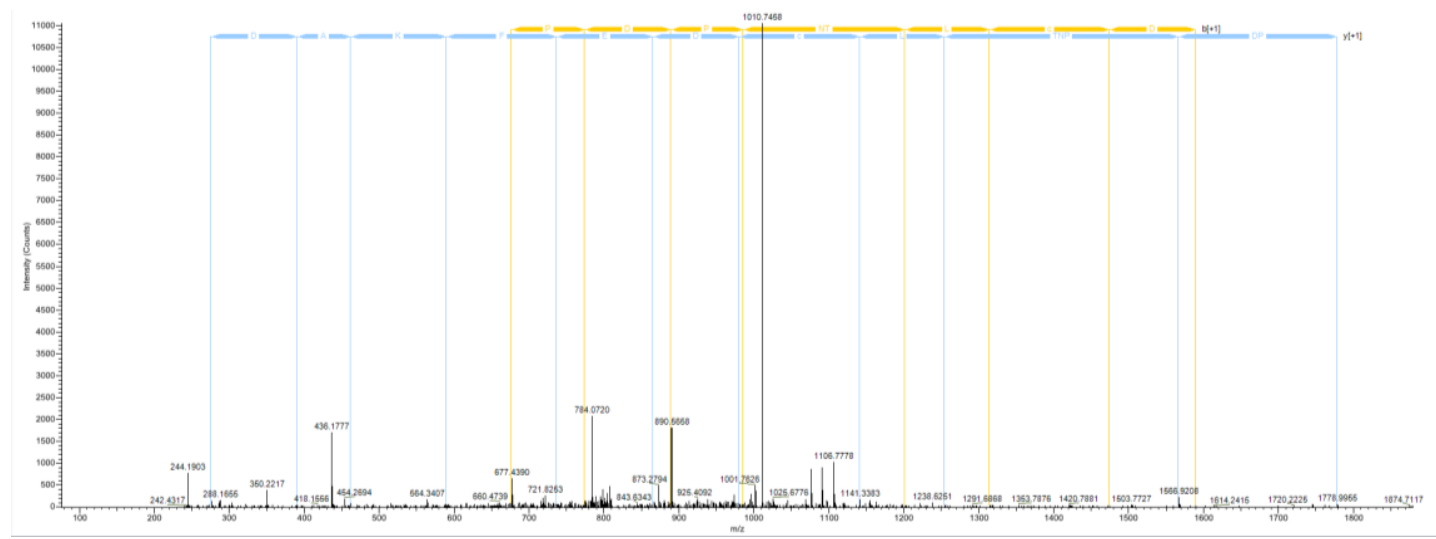

Y6, Y19, and S22

$D \vee c\lrcorner K J N\lrcorner y$ Q E A K D A F L GS F L y $\lceil E\lceil Y s \quad R$

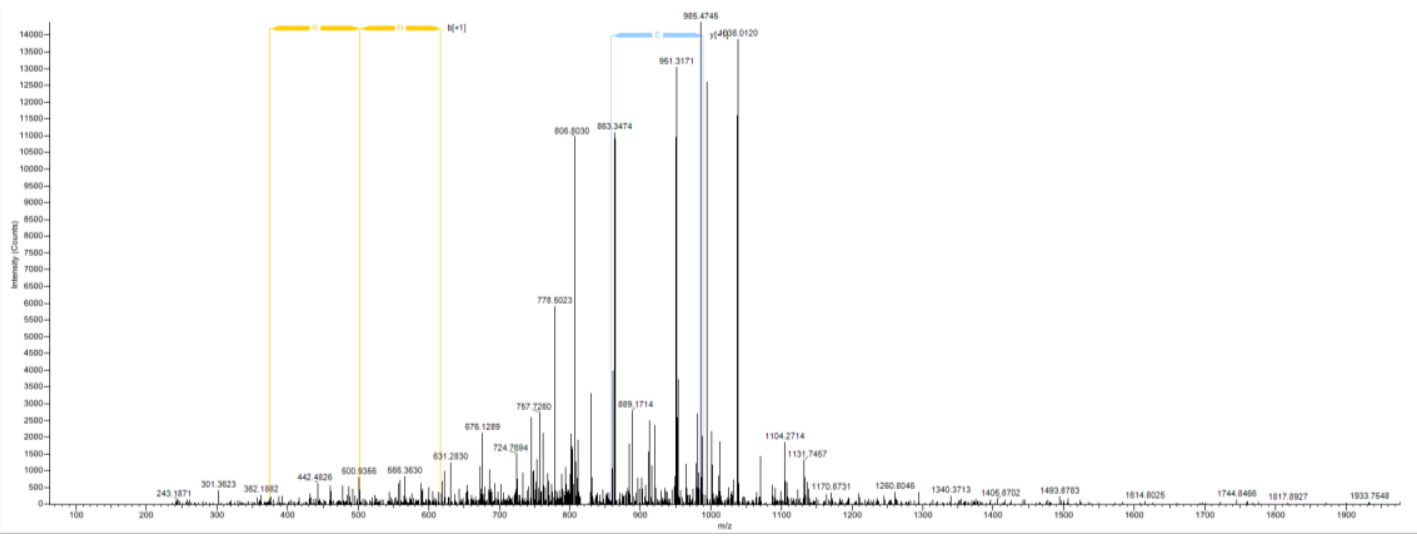

\section{K1}

$\boldsymbol{k}\lrcorner \mathrm{V} J \mathrm{P} \int \mathrm{Q} \int \mathrm{V} \int \mathrm{S} \int T \int \mathrm{P} \Gamma T \Gamma \mathrm{L} \Gamma \mathrm{V} \Gamma \mathrm{E} \Gamma \mathrm{V} \Gamma S \mathrm{R}$

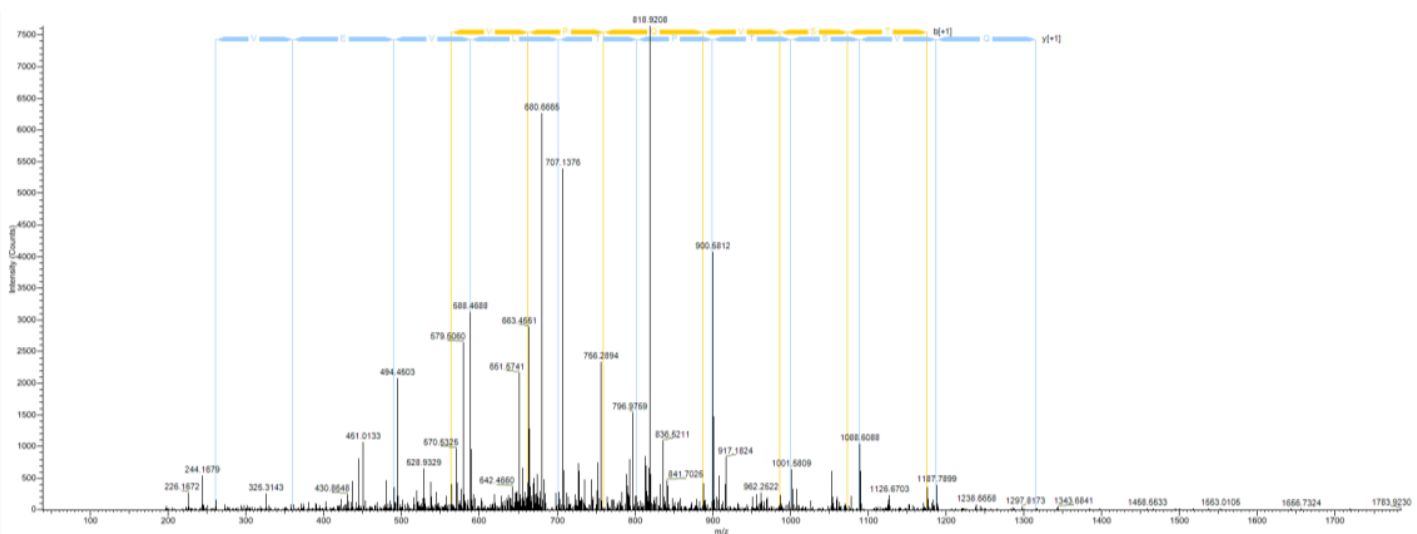


E8

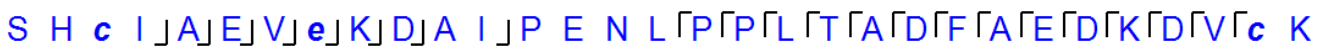

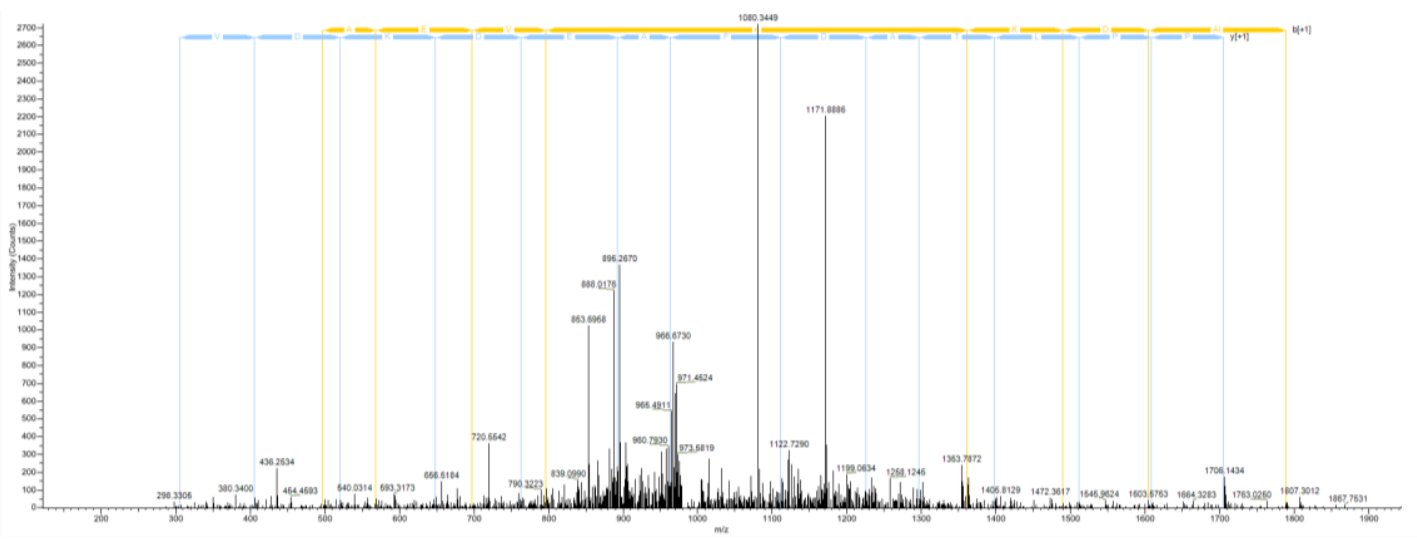

K1

$\boldsymbol{k}\left\lceil\mathrm{Q}\lceil\mathrm{T}\lrcorner \mathrm{A}\left\lceil\mathrm{L} \int \mathrm{V}\left\lceil\mathrm{E}\left\lceil\mathrm{L} \int \mathrm{L}\right\lrcorner \mathrm{K}\right.\right.\right.$

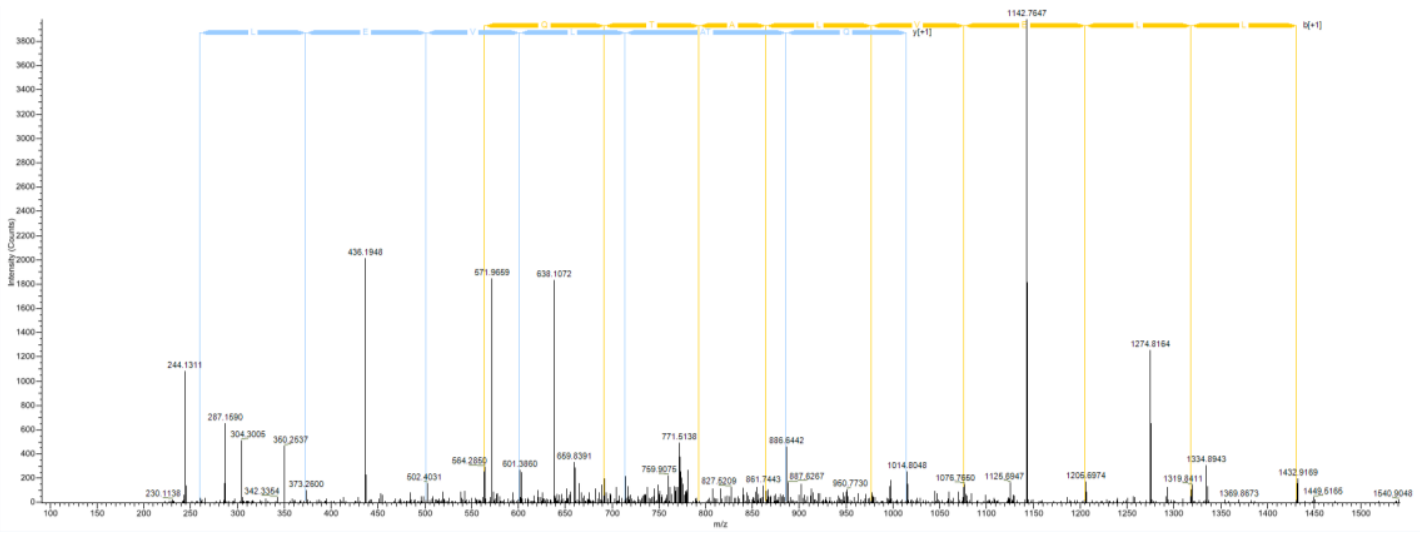

$\mathrm{C} 24$ and $\mathrm{C} 25$

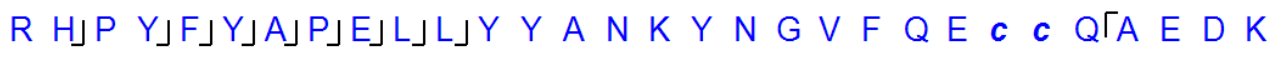

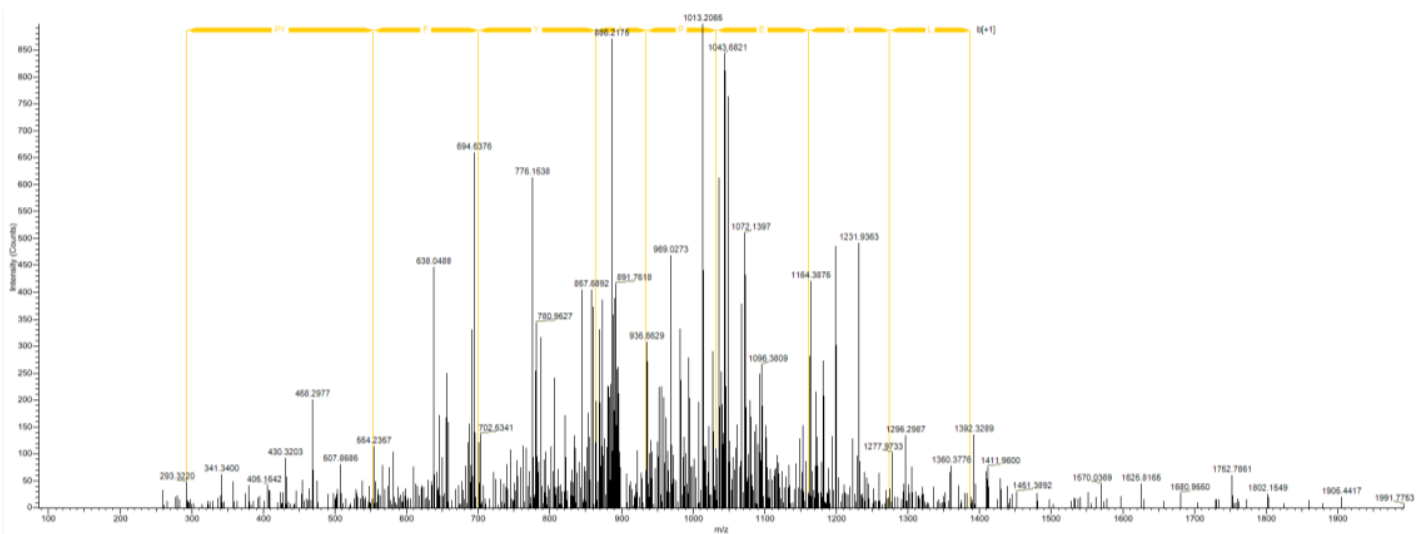


E3

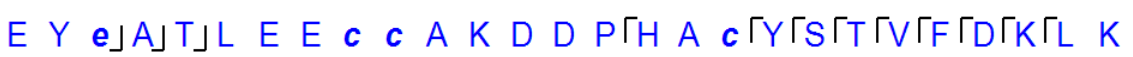

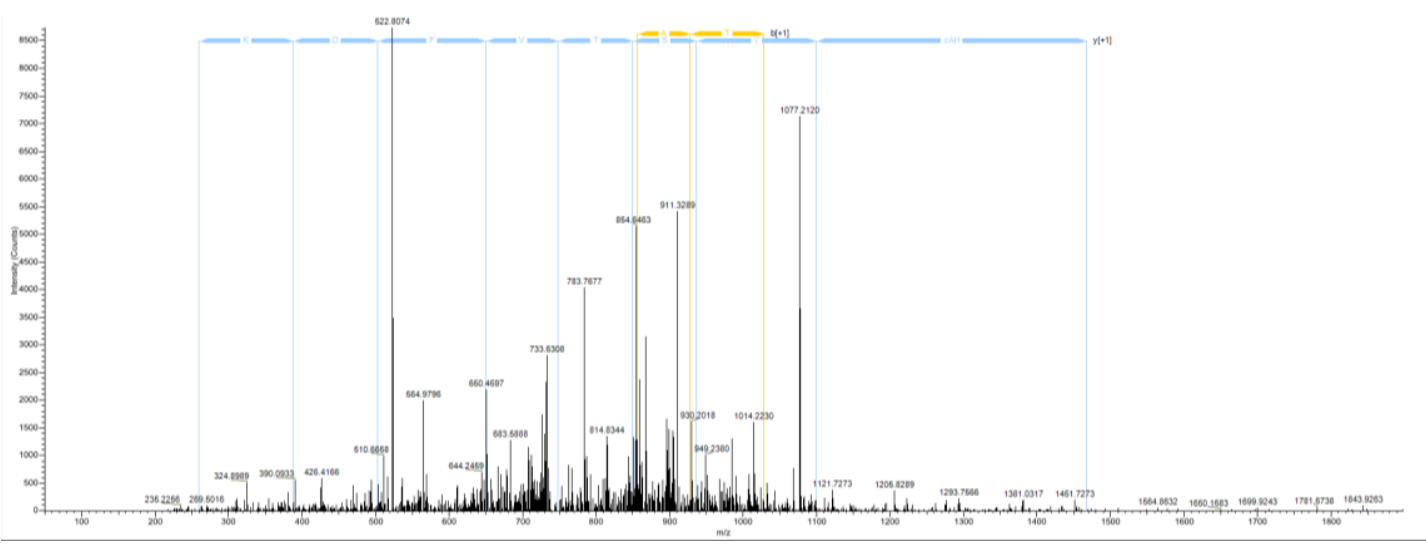

C25, D29

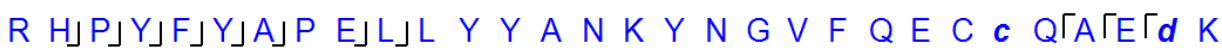

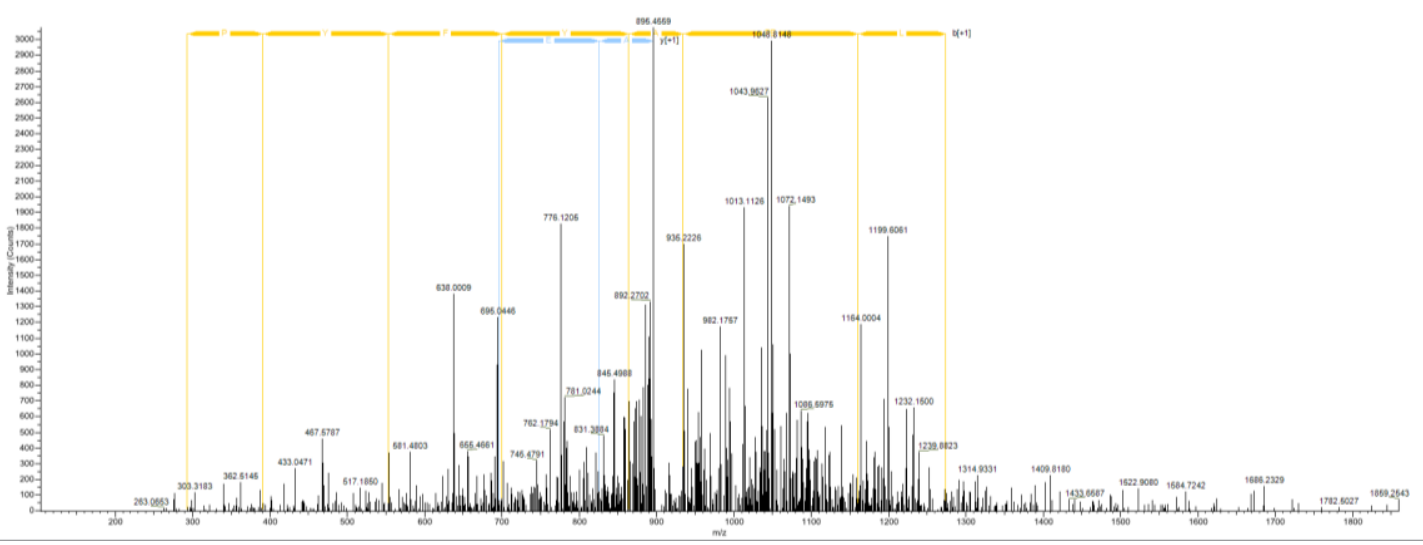

Supplementary Fig. 5 MS/MS analysis of Hyp-L-1-modified peptides on BSA. MS/MS spectra of peptides containing Hyp-L-1-modified residues. 

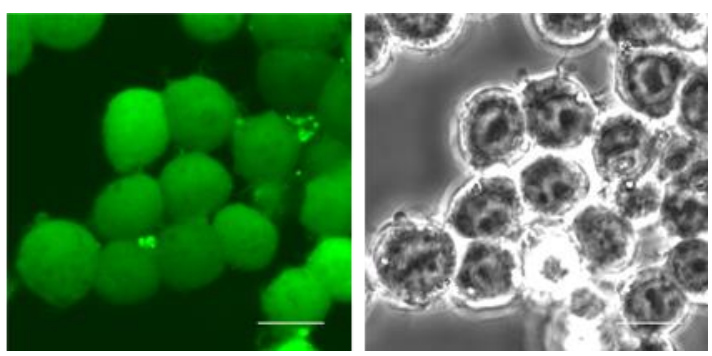

Supplementary Fig. 6 Cell uptake of Hyp-L-2 to living RAW264.7 macrophages. Cells were incubated with $5 \mu \mathrm{M}$ of Hyp-L-2 for 5 min at $37^{\circ} \mathrm{C}$. Scale bars, $10 \mu \mathrm{m}$.

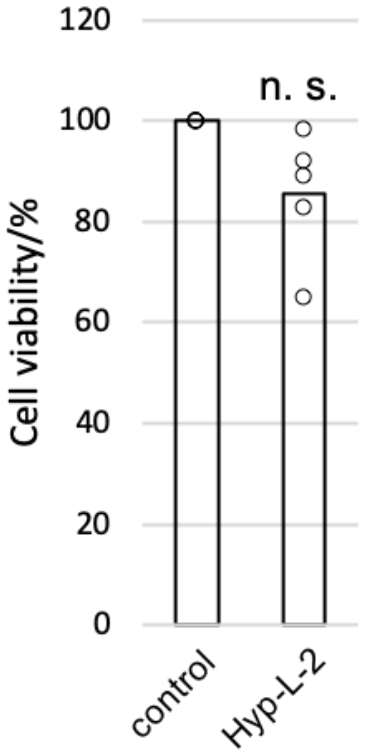

Supplementary Fig. 7 Cytotoxicity of Hyp-L-2 in living RAW264.7 macrophages. Cells were incubated with or without $5 \mu \mathrm{M}$ of Hyp-L-2 for $1 \mathrm{~h}$, followed by the cytotoxicity assay with cell counting kit-8. Statistical analyses were performed with a two-tailed Student's $t$-test $(n=5)$ relative to the data of control, n.s.: not statistically significant. 


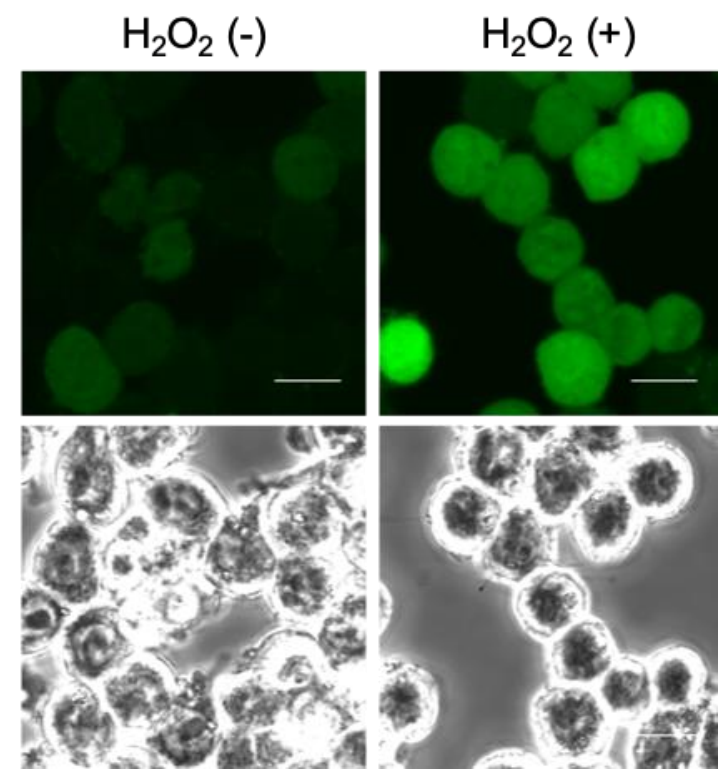

Supplementary Fig. $8 \mathrm{H}_{2} \mathrm{O}_{2}$ imaging by HYDROP in living RAW264.7 macrophages. $100 \mu \mathrm{M}$ of $\mathrm{H}_{2} \mathrm{O}_{2}$ was added to RAW264.7 macrophages that were pretreated with $5 \mu \mathrm{M}$ of HYDROP, and the cells were incubated for $30 \mathrm{~min}$. Scale bars, $10 \mu \mathrm{m}$.

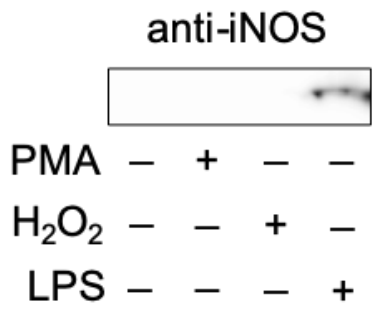

Supplementary Fig. 9 Western blot analysis of the expression of iNOS in RAW264.7 macrophages. Cells were treated with or without $1 \mu \mathrm{g} / \mathrm{mL}$ of PMA for $30 \mathrm{~min}, 1 \mu \mathrm{g} / \mathrm{mL}$ of lipopolysaccharide (LPS) for $6 \mathrm{~h}$, or $100 \mu \mathrm{M}$ of $\mathrm{H}_{2} \mathrm{O}_{2}$ for $30 \mathrm{~min}$, followed by cell lysis. The cell lysates were subjected to SDS-PAGE and western blot. 

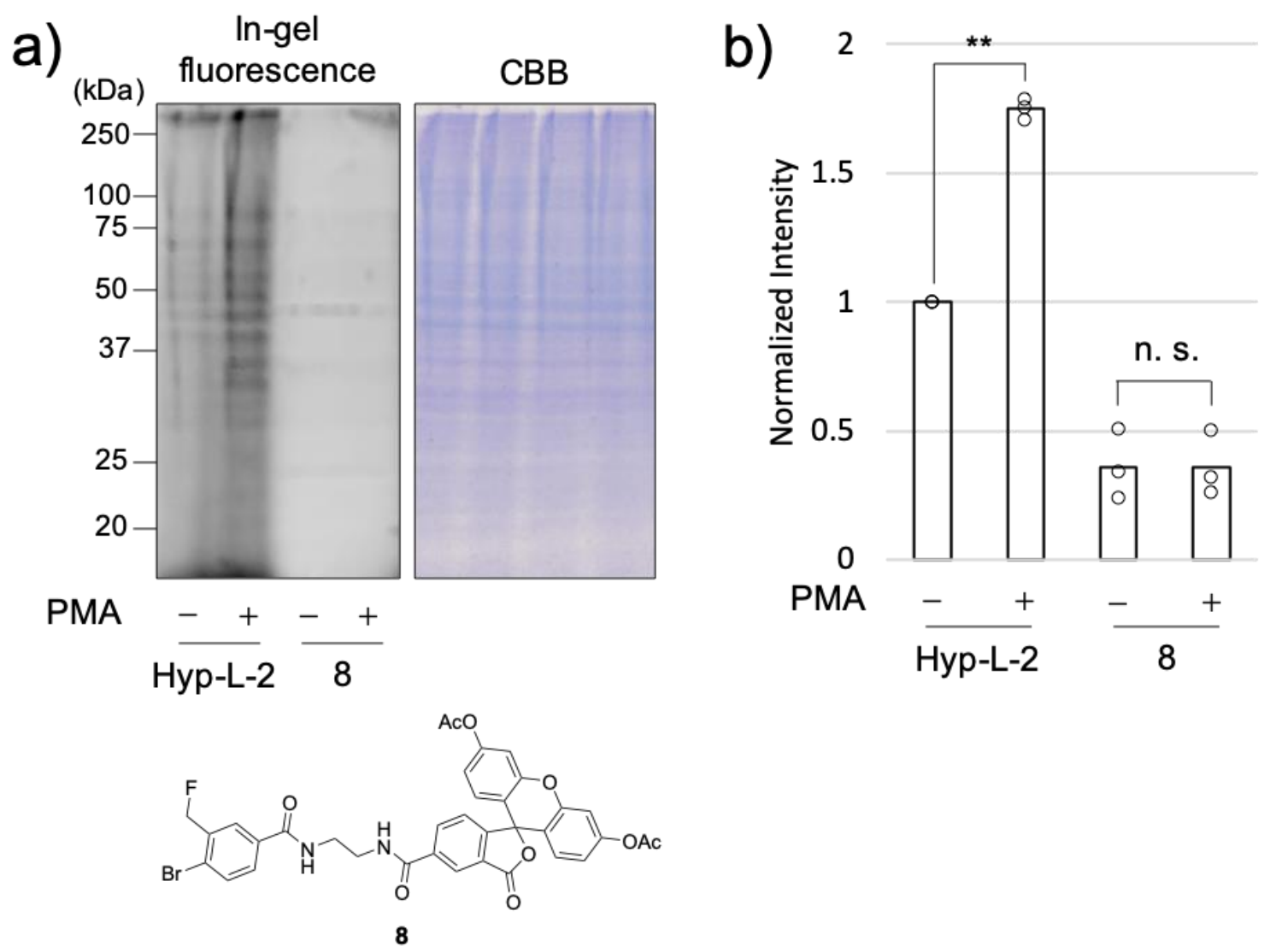

\section{Supplementary Fig. 10 Comparison of Hyp-L-2 with compound 8 for PMA-induced} conditional protein labeling. a) SDS-PAGE analysis. RAW264.7 macrophages were activated with $1 \mu \mathrm{g} / \mathrm{mL}$ of PMA for $30 \mathrm{~min}$, followed by incubation with $5 \mu \mathrm{M}$ of Hyp-L-2 or compound 8 for $30 \mathrm{~min}$. After cell lysis and SDS-PAGE, the protein labeling was assessed by in-gel fluorescence imaging. b) Quantification of the labeling in a). The band intensities were normalized to the data of PMA (-) by Hyp-L-2. Statistical analyses were performed with a two-tailed Student's $t$-test $(n=3) . * * P<0.01$, n.s.: not statistically significant. 

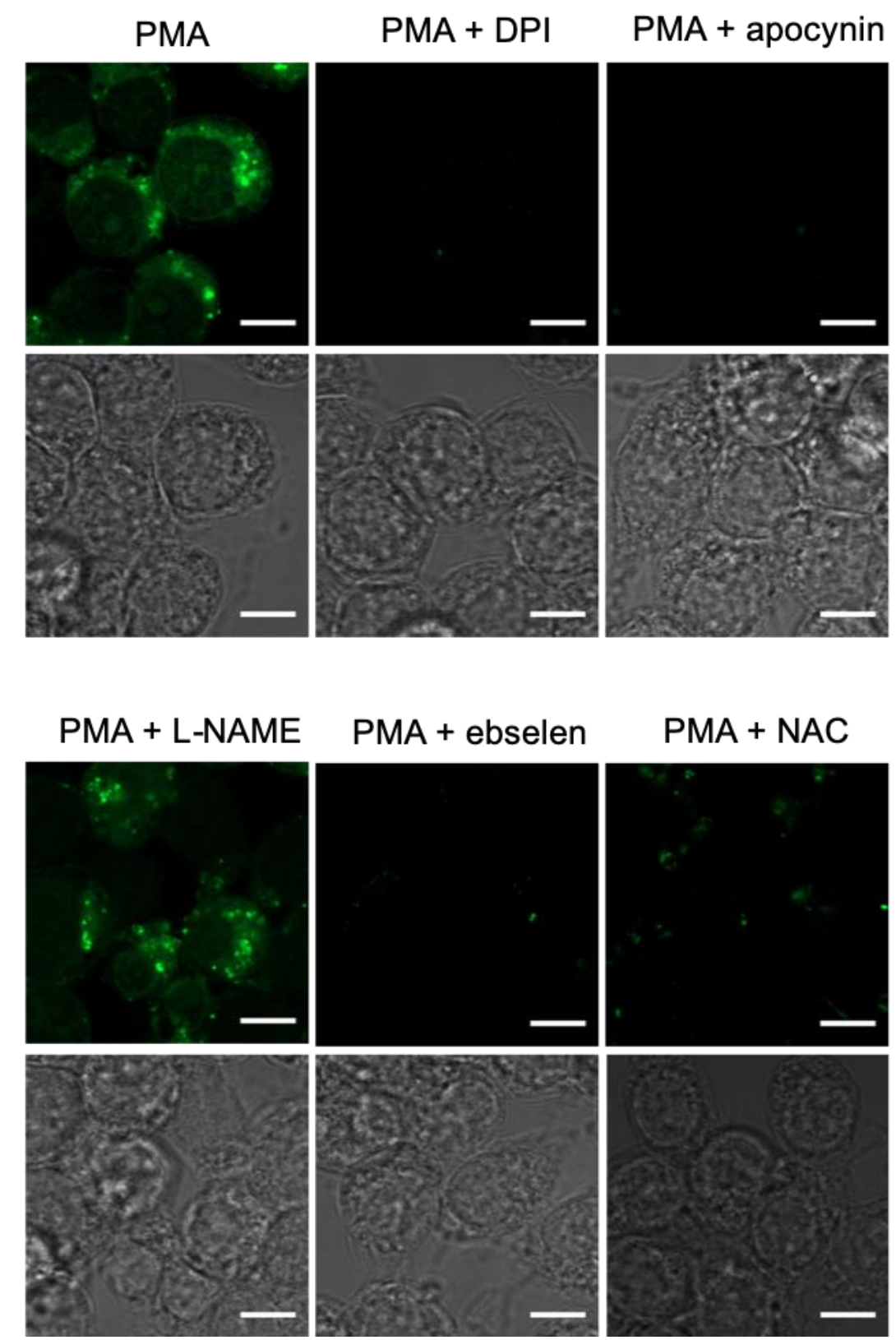

Supplementary Fig. 11 Imaging of PMA-activated RAW264.7 macrophages in the presence of various inhibitors or scavengers. Cells were activated with $1 \mu \mathrm{g} / \mathrm{mL}$ of PMA in the presence of various inhibitors or scavengers for $30 \mathrm{~min}$, followed by incubation with $5 \mu \mathrm{M}$ of Hyp-L-2 for 30 min. CLSM images were recorded after cell fixation by chilled methanol. DPI: $10 \mu \mathrm{M}$, apocynin: $5 \mathrm{mM}$, ebselen: $5 \mu \mathrm{M}$, L-NAME: $5 \mathrm{mM}$, NAC: $10 \mathrm{mM}$. Scale bars, $5 \mu \mathrm{m}$. 

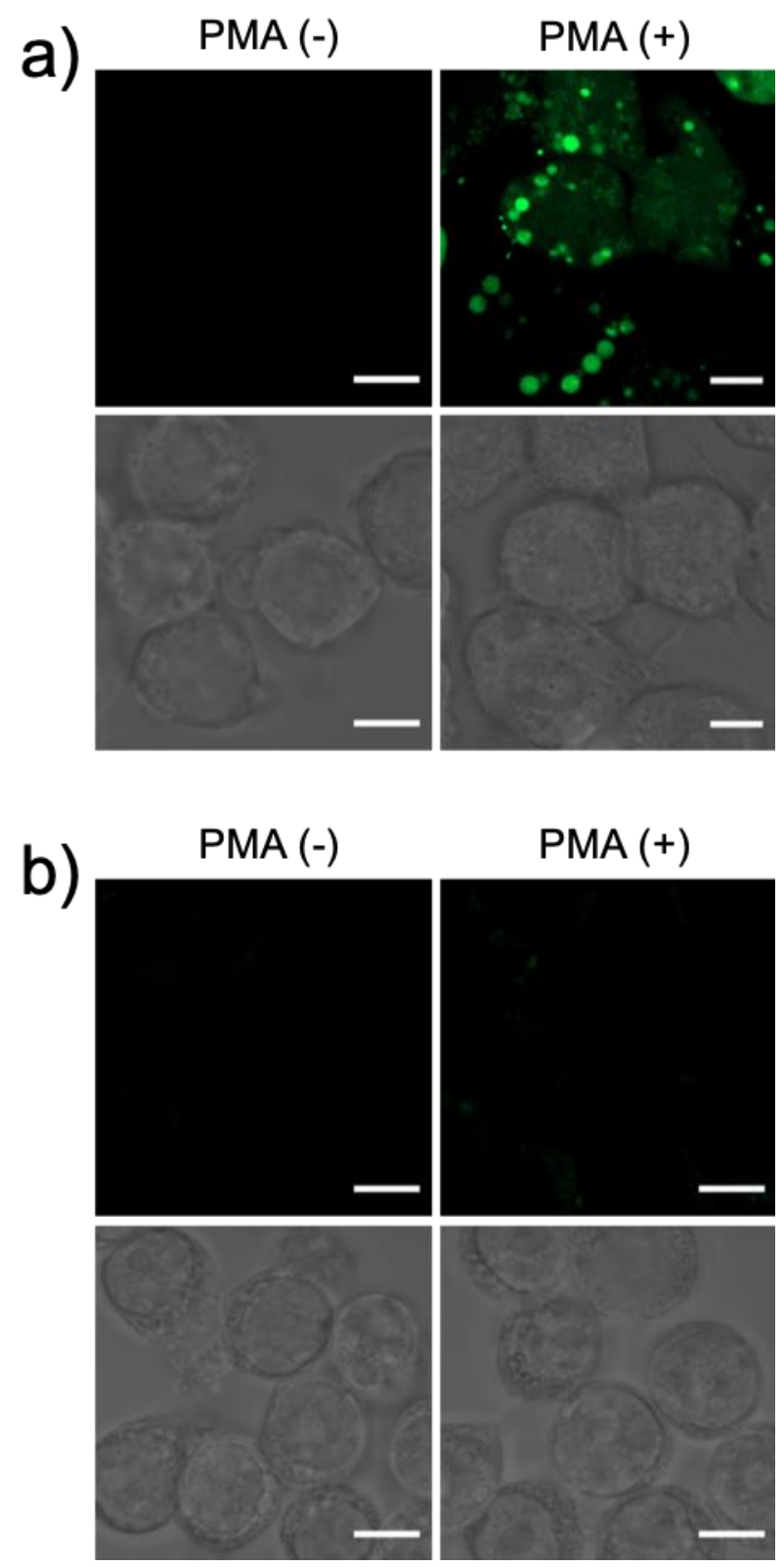

Supplementary Fig. 12 Imaging of $\mathrm{H}_{2} \mathrm{O}_{2}$-rich vesicles by HYDROP in RAW264.7 macrophages. a) Imaging of live cells. After treatment with or without $1 \mu \mathrm{g} / \mathrm{mL}$ of PMA for 30 min, the cells were incubated with $5 \mu \mathrm{M}$ of HYDROP for $30 \mathrm{~min}$. b) Imaging of fixed cells. After the treatment in a), cells were fixed by chilled methanol. Scale bars, $5 \mu \mathrm{m}$. 


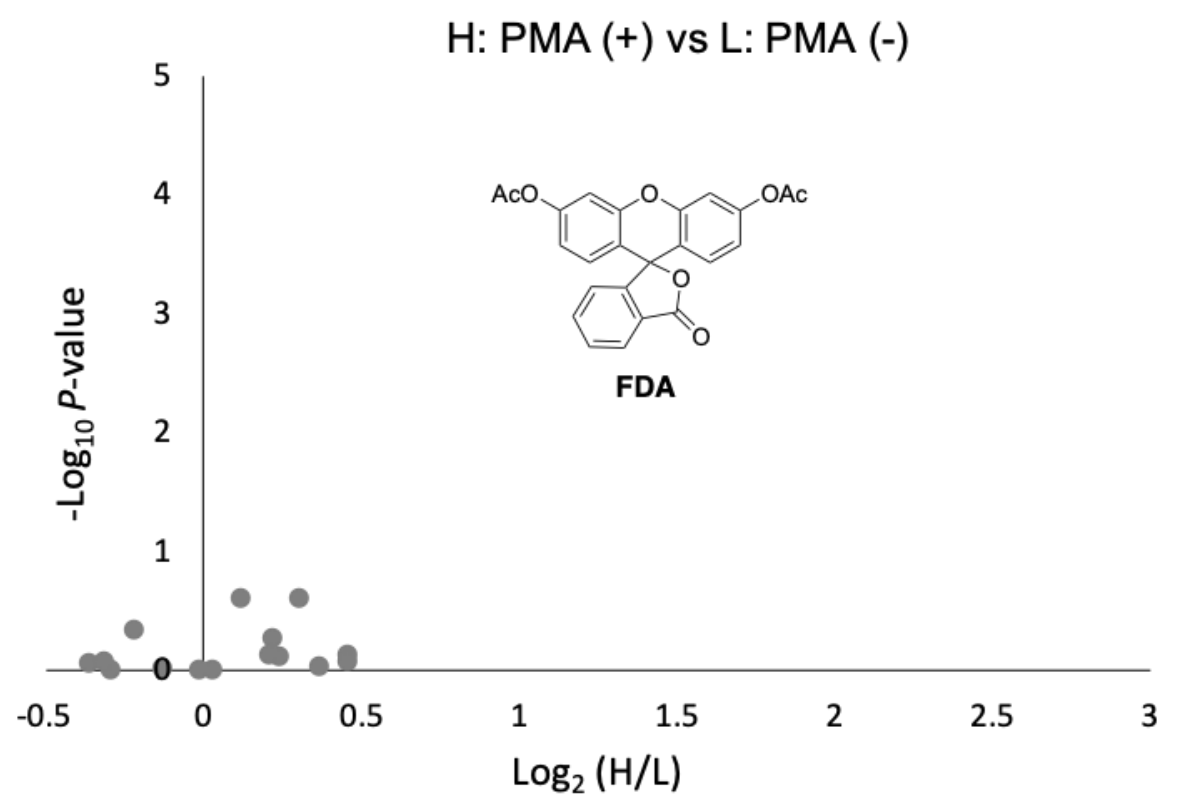

Supplementary Fig. 13 Proteomic analysis with FDA in RAW 264.7 macrophages. After the PMA stimulation, cells were incubated with $5 \mu \mathrm{M}$ of FDA for $30 \mathrm{~min}$, followed by immunoprecipitation, in-gel digestion, TMT tagging, and LC-MS/MS. Three independent biological replicates were carried out, and 15 proteins were identified that were hit at least twice. The volcano plot was obtained by the $P$-value of H: PMA (+) vs L: PMA (-) against $\log _{2}(\mathrm{H} / \mathrm{L})$. $P$-value was calculated by the Benjamini-Hochberg procedure. 


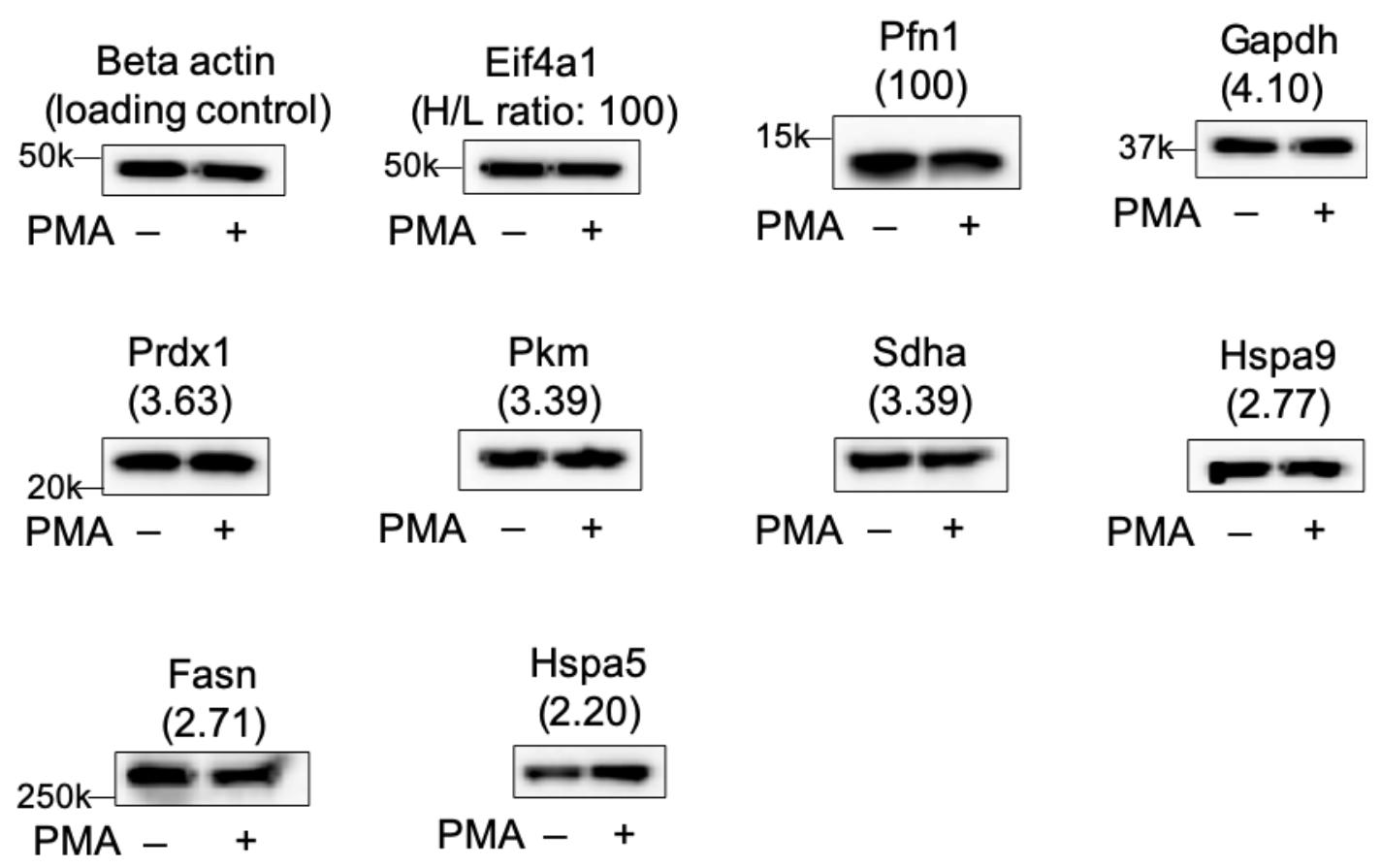

Supplementary Fig. 14 Western blot analysis of protein expression levels with and without PMA stimulation. RAW264.7 macrophages were treated with or without $1 \mu \mathrm{g} / \mathrm{mL}$ of PMA for $30 \mathrm{~min}$, followed by cell lysis. The cell lysates were subjected to SDS-PAGE and western blot. Anti-beta actin was applied as a loading control. The TMT ratios of H/L were shown in parentheses. 


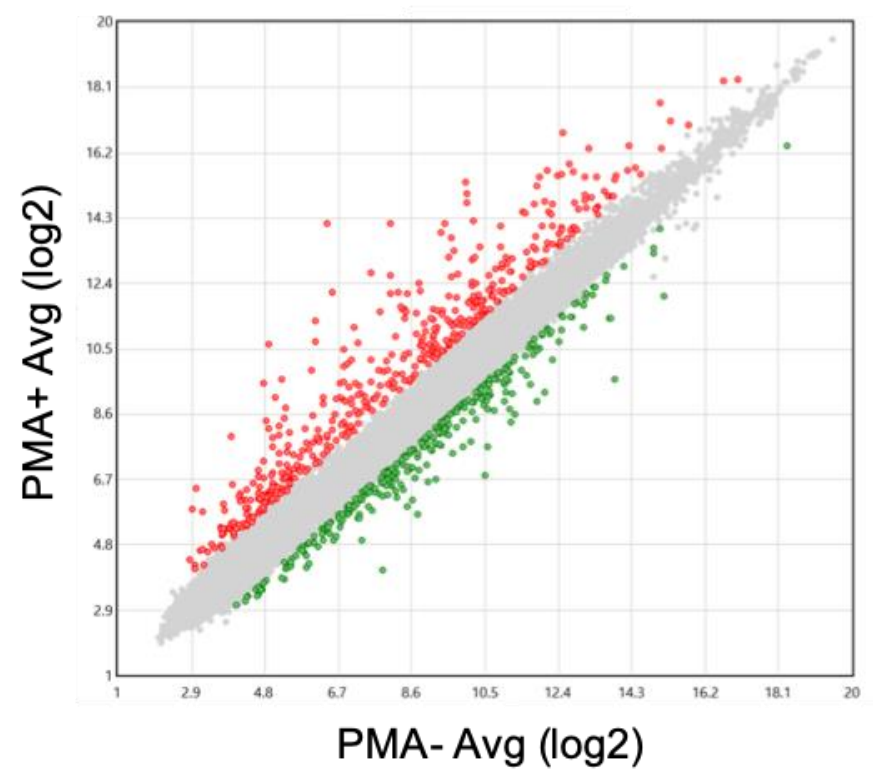

Supplementary Fig. 15 Transcriptome analysis of RAW264.7 macrophages with and without PMA stimulation. Scatter plot of identified genes with a filter of fold change (PMA+ vs PMA-) > 2 or $<-2.22206$ genes were identified in total, among which 457 genes (2.1\%) were up-regulated (marked in red, fold change > 2) and 319 genes (1.4\%) were down-regulated (marked in green, fold change <-2). This result indicated a static gene expression in RAW264.7 macrophages after stimulation with PMA. 


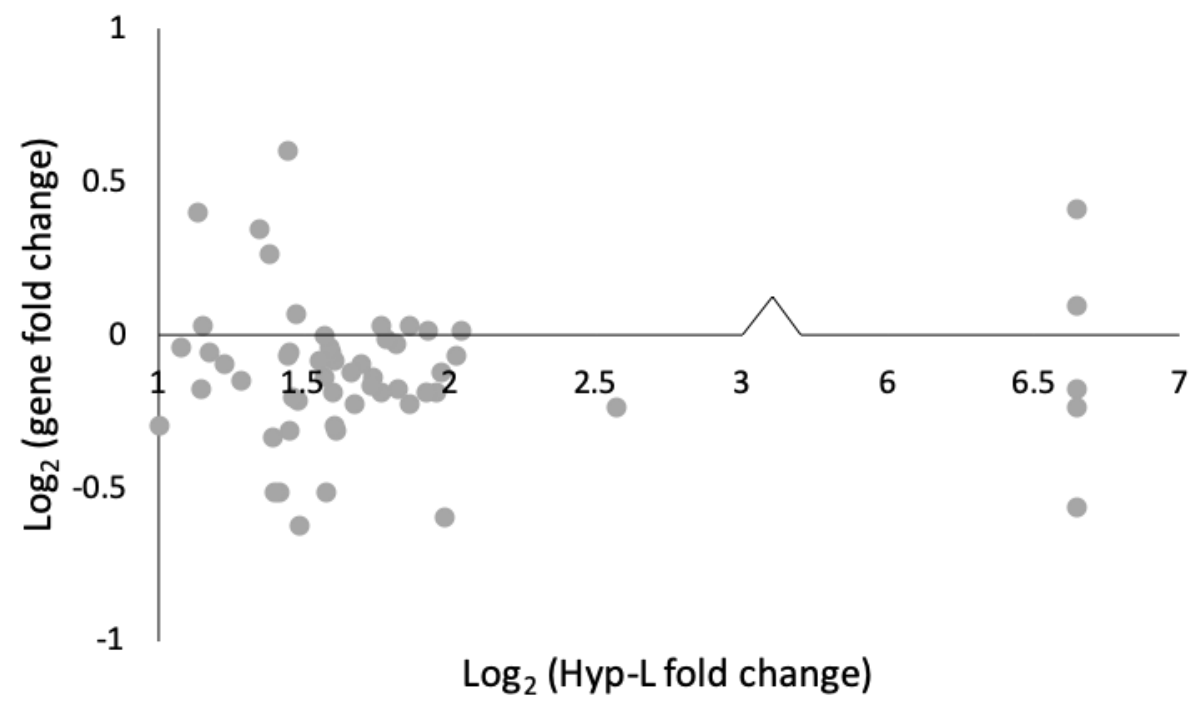

Supplementary Fig. 16 Plot of gene expression fold change with Hyp-L fold change. The proteins in group A were analyzed (56 proteins were mapped). The analyzed proteins all showed a non-significant fold change of gene expression, which is between -2 and 2 .

Supplementary Table 1 List of proteins assigned to specific vesicular organelles in group A. Protein (Gene) TMT ratio Annotation

$(\mathrm{H} / \mathrm{L})$

Coronin-1A (Coro1a) 2.98 phagosome (Uniprot, $\mathrm{GO}^{\mathrm{a}}$ )

Cytochrome b-245 heavy chain (Cybb)

2.63 phagosome (GO)

Receptor of activated protein $\mathrm{C}$ kinase 1 phagosome (GO)

(Rack1)

Ras-related protein Rab-5C (Rab5c) 100 GTP-binding nuclear protein RAN (Ran)

endosome (Uniprot, GO)

Sodium/potassium-transporting ATPase

endosome (GO)

subunit alpha-1 (Atp1a1)

Ras-related protein Rab-1A (Rab1A)

2.52

endosome (GO)

beta-glucuronidase (Gusb)

3.83

endosome (GO)

a: Gene Ontology (GO) 

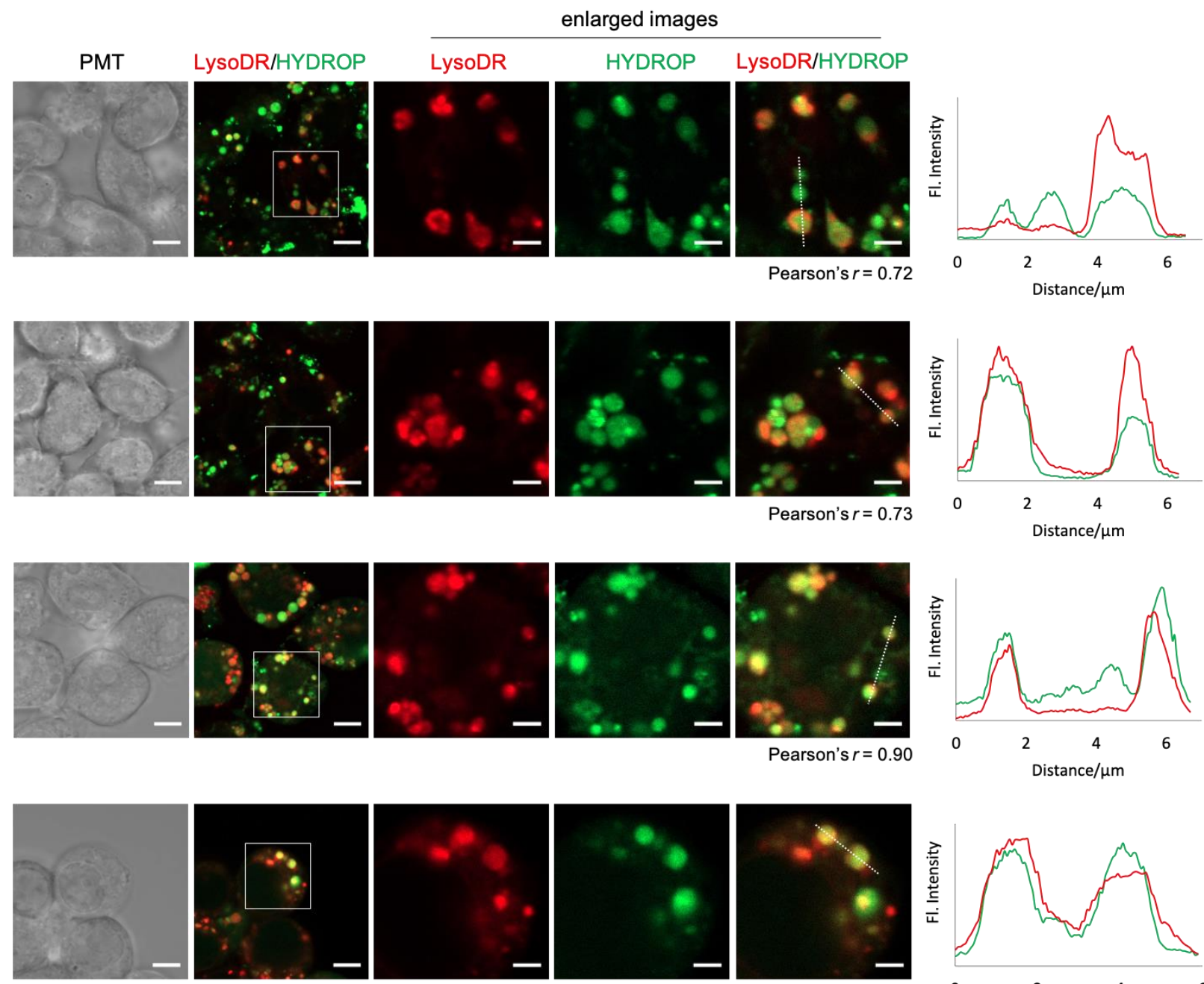

Pearson's $r=0.81$

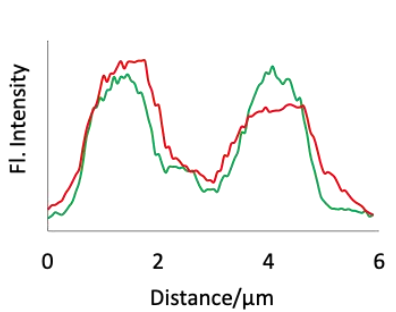

Supplementary Fig. 17 Colocalization imaging of LysoDR with HYDROP in PMAstimulated RAW264.7 macrophages. Cells were activated with $1 \mu \mathrm{g} / \mathrm{mL}$ of PMA for $30 \mathrm{~min}$, followed by labeling by $5 \mu \mathrm{M}$ of HYDROP and $50 \mathrm{nM}$ of LysoTracker Deep Red (LysoDR) for $30 \mathrm{~min}$. Images from 4 separate fields containing over 10 cells were collected and analyzed. Lineplot graphs indicate the fluorescence intensity profiles of LysoDR (red) and Hyp-L-2 (green) along the white dotted lines. Colocalization was quantified using Pearson's $r$. Scale bars, $5 \mu \mathrm{m}$ and $2 \mu \mathrm{m}$ (enlarged images). 


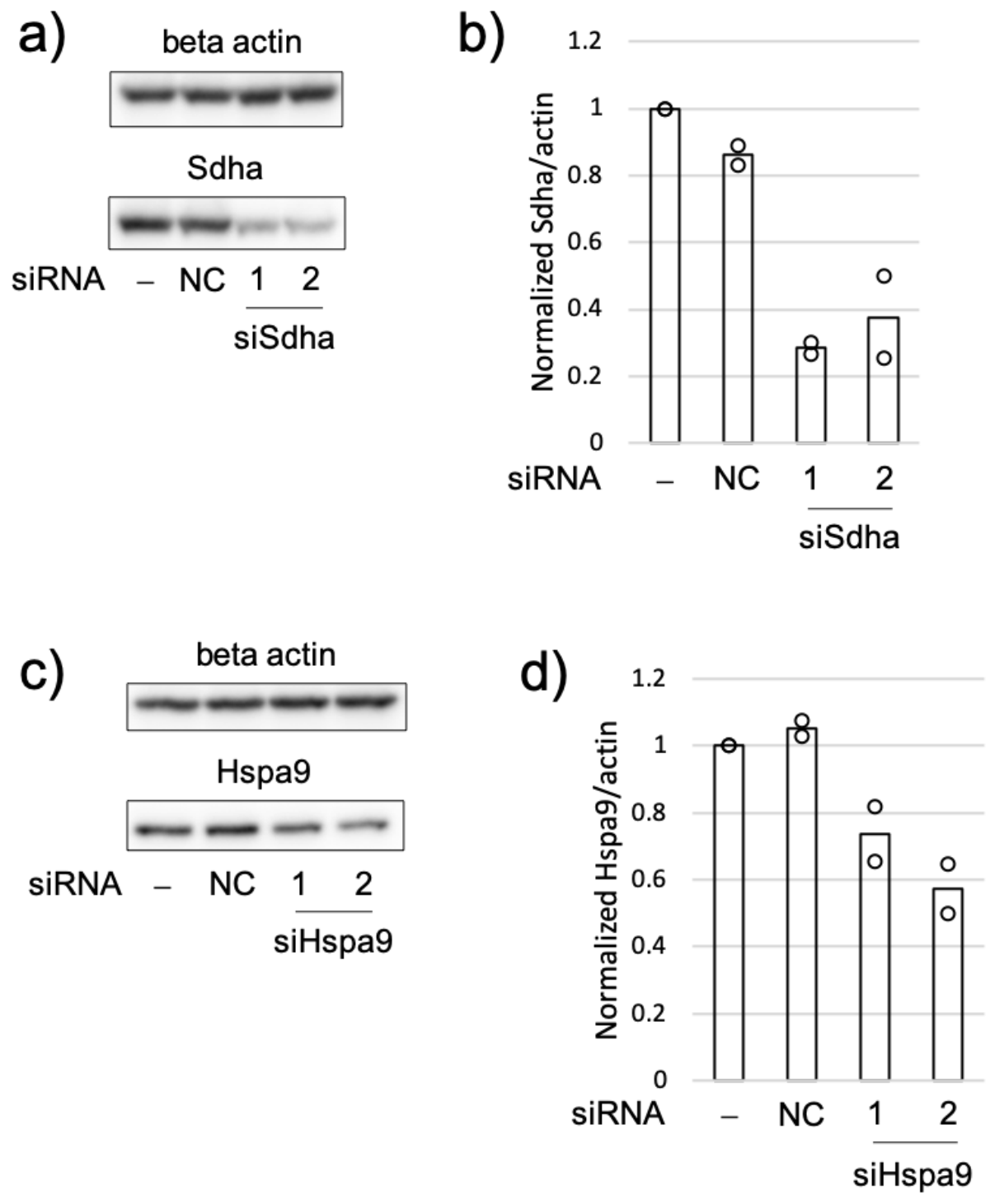

Supplementary Fig. 18 Western blot analysis of knockdown validation of anti-Sdha and antiHspa9. RAW264.7 macrophages were transfected with siRNAs targeting Sdha, Hspa9, or negative control (NC) duplexes, followed by cell lysis, SDS-PAGE and western blot. Anti-beta actin was applied as a loading control. a) Western blot images of anti-Sdha and anti-beta actin. b) Quantification of the band intensities in a). The ratios of Sdha/actin were normalized to the data of siRNA $(-), n=2$. A large decrease $(\sim 50-80 \%)$ in the Sdha expression was observed upon the siSdha transfection. c) Western blot images of anti-Hspa9 and anti-beta actin. d) Quantification of the band intensities in c). The ratios of Hspa9/actin were normalized to the data of siRNA $(-), \mathrm{n}=$ 2. A moderate decrease $(20-50 \%)$ in the $\mathrm{Hspa} 9$ expression was observed upon the siHspa9 transfection. 


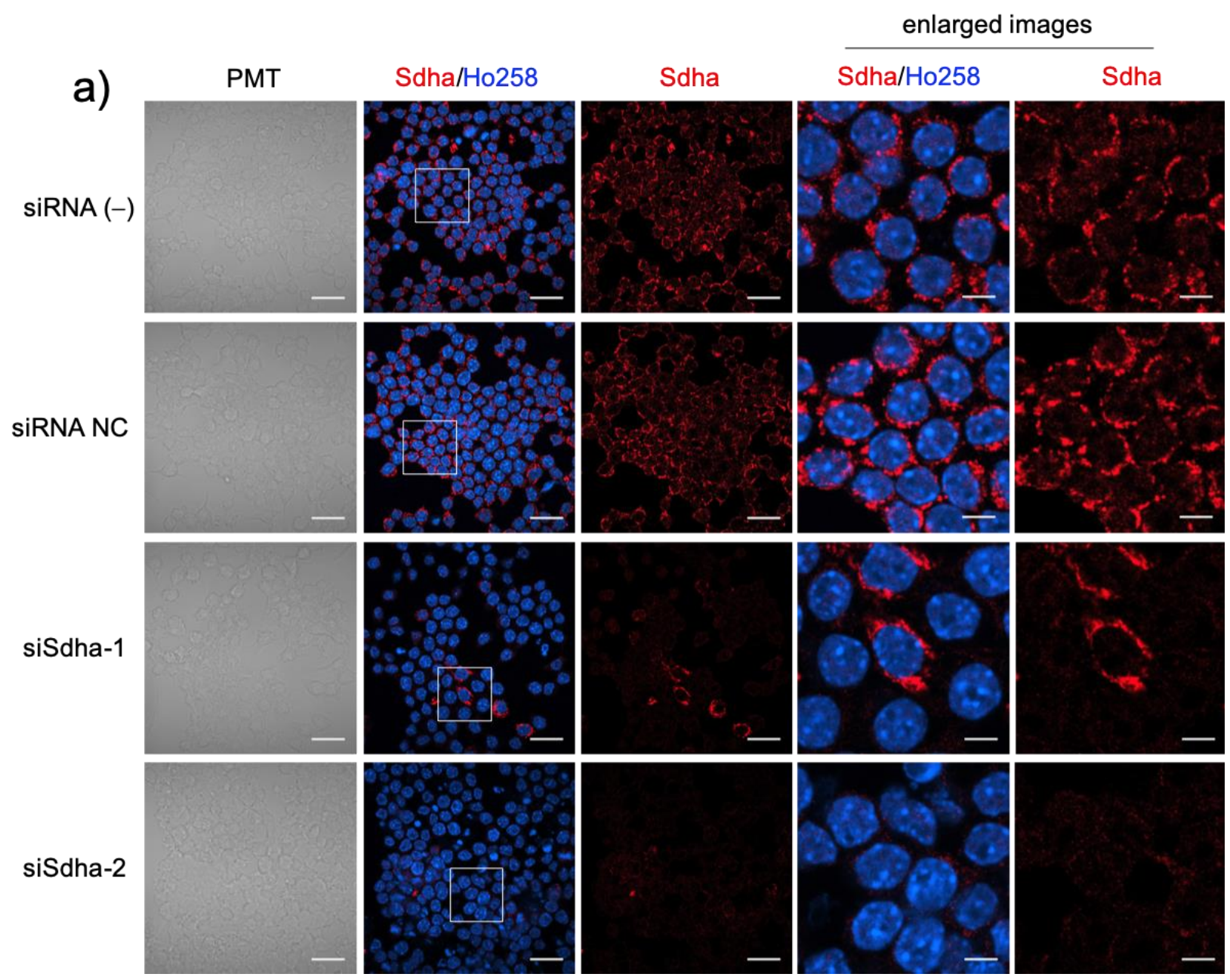

Supplementary Fig. 19 Immunostaining analysis of knockdown validation of anti-Sdha and anti-Hspa9. RAW264.7 macrophages were transfected with siRNAs targeting Sdha, Hspa9, or negative control (NC) duplexes. After fixation, permeabilization, and blocking, the cells were incubated with anti-Sdha or anti-Hspa9 at $4{ }^{\circ} \mathrm{C}$ overnight, followed by incubation with secondary antibody and Hoechst 33258 (Ho258) at room temperature for 1 h. Scale bars, $20 \mu \mathrm{m}$ and $5 \mu \mathrm{m}$ (enlarged images). Consistent with the western blot results in Supplementary Fig. 18, the immunofluorescence against Sdha and Hspa9 was decreased upon the siRNA transfection. Some cells remained the bright fluorescence as that in the siRNA (-) and NC cells, which was likely due to the inefficient transfection. 


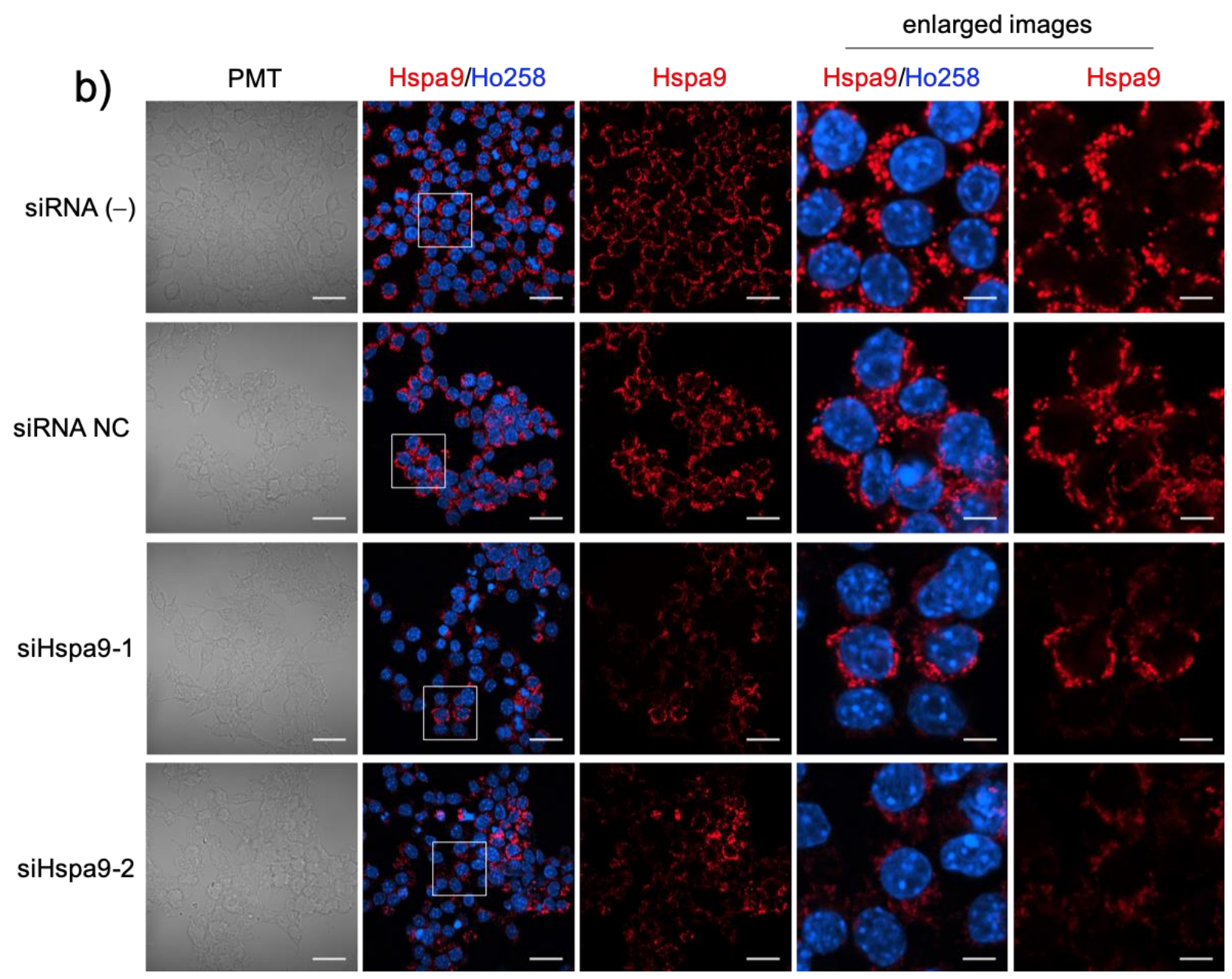

Supplementary Fig. 19 (continued) 


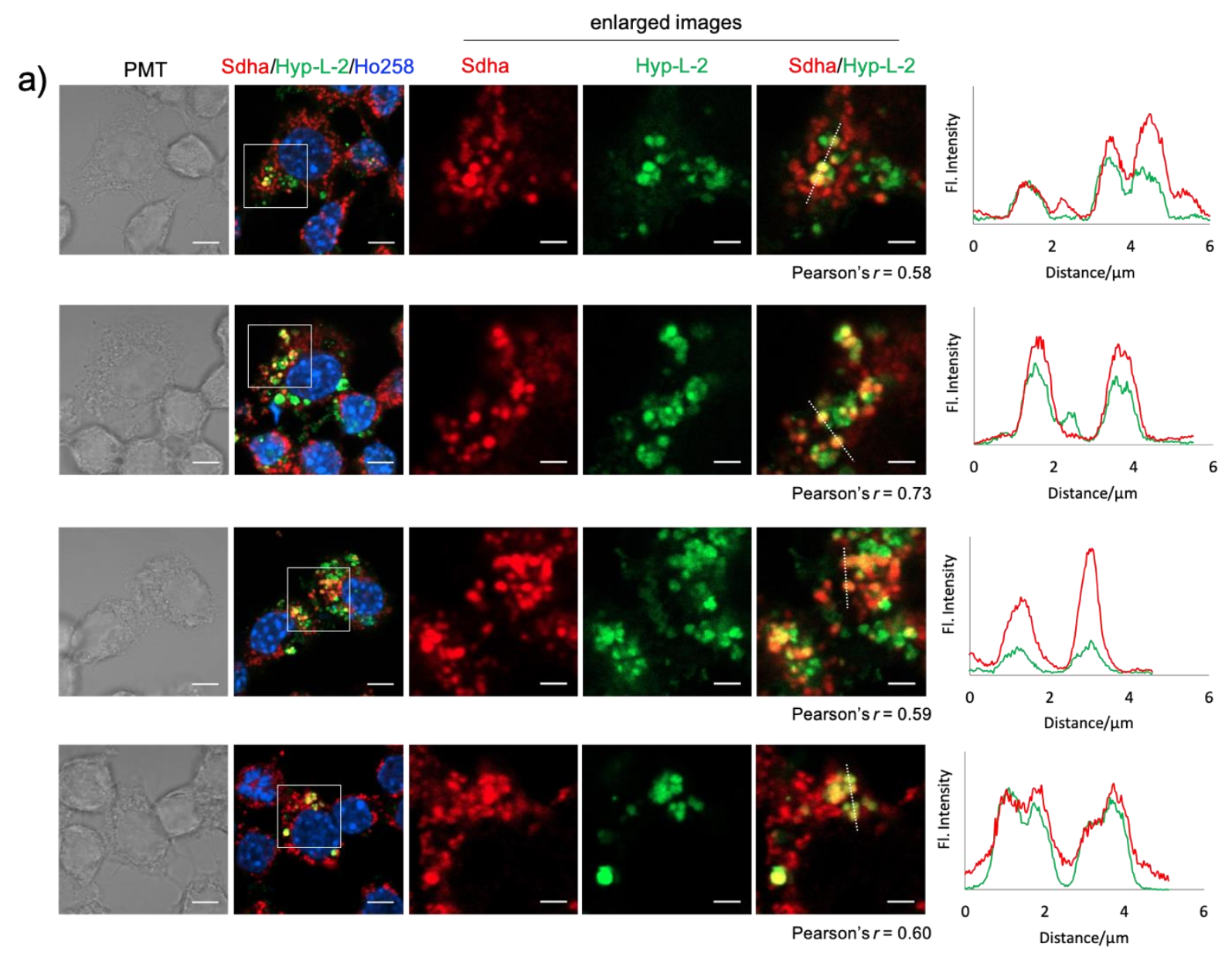

Supplementary Fig. 20 CLSM imaging of the immunofluorescence against Sdha and Hspa9 that were partially merged with Hyp-L-2-labeled vesicles. RAW264.7 macrophages were activated by $1 \mu \mathrm{g} / \mathrm{mL}$ of PMA for $30 \mathrm{~min}$, followed by incubation with Hyp-L-2 for $30 \mathrm{~min}$. After fixation, permeabilization, and blocking, the cells were incubated with primary antibody at $4{ }^{\circ} \mathrm{C}$ overnight, followed by incubation with secondary antibody and Hoechst 33258 (Ho258) at room temperature for $1 \mathrm{~h}$. Images from 4 separate fields containing over 10 cells were collected and analyzed for each antibody. Line-plot graphs indicate the fluorescence intensity profiles of antibodies (red) and Hyp-L-2 (green) along the white dotted lines. Colocalization was quantified using Pearson's $r$. Scale bars, $5 \mu \mathrm{m}$ and $2 \mu \mathrm{m}$ (enlarged images). 
enlarged images

b)

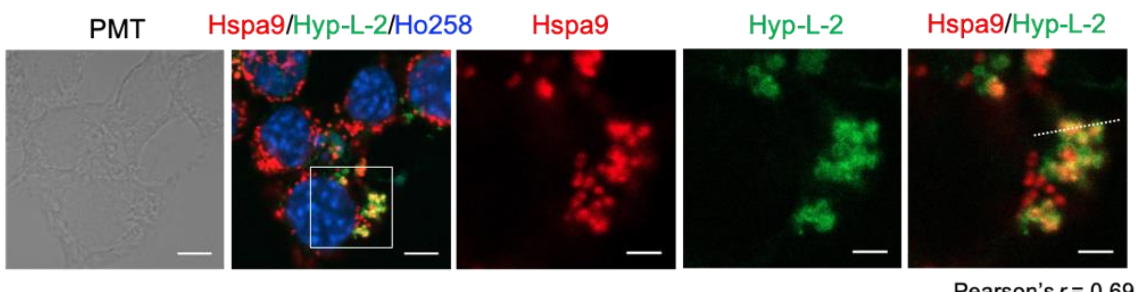

Pearson's $r=0.69$
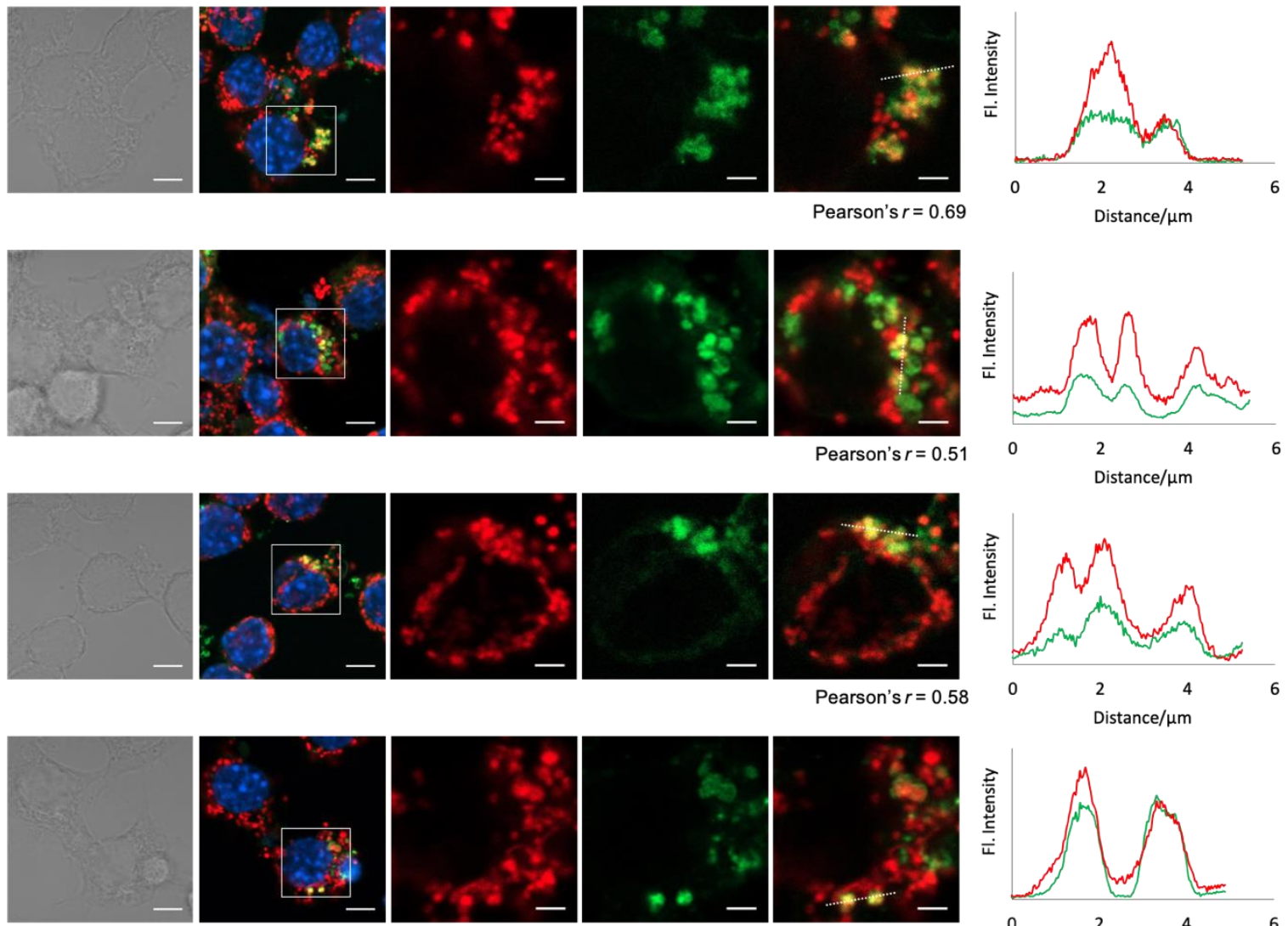

Pearson's $r=0.52$

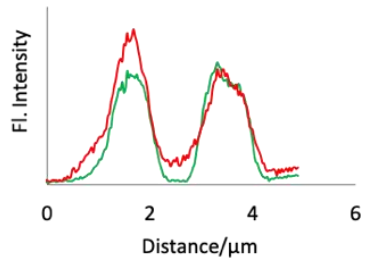

Supplementary Fig. 20 (continued) 

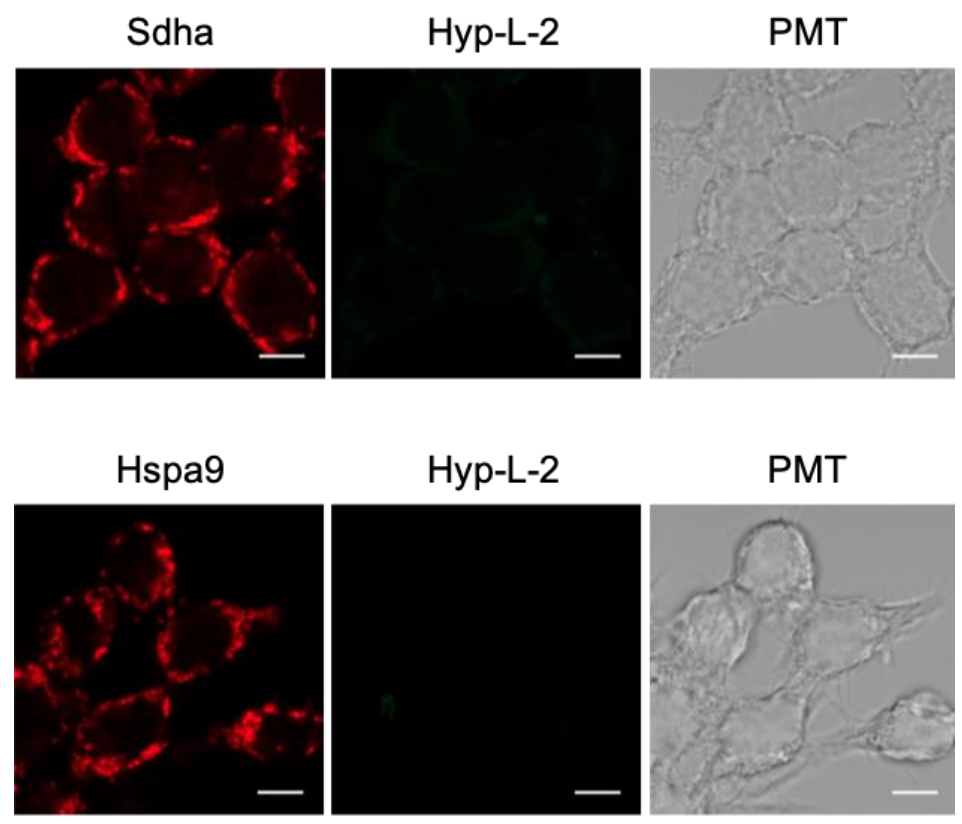

Supplementary Fig. 21 CLSM imaging of the immunofluorescence against Sdha and Hspa9 in untreated cells. RAW264.7 macrophages were incubated with Hyp-L-2 for 30 min. After fixation, permeabilization, and blocking, the cells were incubated with primary antibody at $4{ }^{\circ} \mathrm{C}$ overnight, followed by incubation with secondary antibody at room temperature for $1 \mathrm{~h}$. Scale bar, $5 \mu \mathrm{m}$.

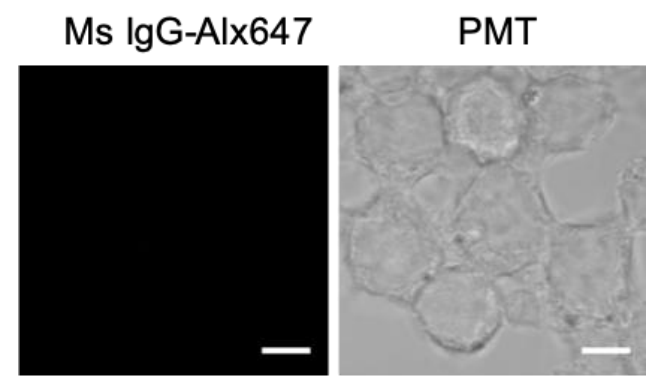

Supplementary Fig. 22 Negative controls of $2^{\text {nd }}$ antibody only for the immunostaining experiments. RAW264.7 macrophages were activated by $1 \mu \mathrm{g} / \mathrm{mL}$ of PMA for $30 \mathrm{~min}$, followed by incubation with Hyp-L-2 for $30 \mathrm{~min}$. After fixation, permeabilization, and blocking, the cells were incubated without primary antibody at $4{ }^{\circ} \mathrm{C}$ overnight, followed by incubation with secondary antibody at room temperature for $1 \mathrm{~h}$. Scale bar, $5 \mu \mathrm{m}$. 


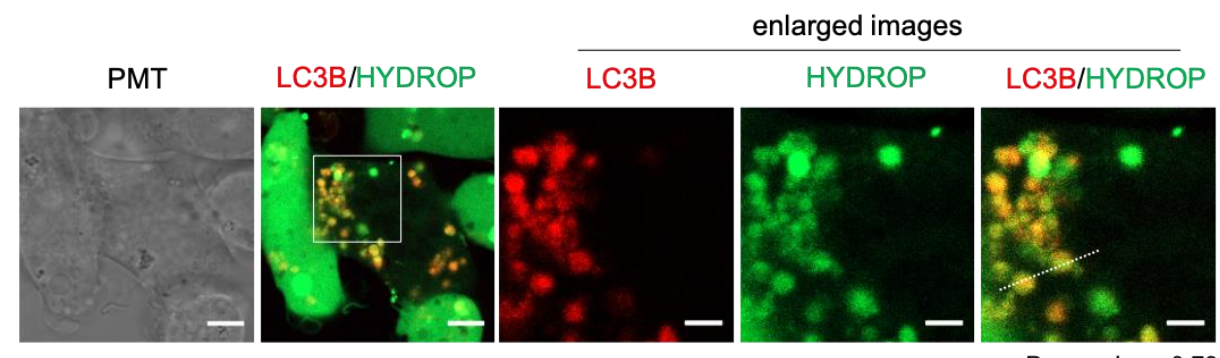

Pearson's $r=0.73$
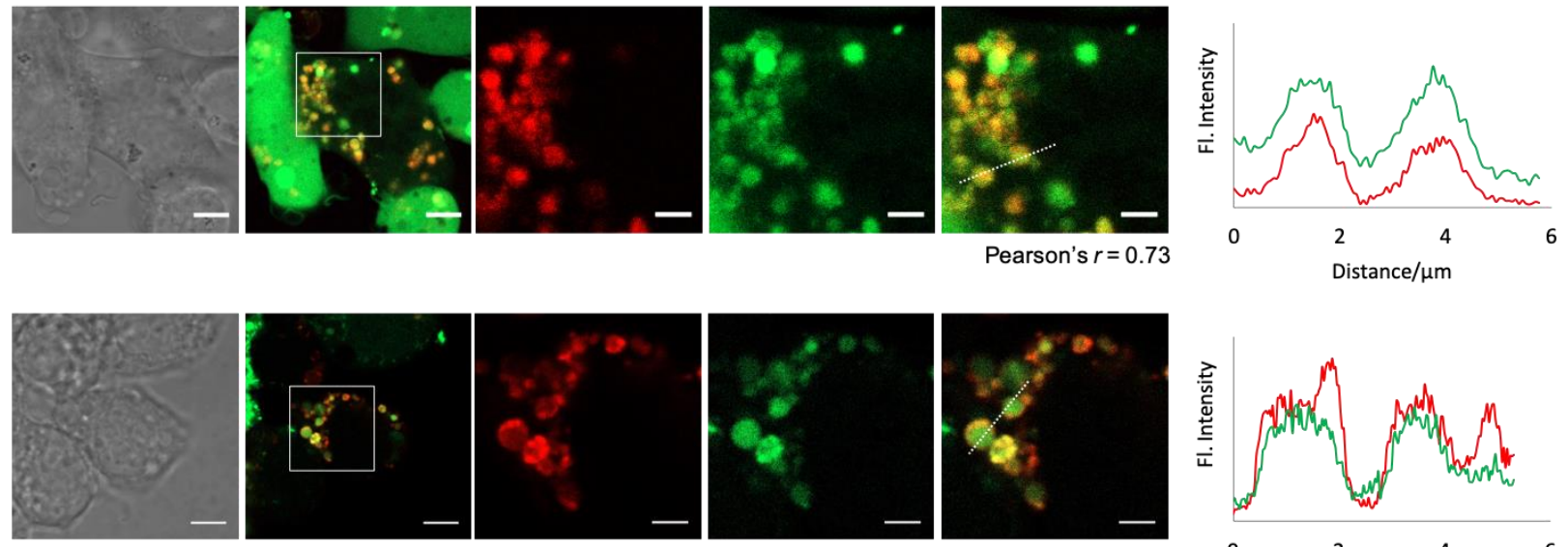

Pearson's $r=0.72$
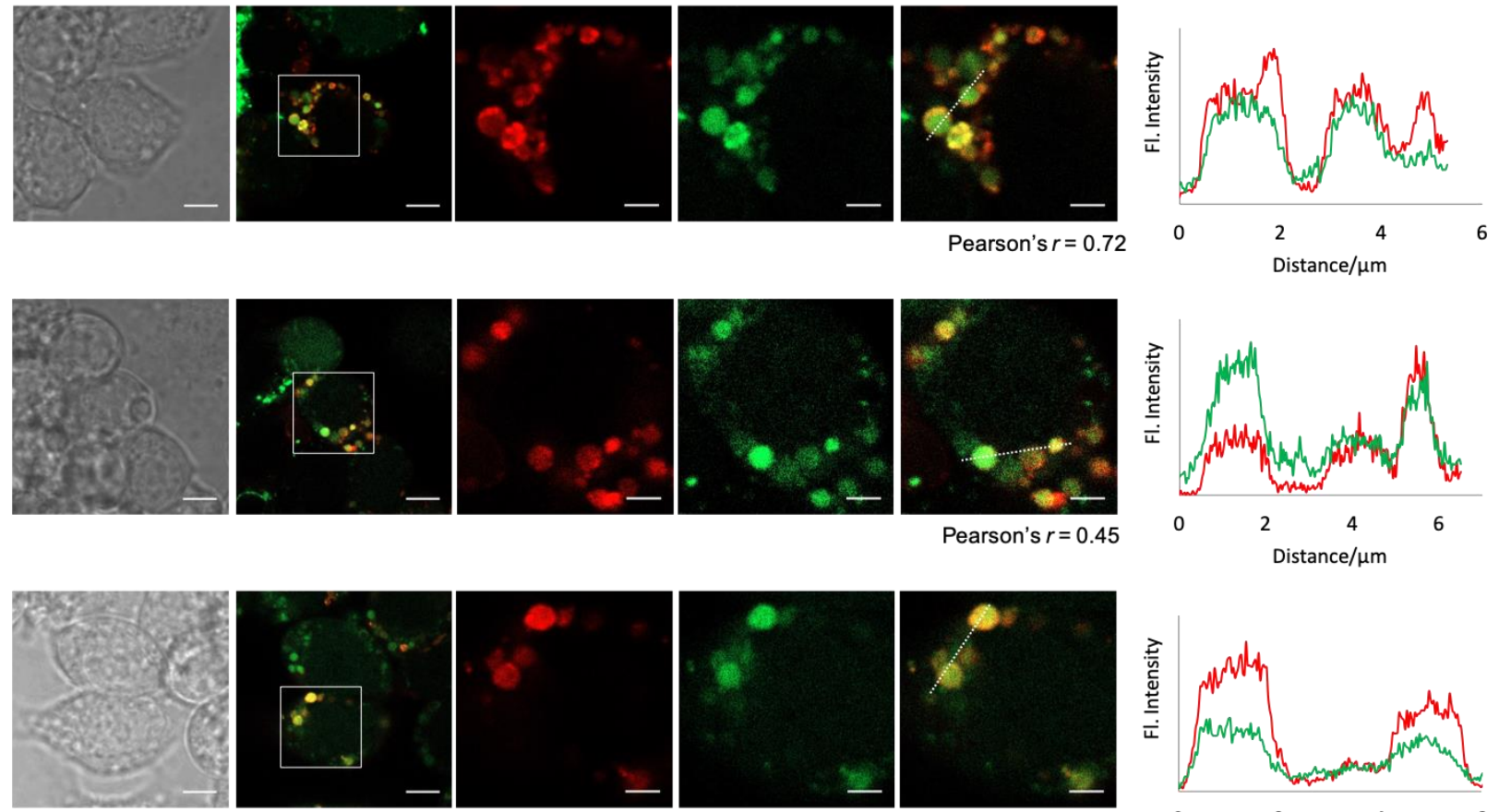

Pearson's $r=0.66$

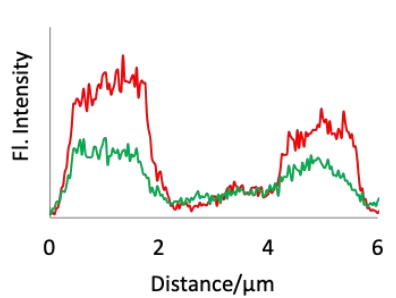

Supplementary Fig. 23 Colocalization imaging of mCherry-LC3B with HYDROP in PMAstimulated RAW264.7 macrophages. Cells were transfected with mCherry-LC3B, followed by activation with $1 \mu \mathrm{g} / \mathrm{mL}$ of PMA for $30 \mathrm{~min}$ and labeling by $5 \mu \mathrm{M}$ of HYDROP for $30 \mathrm{~min}$. Images from 4 separate fields containing over 10 cells were collected and analyzed. Line-plot graphs indicate the fluorescence intensity profiles of mCherry-LC3B (red) and Hyp-L-2 (green) along the white dotted lines. Colocalization was quantified using Pearson's $r$. Scale bars, $5 \mu \mathrm{m}$ and $2 \mu \mathrm{m}$ (enlarged images). 

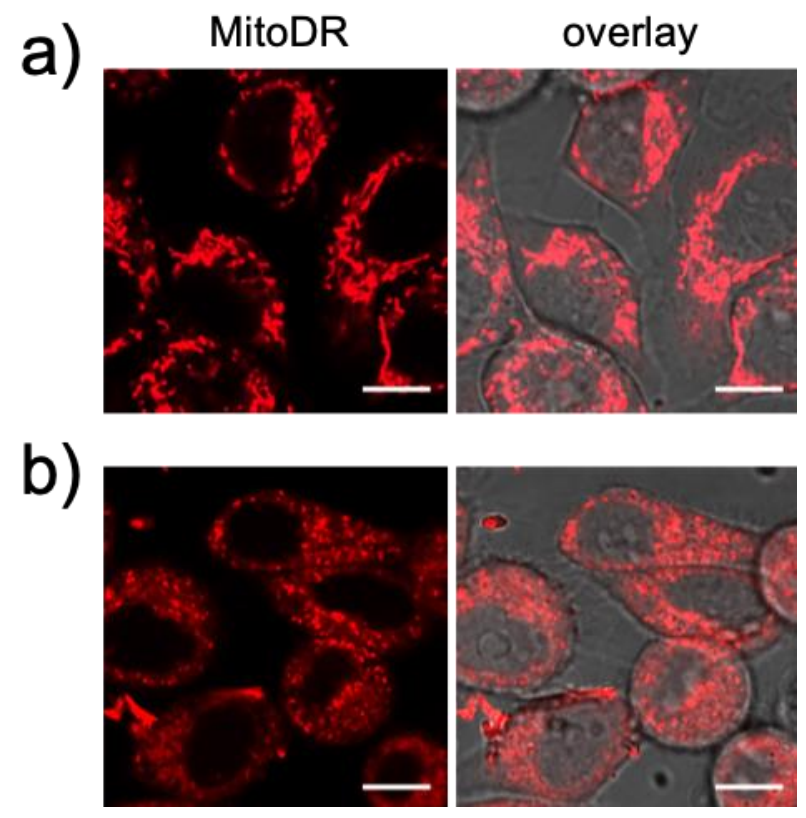

Supplementary Fig. 24 CLSM imaging of HeLa cells labeled with MitoDR. a) Cells were not treated with TTFA. b) Cells were treated with TTFA. HeLa cells were stained with $200 \mathrm{nM}$ of MitoDR for $15 \mathrm{~min}$, followed by treatment with TTFA (1 mM, $30 \mathrm{~min})$. Scale bars, $10 \mu \mathrm{m}$. 
a)

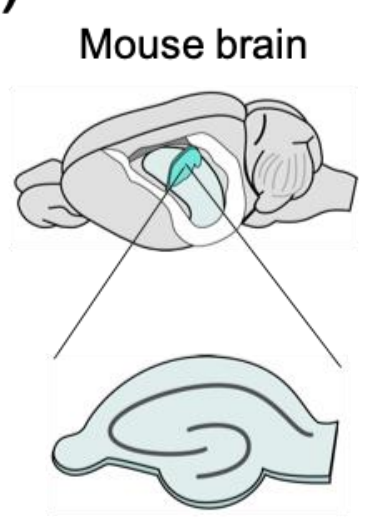

Hippocampal slice
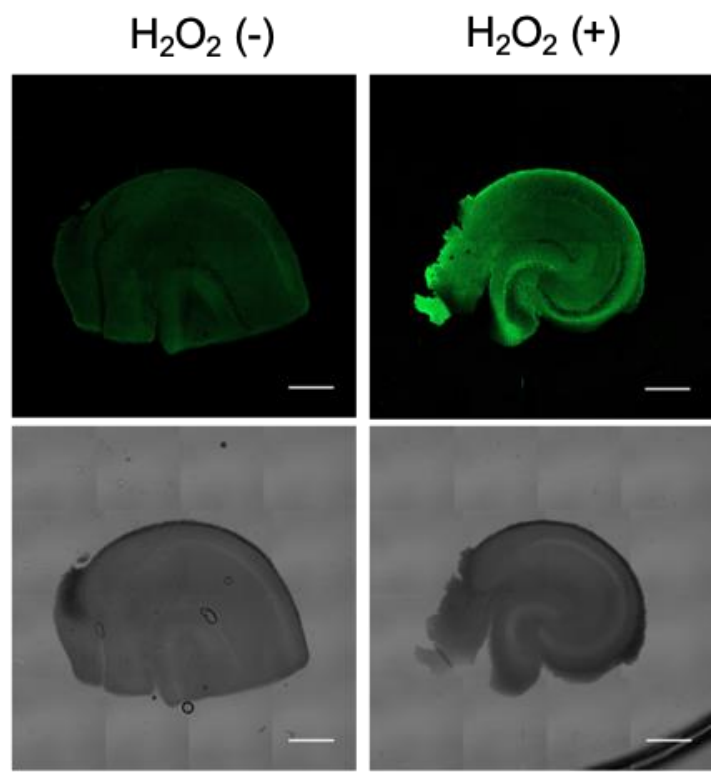

b)
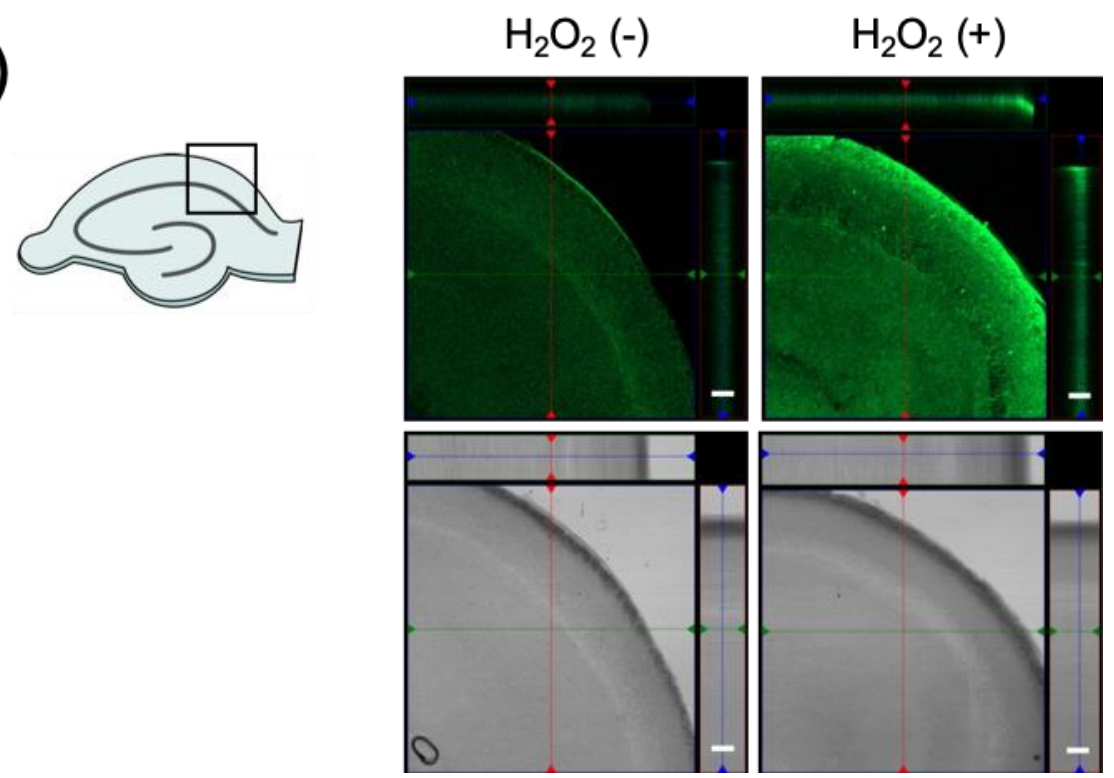

Supplementary Fig. 25 CLSM imaging of the $\mathrm{H}_{2} \mathrm{O}_{2}$-responsive labeling in hippocampal slices. Acutely prepared slices were incubated with $5 \mu \mathrm{M}$ of Hyp-L-2 for $60 \mathrm{~min}$, followed by the treatment with $1 \mathrm{mM} \mathrm{H} \mathrm{O}_{2}$ for $30 \mathrm{~min}$. The slices were fixed and permeabilized before CLSM imaging. a) Imaging of the whole slices. Scale bars, $500 \mu \mathrm{m}$. b) Z-stack imaging. Images were recorded with an interval of $5 \mu \mathrm{m}$. Scale bars, $100 \mu \mathrm{m}$. 

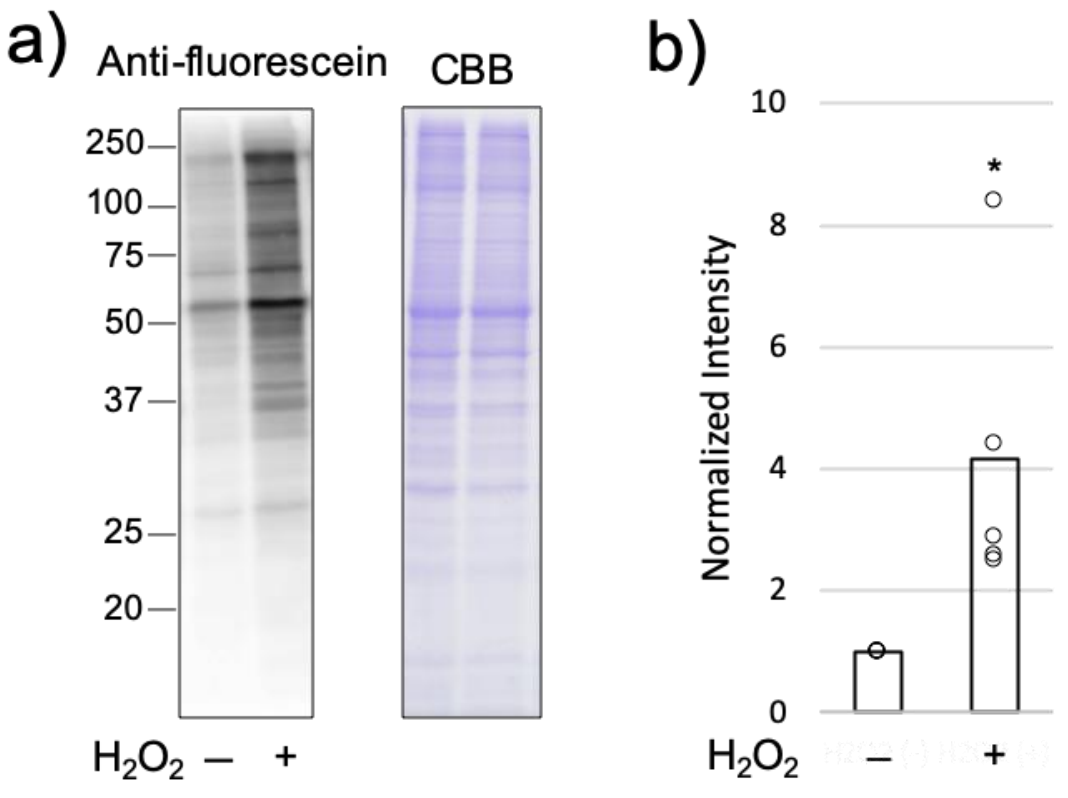

Supplementary Fig. 26 Western blot analysis of the $\mathrm{H}_{2} \mathrm{O}_{2}$-responsive labeling. Acutely prepared slices were incubated with $5 \mu \mathrm{M}$ of Hyp-L-2 for $60 \mathrm{~min}$, followed by the treatment with $1 \mathrm{mM} \mathrm{H}_{2} \mathrm{O}_{2}$ for 30 min. a) Western blot imaging. b) Quantification of the labeling in a). The band intensities were normalized to the data of $\mathrm{H}_{2} \mathrm{O}_{2}(-)$. Statistical analyses were performed with a two-tailed Student's $t$-test $(n=5)$ relative to the data of $\mathrm{H}_{2} \mathrm{O}_{2}(-) . * P<0.05$. 


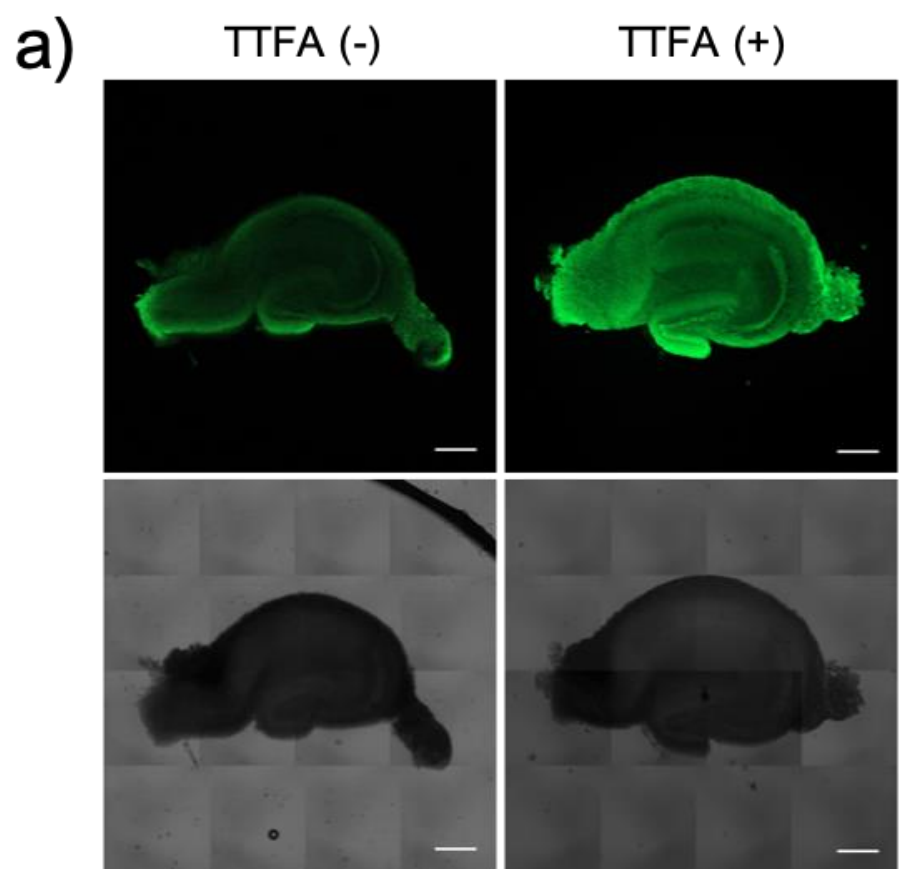

b)

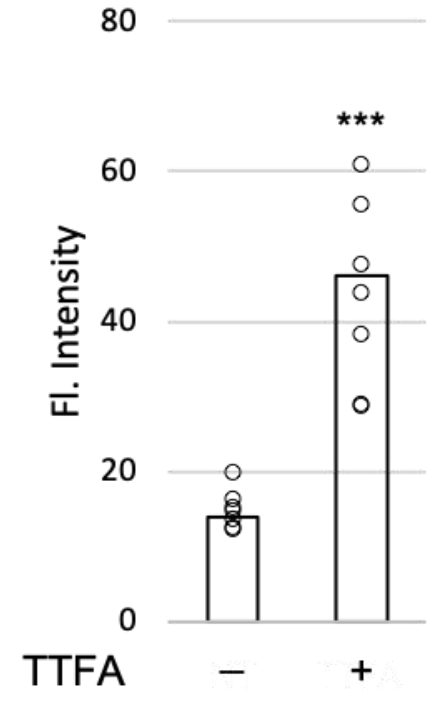

Supplementary Fig. $27 \mathrm{H}_{2} \mathrm{O}_{2}$ detection by HYDROP in TTFA-stimulated hippocampal slices.

a) CLSM imaging of living slices. Acutely prepared slices were treated with $1 \mathrm{mM}$ of TTFA for $30 \mathrm{~min}$, followed by incubation with $5 \mu \mathrm{M}$ of HYDROP for $60 \mathrm{~min}$. Scale bars, $500 \mu \mathrm{m}$. b) Quantification of the imaging in a). The fluorescence intensities were extracted from seven POIs in each image of a). Statistical analyses were performed with a two-tailed Student's $t$-test $(n=7)$ relative to the data of TTFA $(-) .{ }^{* * *} P<0.001$. 
a)
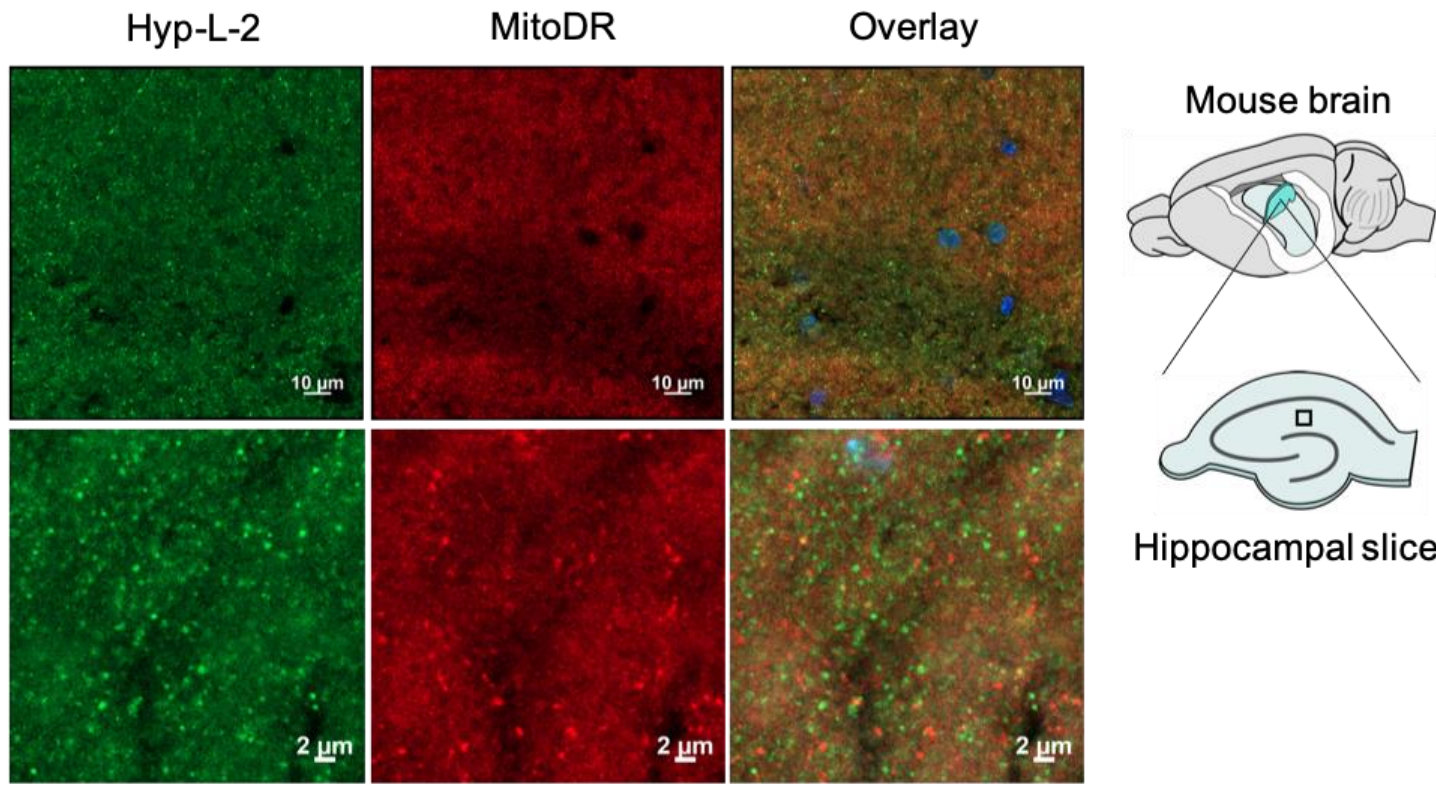

Hippocampal slice

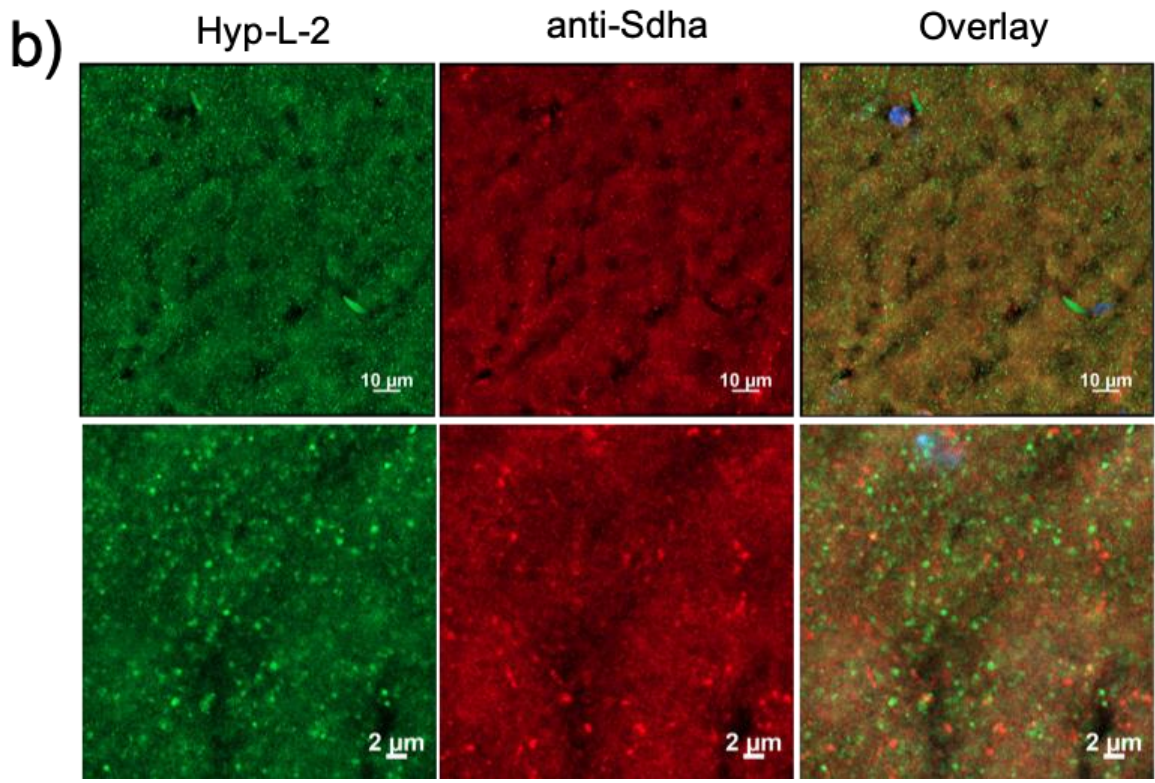

Supplementary Fig. 28 Colocalization imaging in TTFA-treated hippocampal slices. Acutely prepared slices were stained with $200 \mathrm{nM}$ of MitoDR for $60 \mathrm{~min}$, followed by TTFA stimulation (1 mM, $30 \mathrm{~min}$ ) and Hyp-L-2 labeling (5 $\mu \mathrm{M}, 60 \mathrm{~min})$. After PFA fixation and permeabilization with chilled methanol, the slices were trimmed to $40 \mu \mathrm{m}$ by cryostat. The thin slices were blocked and subject to immunostaining. Nucleus was stained by Hoechst $33258(1 \mu \mathrm{g} / \mathrm{mL})$. a) Imaging of Hyp-L-2 with MitoDR. b) Imaging of Hyp-L-2 with immunofluorescence towards anti-Sdha. The lower panels are enlarged from the upper ones. Images were recorded under the Airyscan mode. 


\section{General materials and methods for the biochemical experiments}

SDS-polyacrylamide gel electrophoresis (SDS-PAGE) and western blotting were carried out using a Bio-Rad Mini-Protean III electrophoresis apparatus. Chemical luminescence signals generated with ECL Prime (GE Healthcare) and fluorescence gel images were acquired with a LAS4000 (GE Healthcare) or FUSION-FX7 (Vilber-Lourmat) imaging system. Cell imaging was performed with a confocal laser scanning microscope (CLSM) (Olympus FV10i or Carl Zeiss LSM800) equipped with a $63 \times$ or $100 \times$ objectives lens. Tissue imaging was performed with a CLSM (Carl Zeiss LSM800) equipped with a $5 \times, 20 \times$, or $63 \times$ objectives lens.

\section{Estimation of the diffusion radius of QM}

The diffusion radius of QM was estimated using Fick's law, ${ }^{\mathrm{S} 1}$ as shown in Supplementary equation (1).

$\Delta x=-\frac{\ln \left([Q M] /[Q M]_{0}\right)}{\sqrt{\ln 2 / D t_{1 / 2}}}$

where $\Delta x$ is the diffusion radius, $\mathrm{D}$ is the diffusion coefficient, and $\mathrm{t}_{1 / 2}$ is the half-life for $\mathrm{QM}$. The distance over which the $\mathrm{QM}$ concentration $[Q M]$ drops to a tenth, that is $[Q M] /[Q M]_{0}=0.1$, is taken as its $\Delta x .{ }^{\mathrm{S} 2} \mathrm{D}$ refers to that of fluorescein in the water at $25{ }^{\circ} \mathrm{C} .{ }^{\mathrm{S} 3} \mathrm{The} \mathrm{t}_{1 / 2}$ of $\mathrm{QM}$ in biological systems was estimated in the presence of excess thiols, following a pseudo-first-order reaction equation (Supplementary equation (2)).

$t_{1 / 2}=\frac{\ln 2}{k[R S H]_{0}}$

where $\mathrm{k}$ is the second-order decay rate constant of $\mathrm{QM}$ in the presence of thiols ${ }^{\mathrm{S} 4}$ and $[R S H]_{0}$ applies a nominal cellular GSH concentration of $2 \mathrm{mM}^{\mathrm{S} 2}$ According to the equations (1) and (2), the diffusion radius of QM in biological systems was estimated as $437 \mathrm{~nm}$.

\section{Hydrolysis assay}

To evaluate the time course of hydrolysis, $\mathrm{H}_{2} \mathrm{O}_{2}(500 \mu \mathrm{M})$ was added to a solution of Hyp-L-1 (50 $\mu \mathrm{M})$ in PBS (-) buffer containing $250 \mu \mathrm{M}$ of terephthalic acid as the internal standard. After incubation at $37^{\circ} \mathrm{C}$ for $0,1,5,15$, or $30 \mathrm{~min}$, the solutions were mixed with $2 \mathrm{mM} \mathrm{of} \mathrm{Na}_{2} \mathrm{~S}_{2} \mathrm{O}_{3}$ to stop the reactions and subjected to RP-HPLC analyses (column: YMC-pack ODS-A, $250 \times 4.6$ mm; mobile phase: $\mathrm{CH}_{3} \mathrm{CN}$ (containing $0.1 \%$ TFA) $/ \mathrm{H}_{2} \mathrm{O}$ (containing $0.1 \%$ TFA) $=(30 / 70$ to $60 / 40)$ 
(linear gradient over $40 \mathrm{~min}$ ); flow rate: $1.0 \mathrm{~mL} / \mathrm{min}$; detection: UV-Vis $(220-600 \mathrm{~nm})$ ). The products were identified by MALDI-TOF-MS and the hydrolysis ratios were determined by the $\mathrm{Abs}_{420}$ area. To investigate the $\mathrm{H}_{2} \mathrm{O}_{2}$-concentration-dependent hydrolysis, various concentrations of $\mathrm{H}_{2} \mathrm{O}_{2}(0,10,50,100,200$, or $500 \mu \mathrm{M})$ were added, and the reaction mixture was incubated at $37^{\circ} \mathrm{C}$ for $30 \mathrm{~min}$.

\section{Protein labeling in vitro}

Bovine serum albumin (BSA) was purchased from Sigma-Aldrich (A2153). To evaluate the timecourse of BSA labeling, $\mathrm{H}_{2} \mathrm{O}_{2}(200 \mu \mathrm{M})$ was added to a PBS (-) buffer containing $10 \mu \mathrm{M}$ of BSA and $50 \mu \mathrm{M}$ of Hyp-L-1, followed by incubation at $37^{\circ} \mathrm{C}$ for $0,2,5,10,20,30,45$, or $60 \mathrm{~min}$. The resulting solutions were mixed with $2 \times$ laemmli buffer $(\mathrm{pH} 6.8 ; 125 \mathrm{mM}$ Tris- $\mathrm{HCl}, 20 \%$ glycerol, $4 \%$ SDS, $0.01 \%$ bromophenol blue, $10 \%$ 2-mercaptoethanol) and boiled at $95^{\circ} \mathrm{C}$ for $5 \mathrm{~min}$. The samples were applied to a $12.5 \%$ SDS-PAGE gel and imaged by Coomassie Brilliant Blue (CBB) stain and in-gel fluorescence. To investigate the $\mathrm{H}_{2} \mathrm{O}_{2}$-concentration dependency, various concentrations of $\mathrm{H}_{2} \mathrm{O}_{2}(0,50,100,200,500,700$, or $1000 \mu \mathrm{M})$ were added, and the BSA solutions were incubated at $37^{\circ} \mathrm{C}$ for $30 \mathrm{~min}$. To investigate the selectivity to reactive oxygen species (ROS), $200 \mu \mathrm{M}$ of $\mathrm{H}_{2} \mathrm{O}_{2}, \mathrm{O}_{2}{ }^{-},{ }^{1} \mathrm{O}_{2}, \cdot \mathrm{OH}, \mathrm{OCl}^{-}, \cdot \mathrm{NO}$, or $\mathrm{ONOO}^{-}$was added, and the BSA solutions were incubated at $37^{\circ} \mathrm{C}$ for $30 \mathrm{~min}$. The ROS solutions were prepared freshly: $\mathrm{KO}_{2}$ for $\mathrm{O}_{2}^{-}$, 4-Methyl1,4-etheno-2,3-benzodioxin-1(4H)-propanoic acid (Wako, 137-17891) for ${ }^{1} \mathrm{O}_{2}$, Fenton reaction with $\mathrm{FeSO}_{4}$ and $\mathrm{H}_{2} \mathrm{O}_{2}$ for $\cdot \mathrm{OH}, \mathrm{NaOCl}$ for $\mathrm{OCl}^{-}$, NOC-7 for $\cdot \mathrm{NO}$, and SIN-1 (Cayman Chemical, 82220) for $\mathrm{ONOO}^{-}$.

\section{Determination of labeling yields on BSA}

The labeling yields of Hyp-L-1 on BSA were determined according to a standard coumarinmodified BSA (Dc-BSA) which was prepared as follows. $500 \mu \mathrm{M}$ of 7-(diethylamino)coumarin3-carboxylic acid $N$-succinimidyl ester ${ }^{\mathrm{S} 5}$ was added to a PBS (-) buffer solution containing $50 \mu \mathrm{M}$ of BSA. After incubation at room temperature overnight, the reaction mixture was purified by gel filtration (TOYOPEARL HW-40F) with PBS (-) as the eluent. The labeling yield of Dc-BSA (535\%) was determined according to absorbance data and extinction coefficients of BSA $\left(\varepsilon_{\mathrm{BSA}, 280 \mathrm{~nm}}=43824 \mathrm{M}^{-1} \mathrm{~cm}^{-1}\right)$ and coumarin $\left(\varepsilon \mathrm{Dc}, 280 \mathrm{~nm}=5000 \mathrm{M}^{-1} \mathrm{~cm}^{-1}, \varepsilon_{\mathrm{Dc}, 416 \mathrm{~nm}}=45000 \mathrm{M}^{-1} \mathrm{~cm}^{-1}\right)$. 
The labeling yields of Hyp-L-1 on BSA were calculated according to Supplementary equation (3) with Dc-BSA as the standard.

$Y_{x}=Y_{s} \times \frac{I_{x}}{I_{s}} \times \frac{C_{s}}{C_{x}}$

where $Y$ is labeling yield, $I$ is in-gel fluorescence intensity, $C$ is BSA concentration, $x$ and $s$ represent sample and standard, respectively.

\section{Analysis of coumarin-modified peptides}

BSA $(20 \mu \mathrm{M})$ were treated with Hyp-L-1 $(100 \mu \mathrm{M})$ and $\mathrm{H}_{2} \mathrm{O}_{2}(500 \mu \mathrm{M})$ in PBS (-) buffer for 30 min at $37^{\circ} \mathrm{C}$. The labeled BSA was subjected to in-gel tryptic digestion after dithiothreitol (DTT) $(10 \mathrm{mM})$ reduction and iodoacetamide (IAA) $(55 \mathrm{mM})$ alkylation. The sample was analyzed by nanoflow reverse-phase liquid chromatography followed by tandem MS using an LTQ-orbitrap XL hybrid mass spectrum (Thermo Fisher Scientific) as described in our previous work. ${ }^{\text {S6 }}$ Searches were performed by using SEQUEST (Thermo Fisher Scientific) against the latest Swissprot database for peptide and protein identification. Searches parameters were set as follows: (i) SEQUEST, enzyme selected as used with five maximum missing cleavage sites; (ii) species limited to bovine; (iii) a mass tolerance of 5 p.p.m. for peptide tolerance, 0.5 Da for MS/MS tolerance; (iv) variable modification of carbamidomethyl (C), oxidation (M), and coumarin modification (H, K, C, D, E, Y, T, S). Positive protein identifications were based on significant Xcorr (1\% false discovery rate (FDR)). 2 biological replicates were performed and combined.

\section{Cell culture}

RAW264.7 macrophages and HeLa cells were cultured in high glucose Dulbecco's Modified Eagle Medium (DMEM, $4.5 \mathrm{~g}$ of glucose/L) supplemented with $10 \%$ fetal bovine serum (FBS) and $1 \%$ Antibiotic-Antimycotic (Anti-Anti, gibco) under a humidified atmosphere of $5 \% \mathrm{CO}_{2}$ in air at $37^{\circ} \mathrm{C}$. Cells were harvested from subconfluent cultures using a cell scraper method (RAW264.7) or trypsin-EDTA (HeLa) and then resuspended in a fresh medium. A subculture was performed every 2-3 days.

\section{Cytotoxicity in RAW264.7 macrophages}

RAW264.7 macrophages were seeded in a 96-well plate under a humidified atmosphere of 5\% $\mathrm{CO}_{2}$ in air at $37^{\circ} \mathrm{C}$ for $48 \mathrm{~h}$ in DMEM. The cells were washed three times with serum-free DMEM 
and incubated in serum-free DMEM containing Hyp-L-2 $(5 \mu \mathrm{M})$. After $1 \mathrm{~h}$, the cells were washed once with serum-free DMEM and incubated in serum-free DMEM containing $10 \%$ cell counting kit-8 (Dojindo) solution for $1.6 \mathrm{~h}$. The absorbance at $450 \mathrm{~nm}$ was measured and the cell viability was calculated according to Supplementary equation (4).

Cell viability $(\%)=\left(A_{\text {sample }}-A_{b}\right) /\left(A_{c}-A_{b}\right) \times 100$

\section{$\mathrm{H}_{2} \mathrm{O}_{2}$-responsive labeling in $\mathrm{RAW} 264.7$ macrophages}

RAW264.7 macrophages $\left(2.0 \times 10^{5}\right.$ cells $)$ were cultured on $35 \mathrm{~mm}$ dishes under a humidified atmosphere of $5 \% \mathrm{CO}_{2}$ in air at $37^{\circ} \mathrm{C}$ for $48 \mathrm{~h}$ in DMEM. The cells were washed three times with serum-free DMEM, and incubated in serum-free DMEM containing Hyp-L-2 (5 $\mu \mathrm{M})$ for 10 min, followed by treatment with various concentrations of $\mathrm{H}_{2} \mathrm{O}_{2}(0,10,50,100,200,500$, or $1000 \mu \mathrm{M})$ for $30 \mathrm{~min}$. The cells were washed three times with PBS and lysed with RIPA buffer (25 mM Tris$\mathrm{HCl}, 150 \mathrm{mM} \mathrm{NaCl}, 1 \%$ Nonidet P-40, $0.1 \%$ sodium dodecyl sulfate, $0.25 \%$ sodium deoxycholate, pH 7.4) containing $1 \%$ protease inhibitor cocktail set III (Calbiochem, 39134) on ice. The protein concentrations were measured by bicinchoninic acid assay (BCA Protein Assay Kit, Thermo Fisher Scientific). The lysates were mixed with $5 \times$ laemmli buffer (325 mM Tris-HCl, 15\% SDS, $20 \%$ sucrose, and $0.2 \% \mathrm{BPB}, \mathrm{pH} 6.8$ ) containing $250 \mathrm{mM}$ of DTT. After vortex at room temperature for $1 \mathrm{~h}$, the samples were applied to a 12.5\% SDS-PAGE gel and imaged by the Coomassie Brilliant Blue (CBB) stain and in-gel fluorescence.

\section{PMA-induced labeling in RAW264.7 macrophages}

RAW264.7 macrophages $\left(2.0 \times 10^{5}\right.$ cells $)$ were cultured on $35 \mathrm{~mm}$ dishes under a humidified atmosphere of $5 \% \mathrm{CO}_{2}$ in air at $37^{\circ} \mathrm{C}$ for $48 \mathrm{~h}$ in DMEM. After washing with serum-free DMEM, the cells were activated by $1 \mu \mathrm{g} / \mathrm{mL}$ of PMA (Wako, 162-23591) in the absence or presence of DPI $(10 \mu \mathrm{M})$, apocynin $(5 \mathrm{mM})$, L-NAME $(5 \mathrm{mM})$, ebselen $(5 \mu \mathrm{M})$, or $N$-acetyl cysteine $(10 \mathrm{mM})$ for $30 \mathrm{~min}$, followed by incubation with $5 \mu \mathrm{M}$ of Hyp-L-2 for $30 \mathrm{~min}$. The cells were washed three times with PBS and lysed with RIPA buffer containing 1\% protease inhibitor cocktail set III on ice. The protein concentrations were measured by BCA assay. The lysates were mixed with $5 x$ laemmli buffer containing $250 \mathrm{mM}$ of DTT and vortexed for $1 \mathrm{~h}$. The samples were applied to SDS-PAGE and electrotransferred onto ImmunBlot PVDF membranes (Bio-Rad). The membranes were blocked with 5\% skim milk in Tris-buffered saline (TBS) containing $0.05 \%$ Tween 20 
(Sigma-Aldrich) and stained with rabbit anti-fluorescein antibody (Abcam, ab19491, ×3000), followed by the reaction with HRP-conjugated goat anti-rabbit IgG (Cell signaling Technology, 7074 S, $\times 5000)$. The membranes were developed with ECL prime. To evaluate the expression of iNOS, rabbit anti-iNOS antibody (Abcam, ab15323, ×1000) was used.

\section{CLSM imaging by Hyp-L-2 and HYDROP in RAW264.7 macrophages}

RAW264.7 cells were cultured on $35 \mathrm{~mm}$ glass-bottom dishes (IWAKI). For the response to exogenous $\mathrm{H}_{2} \mathrm{O}_{2}$, cells were incubated in serum-free DMEM containing $5 \mu \mathrm{M}$ of Hyp-L-2 or HYDROP (GORYO Chemical) for $10 \mathrm{~min}$, followed by treatment $100 \mu \mathrm{M}$ of $\mathrm{H}_{2} \mathrm{O}_{2}$ for 30 min. For the response to endogenous $\mathrm{H}_{2} \mathrm{O}_{2}$ induced by PMA, cells were activated by $1 \mu \mathrm{g} / \mathrm{mL}$ of PMA for $30 \mathrm{~min}$, followed by incubation with $5 \mu \mathrm{M}$ of Hyp-L-2 or HYDROP for $30 \mathrm{~min}$. The cells were subsequently fixed in chilled methanol for $15 \mathrm{~min}$ at $-30^{\circ} \mathrm{C}$, washed with PBS thrice, and imaged by CLSM.

\section{Enrichment of labeled proteins in RAW264.7 macrophages}

RAW264.7 cells $\left(5.0 \times 10^{5}\right.$ cells $)$ were cultured on $10 \mathrm{~cm}$ dishes under a humidified atmosphere of $5 \% \mathrm{CO}_{2}$ in air at $37^{\circ} \mathrm{C}$ for $72 \mathrm{~h}$ in DMEM. After washing with serum-free DMEM, the cells were activated by $1 \mu \mathrm{g} / \mathrm{mL}$ of PMA for $30 \mathrm{~min}$, followed by incubation with $5 \mu \mathrm{M}$ of Hyp-L-2 for 30 min. The labeled cells were rinsed twice with chilled PBS, lysed by sonication in 1\% SDSRIPA buffer containing $1 \%$ protease inhibitor cocktail set III. After boiling at $95{ }^{\circ} \mathrm{C}$ for 3 min, the lysates were centrifuged $\left(12,000 \mathrm{G}, 10 \mathrm{~min}, 4^{\circ} \mathrm{C}\right)$. The supernatants were subjected to dialysis $($ Spectra/Por 6, MWCO = 3.5 kDa) in 0.5\% SDS-Tris (25 mM Tris, $150 \mathrm{mM} \mathrm{NaCl,} \mathrm{pH} \mathrm{7.4)} \mathrm{to}$ remove small molecules. After dialysis, the lysates were diluted 5 times with RIPA buffer (final SDS concentration was $\sim 0.1 \%$ ) and centrifuged. The protein concentrations were determined by BCA assay and $1.2 \mathrm{mg}$ of proteins were applied to immunoprecipitation. $50 \mu \mathrm{L}$ of nProtein A sepharose 4 Fast Flow (GE Healthcare) was incubated with $30 \mu \mathrm{L}$ of an anti-fluorescein antibody for $2 \mathrm{~h}$ at $4{ }^{\circ} \mathrm{C}$ with rotation. The beads were washed with RIPA buffer twice followed by the addition of $1.2 \mathrm{mg}$ of lysates and further incubation at $4{ }^{\circ} \mathrm{C}$ for $4 \mathrm{~h}$. After incubation, the beads were washed with RIPA buffer for 5 times, vortex for $5 \mathrm{~min}$, and boiled for $5 \mathrm{~min}$ in $2 \times$ laemmli buffer containing $100 \mathrm{mM}$ DTT. 


\section{In-gel tryptic digestion and peptide extraction}

The samples of enriched proteins in laemmli buffer were loaded to a 7.5\% SDS-PAGE gel (MiniPROTEAN TGX Gels) and resolved $\sim 1 \mathrm{~cm}$ by the running gel. The gel containing protein samples was manually cut into gel slices, fixed with $47.5 \%$ methanol/water containing $5 \%$ acetic acid for $20 \mathrm{~min}$, and rinsed with pure water. After dehydration in acetonitrile, the gels were swelled with $200 \mu \mathrm{L}$ of $10 \mathrm{mM}$ DTT in $100 \mathrm{mM}$ TEAB (triethylamine bicarbonate) buffer (Sigma-Aldrich) and heated at $56^{\circ} \mathrm{C}$ for $30 \mathrm{~min}$. The DTT solutions were replaced with $55 \mathrm{mM}$ IAA in $100 \mathrm{mM}$ TEAB buffer and allowed to react for $45 \mathrm{~min}$ in the dark. The gel fractions were washed with $100 \mathrm{mM}$ TEAB buffer, dehydrated in acetonitrile, rehydrated in $100 \mathrm{mM}$ TEAB buffer, and dehydrated in acetonitrile again. The gels were swelled in $100 \mathrm{mM}$ TEAB buffer containing $10 \mathrm{ng} / \mu \mathrm{L}$ Sequence Grade Trypsin (Promega) and incubated overnight at $37^{\circ} \mathrm{C}$. After the digestion, we transferred the supernatant to a new tube and added $50 \mu \mathrm{L}$ of an extraction solution (50\% acetonitrile, $0.1 \% \mathrm{TFA})$ to the gel pieces. The supernatants were collected after 10 min incubation and we repeated this process two additional times. Extracted peptides were concentrated by the centrifugal concentrator.

\section{Preparation of TMT-labeled peptide mixture}

The concentrated peptides were reconstituted with $25 \mu \mathrm{L}$ of $100 \mathrm{mM}$ TEAB buffer. To the solutions, a $10.25 \mu \mathrm{L}$ of TMT reagent $(0.8 \mathrm{mg} / 41 \mu \mathrm{L})$ in acetonitrile was added. We used 6-plex TMT reagents (Thermo Fisher Scientific) for PMA (-) and PMA (+) samples (light tag for PMA $(-)$, heavy tag for PMA (+)). The peptides were allowed to react for $1 \mathrm{~h}$ at room temperature, and the reactions were quenched by the addition of $5 \%$ hydroxylamine $(2 \mu \mathrm{L})$. Two different solutions were mixed in a 1:1 ratio and concentrated by the centrifugal concentrator. The peptides were reconstituted in $200 \mu \mathrm{L}$ of $5 \%$ acetonitrile/0.1\% TFA mixture and loaded onto GL-Tip SDB (GL Sciences). After washing with 5\% acetonitrile/0.1\% TFA mixture, and peptides were eluted by $80 \%$ acetonitrile/0.1\% TFA mixture.

\section{NanoLC-MS/MS analyses}

NanoLC-MS/MS analyses were performed on a Q-Exactive mass spectrometer (Thermo Fisher Scientific) and an Ultimate 3000 nanoLC pump (AMR) as described previously. ${ }^{\text {S7 }}$ Samples were automatically injected using PAL system (CTC analytics, Zwingen, Switzerland) into a peptide Ltrap column OSD $(5 \mu \mathrm{m})$ attached to an injector valve for desalinating and concentrating peptides. 
After washing the trap with MS-grade water containing 0.1\% TFA and 2\% acetonitrile, the peptides were loaded into a nano HPLC capillary column (C18 packed with the gel particle size of $3 \mu \mathrm{m}, 0.1 \times 125 \mathrm{~mm}$, Nikkyo Technos, Tokyo Japan) by switching the valve. The injection volume was $10 \mu \mathrm{L}$ and the flow rate was $500 \mathrm{~nL} / \mathrm{min}$. The mobile phases consisted of (A) $0.5 \%$ acetic acid and (B) $0.5 \%$ acetic acid and 80\% acetonitrile. A two-step linear gradient of 5-45\% B in 60 min, 45-95\% B in $1 \mathrm{~min}, 95 \%$ B for $20 \mathrm{~min}$ was employed. Spray voltages of 2,000 V were applied. The mass scan ranges were $m / z, 350-1,800$, and the top ten precursor ions were selected in each MS scan for subsequent MS/MS scans. The normalized collision energy was set to be 30 . The raw MS data files were analyzed by Proteome Discoverer 2.2 (Thermo Fisher Scientific) to create peak lists based on the recorded fragmentation spectra. Peptides and proteins were identified using automated database searching using Sequest HT (Thermo Fisher Scientific) against UniprotKB/Swiss-Prot release 2018-04-14 with a precursor mass tolerance of 10 p.p.m., a fragment ion mass tolerance of $0.02 \mathrm{Da}$, and trypsin specificity that allows for up to three or two missed cleavages. TMTs on lysine residues and peptide $\mathrm{N}$ termini and cysteine carbamidomethylation were set as fixed modifications. Methionine oxidation was allowed as a variable modification. A reversed decoy database search was conducted to set false discovery rates (FDRs) of less than $1 \%$ both at peptide and protein levels. We performed three independent biological replicates in TMT quantitative analysis and the proteins hit at least twice were considered as the identified proteins, in which several keratins (contaminants) were excluded. The control experiment with FDA was carried out under the same condition.

\section{Western blotting analysis of expression levels of hit proteins}

RAW264.7 cells $\left(5.0 \times 10^{5}\right.$ cells $)$ were cultured on $10 \mathrm{~cm}$ dishes under a humidified atmosphere of $5 \% \mathrm{CO}_{2}$ in air at $37^{\circ} \mathrm{C}$ for $72 \mathrm{~h}$ in DMEM. After washing with serum-free DMEM, the cells were activated by $1 \mu \mathrm{g} / \mathrm{mL}$ of PMA for $30 \mathrm{~min}$. The cells were rinsed twice with chilled PBS, lysed by sonication in $1 \%$ SDS-RIPA buffer containing $1 \%$ protease inhibitor cocktail set III. The lysates were diluted 5 times with RIPA buffer (final SDS concentration was around 0.1\%) and centrifuged. The supernatants were mixed with $5 \times$ laemmli buffer containing $250 \mathrm{mM}$ of DTT and vortexed for $1 \mathrm{~h}$. The samples were resolved by SDS-PAGE (10 $\mu$ g protein/lane), and the proteins were electrotransferred onto ImmunBlot PVDF membranes. The membranes were blocked with $5 \%$ skim milk in Tris-buffered saline (TBS) containing $0.05 \%$ Tween 20. Primary antibody 
reaction was conducted with rabbit anti-Pkm (1: 1000, CST, 4053), rabbit anti-profilin (1: 1000, CST, 3237), mouse anti-Fas (1: 1000, CST, 3180), rabbit anti-Eif4a1 (1: 1000, abcam, ab31217), rabbit anti-Prdx1 (1: 1000, abcam, ab41906), mouse anti-Grp75 (Hspa9, 1: 1000, abcam, ab2799), rabbit anti-Grp78 (Hspa5, 1: 1000, abcam, ab21685), mouse anti-Sdha (1: 1000, abcam, ab14715), rabbit anti-Gapdh (1: 1000, CST, 5174), or mouse anti-beta actin (1: 5000, abcam, ab8226) at 4 ${ }^{\circ} \mathrm{C}$ overnight. Secondary antibody reaction was conducted with goat anti-rabbit IgG HRP (1: 5000, CST, 7074S) and goat anti-mouse IgG HRP (1: 5000, santa cruz, sc-2005) at room temperature for 1h.

\section{Microarray analyses}

RAW264.7 cells $\left(4.0 \times 10^{5}\right.$ cells $)$ were cultured on $60 \mathrm{~mm}$ dishes under a humidified atmosphere of $5 \% \mathrm{CO}_{2}$ in air at $37^{\circ} \mathrm{C}$ for $48 \mathrm{~h}$ in DMEM. The cells were washed with serum-free DMEM, and incubated in serum-free DMEM containing PMA $(1 \mu \mathrm{g} / \mathrm{mL})$ for $30 \mathrm{~min}$. The cells were then harvested for total RNA extraction by NucleoSpin RNA (Macherey-Nagel), and $100 \mathrm{ng}$ of total RNA was processed for hybridization on Clariom S Array (Mouse, Thermo Fisher Scientific). All processes followed the manufacturer's protocols using a GeneChip WT PLUS Reagent Kit and a GeneChip Hybridization, Wash and Stain Kit (Thermo Fisher Scientific). The scanned raw data were analyzed using the Transcriptome Analysis Console 4.0.1 Software (Thermo Fisher Scientific).

\section{Immunostaining of Sdha and Hspa9}

RAW264.7 macrophages $\left(0.5 \times 10^{5}\right.$ cells $)$ were cultured on glass coverslips under a humidified atmosphere of $5 \% \mathrm{CO}_{2}$ in air at $37^{\circ} \mathrm{C}$ for $48 \mathrm{~h}$ in DMEM. After washing with serum-free DMEM, the cells were activated by $1 \mu \mathrm{g} / \mathrm{mL}$ of PMA for $30 \mathrm{~min}$, followed by incubation with $5 \mu \mathrm{M}$ of Hyp-L-2 for $30 \mathrm{~min}$. The cells were subsequently fixed with chilled methanol at $-30{ }^{\circ} \mathrm{C}$ or $4 \%$ paraformaldehyde (PFA) at r.t. for $15 \mathrm{~min}$. In the case of PFA fixation, the fixed cells were permeabilized with $0.1 \%$ triton-X in PBS for 15 min. After fixation, cells were blocked with $10 \%$ normal goat serum in PBS for $1 \mathrm{~h}$. Primary antibody reaction was conducted with mouse anti-Sdha (1: 200, abcam, ab14715) or mouse anti-Grp75 (Hspa9, 1: 200, abcam, ab2799) at $4{ }^{\circ} \mathrm{C}$ overnight. Secondary antibody reaction was conducted with goat anti-mouse IgG-Alexa 633 (1: 1000, 
invitrogen, A21050) at room temperature for $1 \mathrm{~h}$. The nucleus was stained with Hoechst 33258 (1: 1000, Dojindo, 343-07961) at room termperature for $1 \mathrm{~h}$.

\section{Knockdown validation of antibodies for immunostaining}

RAW264.7 cells $\left(5.0 \times 10^{4}\right.$ cells $)$ were cultured in a 24-well plate under a humidified atmosphere of $5 \% \mathrm{CO}_{2}$ in air at $37^{\circ} \mathrm{C}$ in DMEM. After overnight incubation, the cells were transfected with $30 \mathrm{nM}$ of negative control, Sdha-targeting siRNAs, or Hspa9-targeting siRNAs. After incubation for $72 \mathrm{~h}$ (for Sdha) or $48 \mathrm{~h}$ (for Hspa9), the knockdown was assessed by western blot and immunostaining analysis as described above. Predesigned siRNAs targeting Sdha or Hspa9 were obtained from Sigma: siSdha-1 (SASI_Mm01_00116313), siSdha-2 (SASI_Mm01_00116314), siHspa9-1 (SASI_Mm01_00024693), and siHspa9-2 (SASI_Mm01_00024694). Stealth RNAi Negative Control Duplexes were obtained from Invitrogen. The cells were transfected using Mission siRNA transfection reagents (S1452, Sigma) according to the manufacturer's protocol.

\section{Colocalization imaging of $\mathrm{H}_{2} \mathrm{O}_{2}$-rich vesicles with $\mathrm{LysoDR}$ and mCherry-LC3B}

RAW264.7 macrophages were cultured on $35 \mathrm{~mm}$ glass-bottom dishes (IWAKI), activated by PMA, and stained with HYDROP as mentioned above. For imaging of acidic vesicles, cells were stained with $50 \mathrm{nM}$ of LysoTracker Deep Red (Thermo, 12492) for $30 \mathrm{~min}$. For imaging of autophagosomes, cells were transfected with a plasmid encoding mCherry-LC3B $\mathrm{B}^{\mathrm{S} 8}$ using Lipofectamine 2000 (Invitrogen) for $48 \mathrm{~h}$ before PMA stimulation and HYDROP staining.

\section{TTFA-induced labeling in HeLa cells}

HeLa cells were cultured on $35 \mathrm{~mm}$ dishes under a humidified atmosphere of $5 \% \mathrm{CO}_{2}$ in air at $37^{\circ} \mathrm{C}$ for $24 \mathrm{~h}$ in DMEM. After washing with serum-free DMEM, cells were stimulated with 1 $\mathrm{mM}$ of TTFA for $30 \mathrm{~min}$, followed by labeling with $5 \mu \mathrm{M}$ of Hyp-L-2 for $30 \mathrm{~min}$. After cell lysis as mentioned above, the protein samples were resolved by SDS-PAGE and imaged by in-gel fluorescence imaging.

\section{Colocalization imaging of Hyp-L-2 with MitoDR in HeLa cells}

HeLa cells were seeded on $35 \mathrm{~mm}$ glass-bottom dishes (IWAKI), stained with $200 \mathrm{nM}$ of MitoDR for $15 \mathrm{~min}$, stimulated with $1 \mathrm{mM}$ of TTFA for $30 \mathrm{~min}$, and labeled with $5 \mu \mathrm{M}$ of Hyp-L-2 for 30 
min. The cells were subsequently fixed in chilled methanol for $15 \mathrm{~min}$ at $-30^{\circ} \mathrm{C}$, washed with $\mathrm{PBS}$ thrice, and imaged by CLSM.

\section{$\mathrm{H}_{2} \mathrm{O}_{2}$-responsive labeling in hippocampal slices}

Acute hippocampal slices (250 $\mu \mathrm{m}$ thickness) were prepared from P14-21 ICR mice. After

recovery under $95 \% \mathrm{O}_{2} / 5 \% \mathrm{CO}_{2}$ at $37^{\circ} \mathrm{C}$ for $1 \mathrm{~h}$, the hippocampal slices were treated with $5 \mu \mathrm{M}$ of Hyp-L-2 in ACSF solution (125 mM NaCl, $2.5 \mathrm{mM} \mathrm{KCl,} 2 \mathrm{mM} \mathrm{CaCl}_{2}, 1 \mathrm{mM} \mathrm{MgCl} 2,1.25 \mathrm{mM}$ $\mathrm{NaH}_{2} \mathrm{PO}_{4}, 26 \mathrm{mM} \mathrm{NaHCO} 3,10 \mathrm{mM}$ D-glucose and $100 \mu \mathrm{M}$ picrotoxin) at room temperature for 1h under $95 \% \mathrm{O}_{2} / 5 \% \mathrm{CO}_{2}$, followed by the incubation with $1 \mathrm{mM} \mathrm{H}_{2} \mathrm{O}_{2}$ for $30 \mathrm{~min}$. For western blot analysis, the labeled slices were lysed with RIPA buffer containing $1 \%$ protease inhibitor cocktail set III. After mixing with a quarter volume of $5 \times$ laemmli buffer containing $250 \mathrm{mM}$ DTT, the following electrophoresis and western blot were the same as mentioned above. For CLSM imaging, the labeled slices were fixed by $4 \%$ PFA at room temperature for $3 \mathrm{~h}$ and permeabilized with $0.1 \%$ triton-X for $30 \mathrm{~min}$.

\section{TTFA-induced labeling in hippocampal slices}

Hippocampal slices were stimulated by $1 \mathrm{mM}$ of TTFA with or without $10 \mu \mathrm{M}$ of ebselen or skQ1 for $30 \mathrm{~min}$, followed by incubation with $5 \mu \mathrm{M}$ of Hyp-L-2 for $1 \mathrm{~h}$. Tissue lysis and SDS-PAGE were the same as above. For CLSM imaging, after labeling by HYDROP or Hyp-L-2, slices were fixed by $4 \%$ PFA at room temperature for $3 \mathrm{~h}$ and permeabilized with chilled methanol at $-20{ }^{\circ} \mathrm{C}$ for $10 \mathrm{~min}$.

\section{Colocalization imaging of Hyp-L-2 with mitochondrial markers in hippocampal slices} Hippocampal slices were stained with $200 \mathrm{nM}$ of MitoDR for $1 \mathrm{~h}$, followed by TTFA stimulation and Hyp-L-2 labeling. The labeled slices were fixed by 4\% PFA at room temperature for $3 \mathrm{~h}$ and permeabilized with chilled methanol at $-20{ }^{\circ} \mathrm{C}$ for $10 \mathrm{~min}$. The slices were immersed in $30 \%$ sucrose at $4{ }^{\circ} \mathrm{C}$ overnight and trimmed to thinner slices with a thickness of $40 \mu \mathrm{m}$ by cryostat. The thin slices were blocked with $2 \%$ BSA and $2 \%$ NGS in PBS with $0.2 \%$ triton-X. The primary antibody reaction was conducted with mouse anti-Sdha (1: 100, abcam, ab14715) at $4{ }^{\circ} \mathrm{C}$ overnight and a secondary antibody reaction was conducted with goat anti-mouse IgG-Alexa 633 (1: 1000, invitrogen, A21050) at room temperature for $1 \mathrm{~h}$. 


\section{Proteomics of TTFA (+) vs TTFA (-)}

Hippocampal slices (300 $\mu \mathrm{m}$ thickness, 11 slices for TTFA (+) and TTFA (-) each) were treated or non-treated with $1 \mathrm{mM}$ of TTFA for $30 \mathrm{~min}$, followed by labeling with $5 \mu \mathrm{M}$ of Hyp-L-2 for 1 h. The slices were rinsed trice with chilled PBS, lysed by homogenization and sonication in $1 \%$ SDS-RIPA buffer containing 1\% protease inhibitor cocktail set III. The proteins were precipitated in cold acetone at $-80^{\circ} \mathrm{C}$ overnight. After washing with acetone for 3 times, the proteins were redissolved in $1 \%$ SDS-RIPA containing $1 \%$ protease inhibitor cocktail set III upon sonication. The protein concentrations in the supernatant were determined by BCA assay and $450 \mu \mathrm{g}$ of proteins were applied to immunoprecipitation. $25 \mu \mathrm{L}$ of nProtein A sepharose 4 Fast Flow (GE Healthcare) was incubated with $15 \mu \mathrm{L}$ of an anti-fluorescein antibody for $2 \mathrm{~h}$ at $4{ }^{\circ} \mathrm{C}$ with rotation. The beads were washed with RIPA buffer twice followed by the addition of $450 \mu \mathrm{g}$ of lysates and further incubation at $4{ }^{\circ} \mathrm{C}$ for $4 \mathrm{~h}$. After incubation, the beads were washed with RIPA buffer for 5 times, vortex for $5 \mathrm{~min}$, and boiled for $5 \mathrm{~min}$ in $2 \times$ laemmli buffer containing $100 \mathrm{mM}$ DTT. The following in-gel digestion, TMT tagging (light for TTFA (-), heavy for TTFA (+)), nano LCMS/MS analysis were the same as those in PMA (+) vs PMA (-). 


\section{General materials and methods for organic synthesis}

All chemical reagents and solvents were obtained from commercial suppliers (Tokyo Chemical Industry (TCI), Sigma-Aldrich, Wako Pure Chemical Industries, Watanabe Chemical Industries, or Sasaki Chemical) and used without further purification. Thin layer chromatography (TLC) was performed on silica gel 60 F254 precoated aluminum sheets (Merck) and visualized by fluorescence quenching, fluorescence by $365 \mathrm{~nm}$ excitation, $\mathrm{I}_{2}$ staining and ninhydrin staining. Chromatographic purification was accomplished using flash column chromatography on silica gel $60 \mathrm{~N}$ (neutral, 40-50 $\mu \mathrm{m}$, Kanto Chemical). ${ }^{1} \mathrm{H}$ NMR spectra were recorded in deuterated solvents on a Varian Mercury $400(400 \mathrm{MHz})$ spectrometer and calibrated to tetramethylsilane (0 ppm) or residual solvent peak. ${ }^{11} \mathrm{~B}$ and ${ }^{19} \mathrm{~F}$ NMR spectra were recorded on JEOL JNM-ECZ (500 MHz) and calibrated to $\mathrm{BF}_{3} \mathrm{OEt}_{2}(0 \mathrm{ppm})$ and $\mathrm{TfONa}(-78.8 \mathrm{ppm})$. Multiplicities are abbreviated as follows: $\mathrm{s}=$ singlet, brs $=$ broad singlet, $\mathrm{d}=$ doublet, $\mathrm{t}=$ triplet, $\mathrm{q}=$ quartet, $\mathrm{m}=$ multiplet, $\mathrm{dd}=$ double doublet. Matrix-assisted laser desorption/ionization time-of-flight mass spectrometry (MALDI-TOF MS) spectra were recorded on an Autoflex III instrument (Bruker Daltonics) using $\alpha$-cyano-4-hydroxycinnamic acid (CHCA) as the matrix. High-resolution mass spectra were measured on an Exactive (Thermo Scientific) equipped with electron spray ionization (ESI). Reversed-phase HPLC (RP-HPLC) was carried out on a Hitachi LaChrom L-7100 system equipped with a LaChrom L-7400 UV detector, and a YMC-Pack ODS-A column (5 $\mu \mathrm{m}, 250 \times$ $20 \mathrm{~mm}$ ) at a flow rate of $9.999 \mathrm{~mL} / \mathrm{min}$. UV detection was at $220 \mathrm{~nm}$. 


\section{Synthesis}
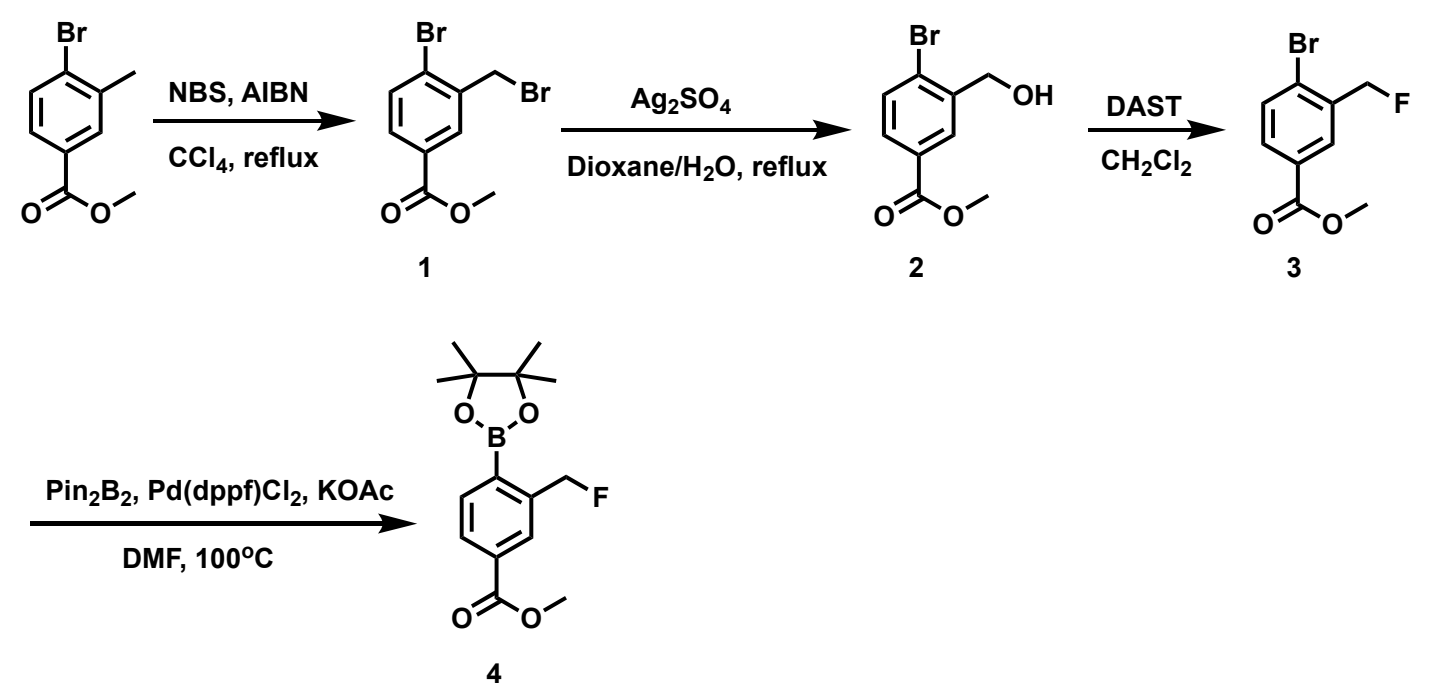

Methyl 4-bromo-3-(bromomethyl)benzoate (1): ${ }^{\mathrm{S} 9}$ A mixture of methyl 4-bromo-3methylbenzoate $(2.3 \mathrm{~g}, 10 \mathrm{mmol})$, NBS $(1.9 \mathrm{~g}, 11 \mathrm{mmol})$, and AIBN $(164 \mathrm{mg}, 1 \mathrm{mmol})$ in $\mathrm{CCl}_{4}$ $(25 \mathrm{~mL})$ was refluxed overnight under Ar. After filtration and evaporation, $1(2.24 \mathrm{~g}, 71.4 \%)$ was obtained after column chromatography $\left(\mathrm{SiO}_{2}, \mathrm{Hexane} / \mathrm{EtOAc}=15 / 1\right) .{ }^{1} \mathrm{H} \mathrm{NMR}\left(400 \mathrm{MHz}, \mathrm{CDCl}_{3}\right)$ $\delta 8.12(\mathrm{~d}, J=2.1 \mathrm{~Hz}, 1 \mathrm{H}), 7.81(\mathrm{dd}, J=8.3,2.1 \mathrm{~Hz}, 1 \mathrm{H}), 7.66(\mathrm{~d}, J=8.3 \mathrm{~Hz}, 1 \mathrm{H}), 4.62(\mathrm{~s}, 2 \mathrm{H})$, $3.93(\mathrm{~s}, 3 \mathrm{H})$.

Methyl 4-bromo-3-(hydroxymethyl)benzoate (2): ${ }^{\text {s10 }}$ To a solution of $\mathbf{1}(308 \mathrm{mg}, 1.0 \mathrm{mmol})$ in dioxane $/ \mathrm{H}_{2} \mathrm{O}(1 / 1,20 \mathrm{~mL}), \mathrm{Ag}_{2} \mathrm{SO}_{4}(499 \mathrm{mg}, 1.6 \mathrm{mmol})$ was added. The reaction mixture refluxed for $1 \mathrm{~h}$ in dark. After filtration, the filtrate was extracted with EtOAc $(20 \mathrm{~mL} \times 2)$. The combined organic layers were washed with brine $(30 \mathrm{~mL} \times 1)$ and dried over $\mathrm{Na}_{2} \mathrm{SO}_{4} .2(235.4 \mathrm{mg}, 96.1 \%)$ was obtained after evaporation. ${ }^{1} \mathrm{H}$ NMR $\left(400 \mathrm{MHz}, \mathrm{CDCl}_{3}\right) \delta 8.17(\mathrm{~d}, J=2.1 \mathrm{~Hz}, 1 \mathrm{H}), 7.82(\mathrm{dd}$, $J=8.3,2.2 \mathrm{~Hz}, 1 \mathrm{H}), 7.63(\mathrm{~d}, J=8.3 \mathrm{~Hz}, 1 \mathrm{H}), 4.79(\mathrm{~s}, 2 \mathrm{H}), 3.92(\mathrm{~s}, 3 \mathrm{H})$.

Methyl 4-bromo-3-(fluoromethyl)benzoate (3): ${ }^{\text {S11 }}$ Diethylaminosulfur trifluoride (380 $\mu \mathrm{L}, 2.88$ mmol) was added to a solution of $2(235.4 \mathrm{mg}, 0.96 \mathrm{mmol})$ in DCM $(15 \mathrm{~mL})$ at $0^{\circ} \mathrm{C}$. The reaction mixture was stirred at r.t. overnight, washed with $\mathrm{H}_{2} \mathrm{O}(20 \mathrm{~mL} \times 3)$ and brine $(20 \mathrm{~mL} \times 1)$. The crude product was purified by column chromatography $\left(\mathrm{SiO}_{2}, \mathrm{Hexane} / \mathrm{EtOAc}=20 / 1\right)$ to afford the fluorinated compound (185.1 mg, 78.1\%). ${ }^{1} \mathrm{H} \mathrm{NMR}\left(400 \mathrm{MHz}, \mathrm{CDCl}_{3}\right) \delta 8.13(\mathrm{~d}, J=2.1 \mathrm{~Hz}, 1 \mathrm{H})$, $7.87(\mathrm{dd}, J=8.3,1.7 \mathrm{~Hz}, 1 \mathrm{H}), 7.65(\mathrm{dd}, J=8.3,1.2 \mathrm{~Hz}, 1 \mathrm{H}), 5.49$ (d, $J=47.0 \mathrm{~Hz}, 2 \mathrm{H}), 3.93(\mathrm{~s}$, $3 \mathrm{H})$. 
methyl 3-(fluoromethyl)-4-(4,4,5,5-tetramethyl-1,3,2-dioxaborolan-2-yl)benzoate (4): ${ }^{\text {S12 }} \mathrm{A}$ mixture of 3 (185.1 mg, $0.75 \mathrm{mmol})$, bis(pinacolato)diboron (228.6 mg, $0.90 \mathrm{mmol})$, [1,1'bis(diphenylphosphino)-ferrocene]dichloropalladium (30.6 mg, $0.0375 \mathrm{mmol}$ ), and potassium acetate $(220.8 \mathrm{mg}, 2.25 \mathrm{mmol})$ in DMF $(2.5 \mathrm{~mL})$ was heated to $100{ }^{\circ} \mathrm{C}$ for $3 \mathrm{~h}$ under Ar. An additional amount of [1,1'-bis(diphenylphosphino)-ferrocene]dichloropalladium (30.6 mg, 0.0375 mmol) was added and the reaction was continued at $100{ }^{\circ} \mathrm{C}$ for another $4 \mathrm{~h}$. The reaction was cooled, diluted with $\mathrm{Et}_{2} \mathrm{O}(30 \mathrm{~mL})$, and washed with $\mathrm{H}_{2} \mathrm{O}(20 \mathrm{~mL} \times 2)$ and brine $(20 \mathrm{~mL} \times 1)$. The organic layer was dried over $\mathrm{Na}_{2} \mathrm{SO}_{4} .4(57.6 \mathrm{mg}, 26.1 \%)$ was obtained after column chromatography $\left(\mathrm{SiO}_{2}, \mathrm{Hexane} / \mathrm{EtOAc}=10 / 1\right) .{ }^{1} \mathrm{H} \mathrm{NMR}\left(400 \mathrm{MHz}, \mathrm{CDCl}_{3}\right) \delta 8.14(\mathrm{~s}, 1 \mathrm{H}), 7.98$ $(\mathrm{d}, J=7.7 \mathrm{~Hz}, 1 \mathrm{H}), 7.91(\mathrm{~d}, J=7.8 \mathrm{~Hz}, 1 \mathrm{H}), 5.72(\mathrm{~d}, J=47.4 \mathrm{~Hz}, 2 \mathrm{H}), 3.93(\mathrm{~s}, 3 \mathrm{H}), 1.35(\mathrm{~s}, 12 \mathrm{H})$.
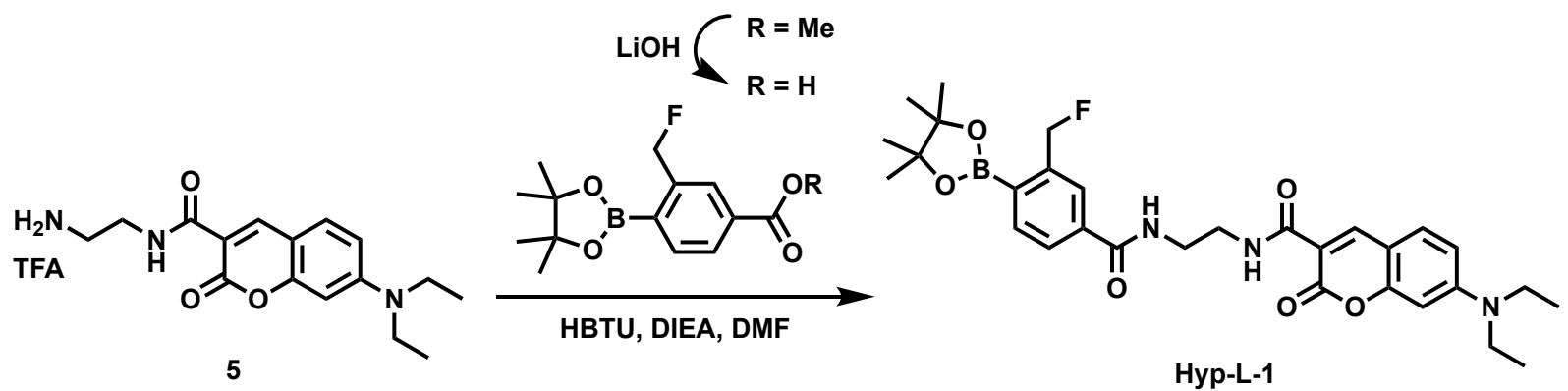

Hyp-L-1: $1 \mathrm{M} \mathrm{LiOH}$ aqueous solution $(150 \mu \mathrm{L}, 0.15 \mathrm{mmol})$ was added to a solution of 4 (15.1 $\mathrm{mg}$, $0.05 \mathrm{mmol})$ in $\mathrm{THF} / \mathrm{H}_{2} \mathrm{O}(0.6 \mathrm{~mL} / 0.2 \mathrm{~mL})$ at $0^{\circ} \mathrm{C}$. The reaction mixture was stirred at r.t. overnight, diluted with $1 \mathrm{~mL}$ of $\mathrm{H}_{2} \mathrm{O}$, neutralized with $1 \mathrm{M} \mathrm{HCl}$ on ice, extracted with EtOAc, and dried over $\mathrm{Na}_{2} \mathrm{SO}_{4}$. The crude product was used in next step without further purification.

To a solution of the carboxylic acid in dry DMF (0.3 mL), HBTU (12.4 mg, $0.0325 \mathrm{mmol})$, DIEA $(17.5 \mu \mathrm{L}, 0.1 \mathrm{mmol})$, and $\mathbf{5}^{\mathrm{S} 5}(11.5 \mathrm{mg}, 0.275 \mathrm{mmol})$ were added. The reaction mixture was stirred at r.t. under Ar overnight. Hyp-L-1 (2.9 mg, $10.3 \%, 2$ steps) was obtained after purification by $\operatorname{HPLC}\left(\mathrm{A} / \mathrm{B}=60 / 40\right.$ to $100 / 0$ over $40 \mathrm{~min}, \mathrm{~A}=\mathrm{CH}_{3} \mathrm{CN}, \mathrm{B}=10 \mathrm{mM} \mathrm{NH}_{4} \mathrm{OAc}$ ).

${ }^{1} \mathrm{H} \mathrm{NMR}\left(400 \mathrm{MHz}, \mathrm{CDCl}_{3}\right) \delta 9.21$ (brs, 1H), 8.74 (s, 1H), $7.96(\mathrm{~s}, 1 \mathrm{H}), 7.91$ (d, J= $\left.7.8 \mathrm{~Hz}, 1 \mathrm{H}\right)$, $7.85(\mathrm{~s}, 1 \mathrm{H}), 7.81(\mathrm{~d}, J=7.8 \mathrm{~Hz}, 1 \mathrm{H}), 7.46(\mathrm{~d}, J=9.0 \mathrm{~Hz}, 1 \mathrm{H}), 6.66(\mathrm{dd}, J=9.0,2.5 \mathrm{~Hz}, 1 \mathrm{H}), 6.50$ $(\mathrm{d}, J=2.3 \mathrm{~Hz}, 1 \mathrm{H}), 5.73(\mathrm{~d}, J=47.5 \mathrm{~Hz}, 2 \mathrm{H}), 3.70(\mathrm{~m}, 4 \mathrm{H}), 3.46(\mathrm{q}, J=7.1 \mathrm{~Hz}, 4 \mathrm{H}), 1.35(\mathrm{~s}, 12 \mathrm{H})$, $1.23(\mathrm{t}, J=7.1 \mathrm{~Hz}, 6 \mathrm{H}) .{ }^{13} \mathrm{C}-\mathrm{NMR}\left(100 \mathrm{MHz}, \mathrm{CDCl}_{3}\right) \delta 167.2,165.6,162.7,157.8,152.8,148.6$, 143.3, 143.1, 136.7, 136.2, 131.4, 126.0, 125.0, 124.9, 110.1, 109.5, 108.4, 96.6, 84.7, 84.1, 83.0, 
45.1, 42.8, 39.0, 24.9, 12.4. ${ }^{11} \mathrm{~B}-\mathrm{NMR}\left(160 \mathrm{MHz}, \mathrm{CDCl}_{3}\right) \delta 30.866 .{ }^{19} \mathrm{~F}-\mathrm{NMR}\left(470 \mathrm{MHz}, \mathrm{CDCl}_{3}\right)$ $\delta$-212.171 (t, $47.68 \mathrm{~Hz}$ ). HR-ESI MS $m / z$ calcd. For $\mathrm{C}_{30} \mathrm{H}_{37} \mathrm{BFN}_{3} \mathrm{O}_{6} \mathrm{Na}[\mathrm{M}+\mathrm{Na}]^{+} 588.2652$, found 588.2643.

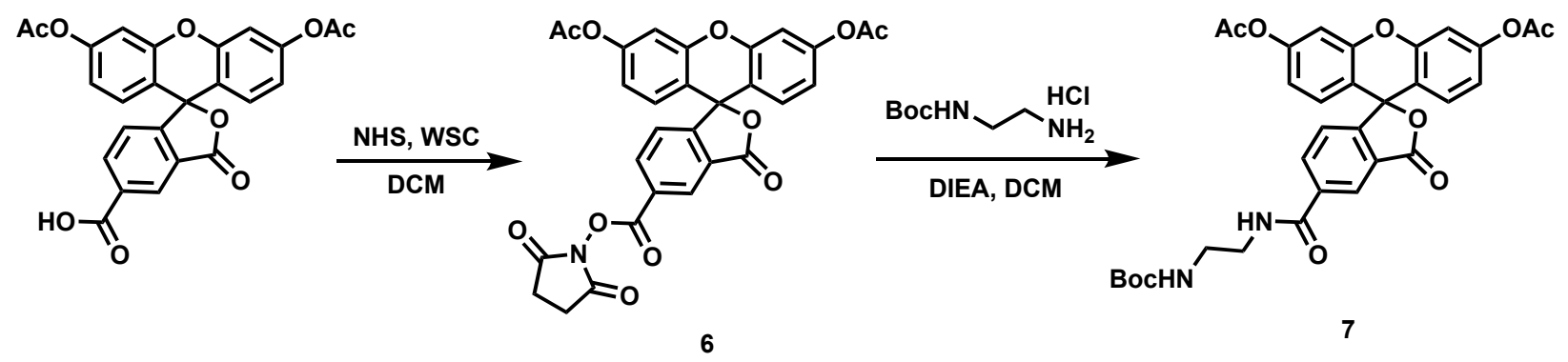

7: A solution of 5-carboxyfluorescein diacetate ${ }^{\mathrm{S} 13}(200 \mathrm{mg}, 0.44 \mathrm{mmol}), \mathrm{WSC} \cdot \mathrm{HCl}(130 \mathrm{mg}, 0.68$ $\mathrm{mmol}$ ), and NHS (80 mg, $0.68 \mathrm{mmol})$ in DCM (4 mL) was stirred at r.t under Ar overnight. The reaction mixture was diluted with EtOAc $(20 \mathrm{~mL})$, washed with $\mathrm{H}_{2} \mathrm{O}(20 \mathrm{~mL} \times 2)$ and brine $(20$ $\mathrm{mL} \times 1$ ), and dried over $\mathrm{Na}_{2} \mathrm{SO}_{4}$. Product 6 was applied in the next step without further purification.

To a solution of tert-butyl (2-aminoethyl)carbamate hydrochloride (104 mg, $0.53 \mathrm{mmol}$ ) in DCM ( $2 \mathrm{~mL}$ ), DIEA ( $152 \mu \mathrm{L}, 0.88 \mathrm{mmol})$ was added, followed by the addition of 6 in $2 \mathrm{~mL}$ of DCM. The reaction mixture was stirred at r.t. under Ar for $1 \mathrm{~h}$, diluted with EtOAc $(20 \mathrm{~mL})$, washed with $\mathrm{H}_{2} \mathrm{O}(20 \mathrm{~mL} \times 2), 5 \%$ citric acid aq. solution $(20 \mathrm{~mL} \times 2)$, and brine $(20 \mathrm{~mL} \times 1) .7: 205.2 \mathrm{mg}, 77 \%$ (2 steps). ${ }^{1} \mathrm{H}$ NMR $\left(400 \mathrm{MHz}, \mathrm{CDCl}_{3}\right) \delta 8.45$ (s, $\left.1 \mathrm{H}\right), 8.18(\mathrm{dd}, J=8.0,1.6 \mathrm{~Hz}, 1 \mathrm{H}), 7.72$ (brs, $1 \mathrm{H}), 7.24(\mathrm{~d}, J=0.6 \mathrm{~Hz}, 1 \mathrm{H}), 7.11(\mathrm{~d}, J=2.1 \mathrm{~Hz}, 2 \mathrm{H}), 6.83-6.79(\mathrm{~m}, 3 \mathrm{H}), 5.04$ (brs, $1 \mathrm{H}), 3.61$ (m, 2H), $3.44(\mathrm{~m}, 2 \mathrm{H}), 2.32(\mathrm{~s}, 7 \mathrm{H}), 1.45(\mathrm{~s}, 12 \mathrm{H})$. 


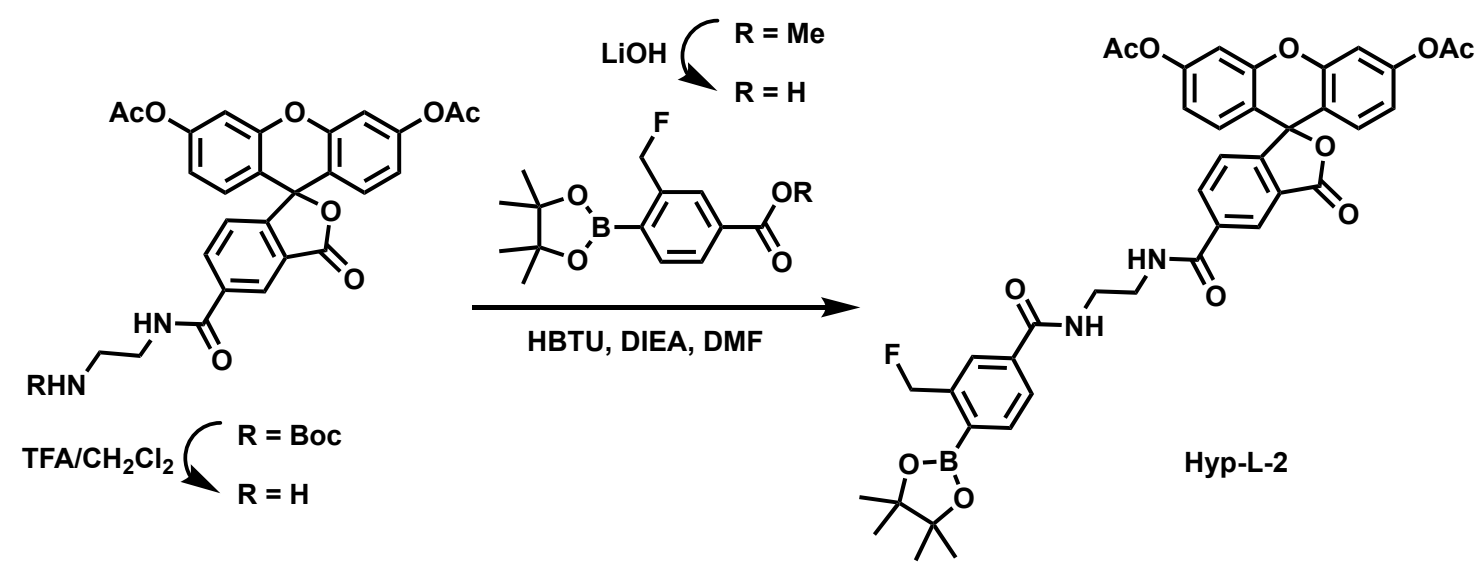

Hyp-L-2: $1 \mathrm{M} \mathrm{LiOH}$ aqueous solution $(238 \mu \mathrm{L}, 0.238 \mathrm{mmol})$ was added to a solution of 4 (23.3 $\mathrm{mg}, 0.079 \mathrm{mmol})$ in $\mathrm{THF} / \mathrm{H}_{2} \mathrm{O}(0.9 \mathrm{~mL} / 0.3 \mathrm{~mL})$ at $0^{\circ} \mathrm{C}$. The reaction mixture was stirred at r.t. overnight, diluted with $1 \mathrm{~mL}$ of $\mathrm{H}_{2} \mathrm{O}$, neutralized with $1 \mathrm{M} \mathrm{HCl}$ on ice, extracted with EtOAc, and dried over $\mathrm{Na}_{2} \mathrm{SO}_{4}$. The crude product was used in next step without further purification.

TFA $(0.2 \mathrm{~mL})$ was added to a solution of $7(20 \mathrm{mg}, 0.033 \mathrm{mmol})$ in $2 \mathrm{~mL}$ of DCM. The reaction mixture was stirred at r.t. for $2 \mathrm{~h}$. After co-evaporation with toluene $(2 \mathrm{~mL} \times 3)$, the amine was obtained quantitatively.

To a solution of the carboxylic acid in dry DMF (0.5 mL), HBTU (19.8 mg, $0.052 \mathrm{mmol})$, DIEA $(37.6 \mu \mathrm{L}, 0.16 \mathrm{mmol})$, and the amine were added. The reaction mixture was stirred at r.t. under Ar overnight. Hyp-L-2 (2.58 mg, $4.3 \%$, 2 steps) was obtained after purification by HPLC (A/B = 60/40 to 85/15 over $\left.25 \mathrm{~min}, \mathrm{~A}=\mathrm{CH}_{3} \mathrm{CN}, \mathrm{B}=10 \mathrm{mM} \mathrm{NH} \mathrm{OAc}\right) .{ }^{1} \mathrm{H}$ NMR $\left(400 \mathrm{MHz}, \mathrm{CDCl}_{3}\right) \delta$ $8.46(\mathrm{~s}, 1 \mathrm{H}), 8.16(\mathrm{dd}, J=8.0,1.6 \mathrm{~Hz}, 1 \mathrm{H}), 7.95-7.86(\mathrm{~m}, 2 \mathrm{H}), 7.77(\mathrm{~d}, J=8.8 \mathrm{~Hz}, 1 \mathrm{H}), 7.64$ (brs, 1H), $7.28(\mathrm{~s}, 1 \mathrm{H}), 7.11(\mathrm{dd}, J=1.9,0.7 \mathrm{~Hz}, 2 \mathrm{H}), 7.00(\mathrm{~s}, 1 \mathrm{H}), 6.82-6.80(\mathrm{~m}, 4 \mathrm{H}), 5.73(\mathrm{~d}, J$ $=47.4 \mathrm{~Hz}, 2 \mathrm{H}), 3.78(\mathrm{~m}, 4 \mathrm{H}), 2.31(\mathrm{~s}, 6 \mathrm{H}), 1.34(\mathrm{~s}, 11 \mathrm{H}) .{ }^{13} \mathrm{C}-\mathrm{NMR}\left(100 \mathrm{MHz}, \mathrm{CDCl}_{3}\right) \delta 168.9$, 168.8, 168.2, 166.6, 155.2, 152.2, 151.5, 143.8, 143.6, 136.6, 136.4, 135.9, 134.4, 129.0, 126.7, 125.8, 124.6, 124.1, 117.9, 115.8, 110.5, 84.3, 82.8, 81.8, 41.7, 40.7, 24.9, 21.1. ${ }^{11} \mathrm{~B}-\mathrm{NMR}$ (160 $\left.\mathrm{MHz}, \mathrm{CDCl}_{3}\right) \delta 32.247 .{ }^{19} \mathrm{~F}-\mathrm{NMR}\left(470 \mathrm{MHz} \mathrm{CDCl}_{3}\right) \delta-213.917$ (t, $\left.47.41 \mathrm{~Hz}\right)$. HR-ESI MS $m / z$ calcd. For $\mathrm{C}_{41} \mathrm{H}_{38} \mathrm{BFN}_{2} \mathrm{O}_{11} \mathrm{Na}[\mathrm{M}+\mathrm{Na}]^{+}$787.2445, found 787.2431.

8: Compound 8 (0.93 mg, 10.2\%) was obtained in the synthesis of Hyp-L-2, while a mixture of compound 4 and $\mathbf{3}$ (4.5: 1.0, according to ${ }^{1} \mathrm{H}$ NMR peak areas) was applied as the starting material. ${ }^{1} \mathrm{H}$ NMR $\left(400 \mathrm{MHz}, \mathrm{CDCl}_{3}\right) \delta 8.44(\mathrm{~d}, J=0.9 \mathrm{~Hz}, 1 \mathrm{H}), 8.16(\mathrm{dd}, J=8.0,1.6 \mathrm{~Hz}, 1 \mathrm{H}), 7.89(\mathrm{~d}, J$ $=1.9 \mathrm{~Hz}, 1 \mathrm{H}), 7.75-7.64(\mathrm{~m}, 2 \mathrm{H}), 7.49$ (brs, 1H), $7.29(\mathrm{~s}, 1 \mathrm{H}), 7.11(\mathrm{~d}, J=2.0 \mathrm{~Hz}, 2 \mathrm{H}), 6.84-$ 
$6.77(\mathrm{~m}, 4 \mathrm{H}), 5.50(\mathrm{~d}, J=46.9 \mathrm{~Hz}, 2 \mathrm{H}), 3.78(\mathrm{~s}, 4 \mathrm{H}), 2.32(\mathrm{~s}, 6 \mathrm{H})$. HR-ESI MS C ${ }_{35} \mathrm{H}_{26} \mathrm{BrFN}_{2} \mathrm{O}_{9} \mathrm{Na}$ $[\mathrm{M}+\mathrm{Na}]^{+}$739.0698, found 739.0679.

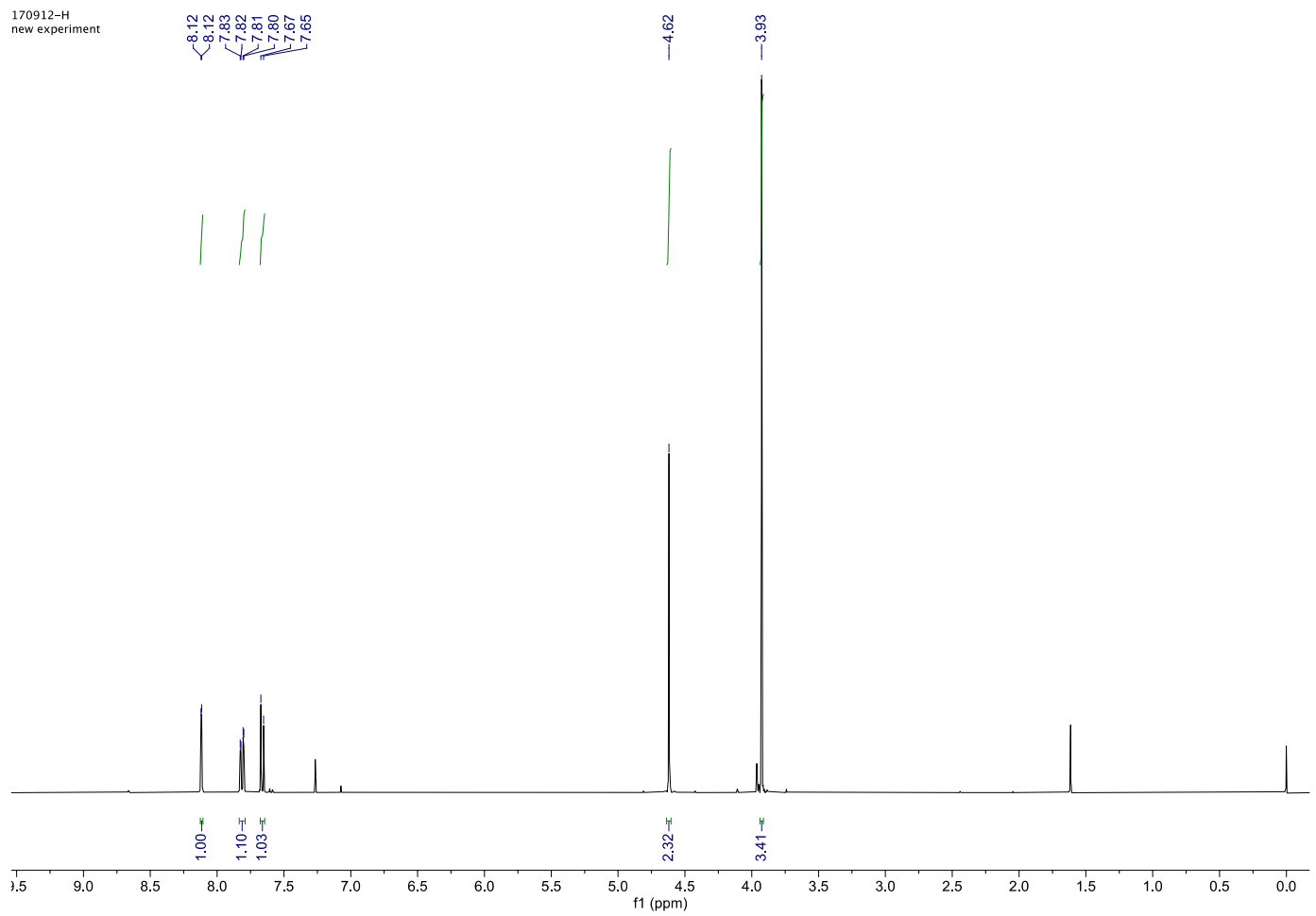

Supplementary Fig. $29{ }^{1} \mathrm{H}$ NMR of compound 1. 


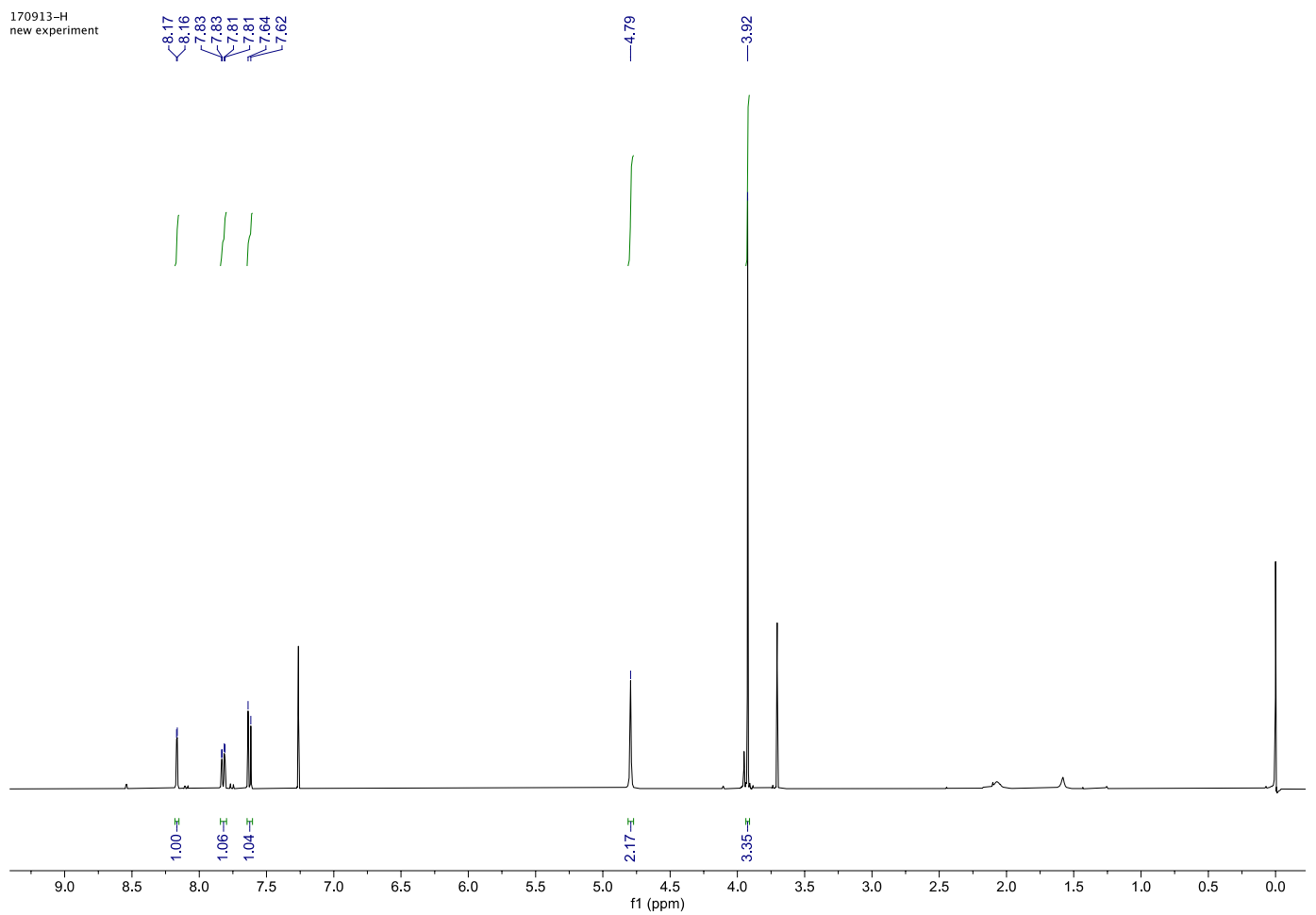

Supplementary Fig. $30{ }^{1} \mathrm{H}$ NMR of compound 2.

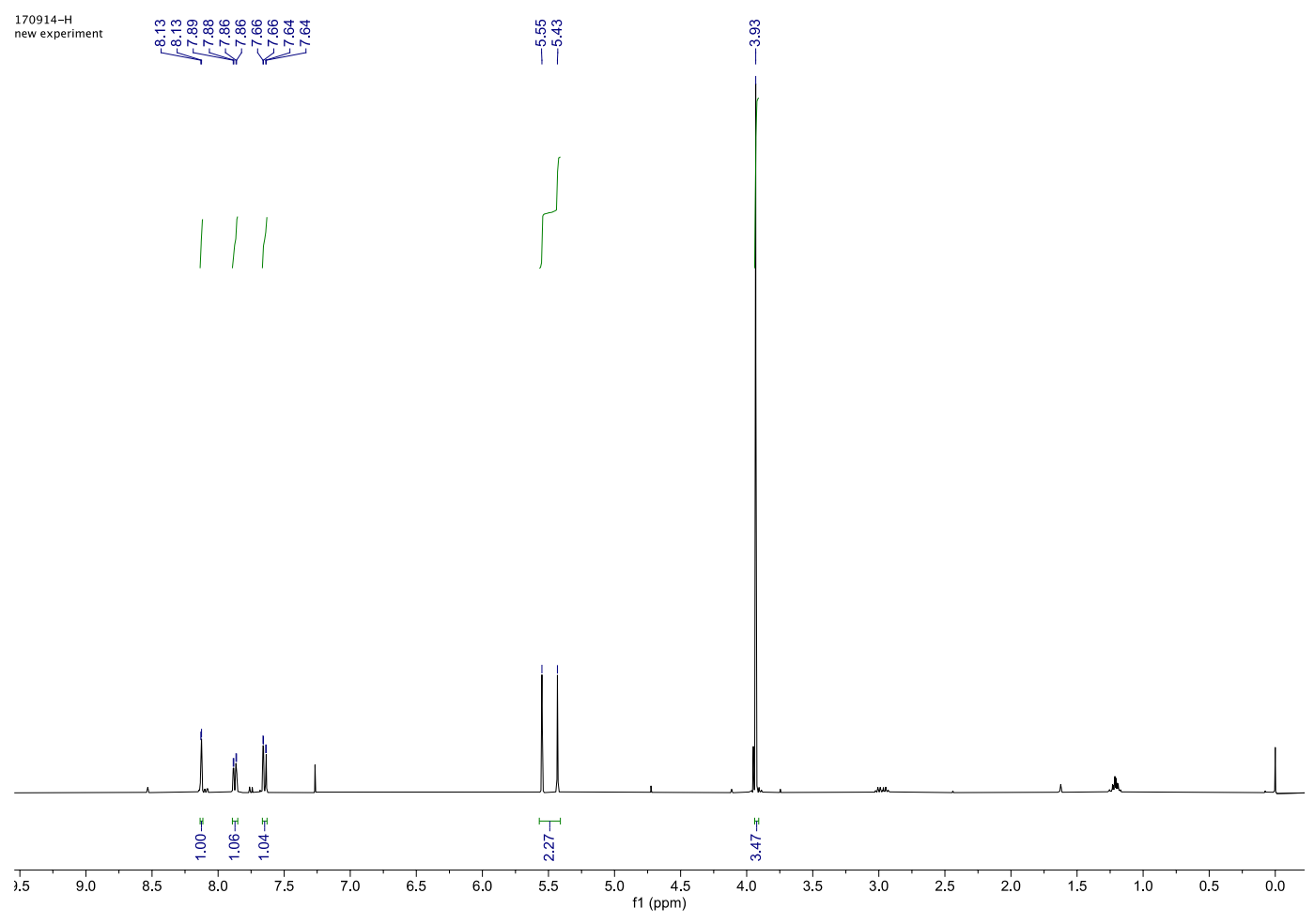

Supplementary Fig. $31{ }^{1} \mathrm{H}$ NMR of compound 3. 


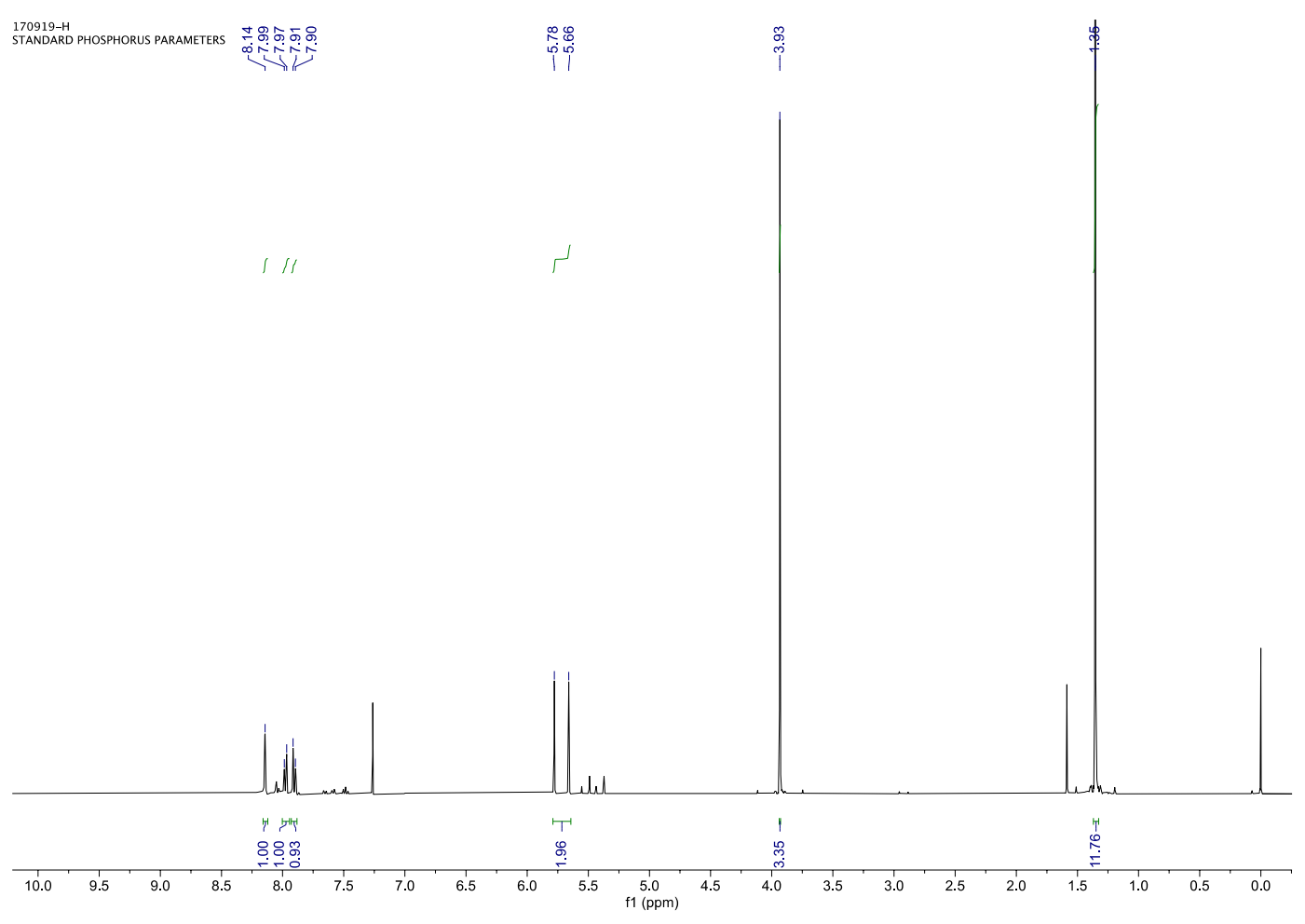

Supplementary Fig. $32{ }^{1} \mathrm{H}$ NMR of compound 4.

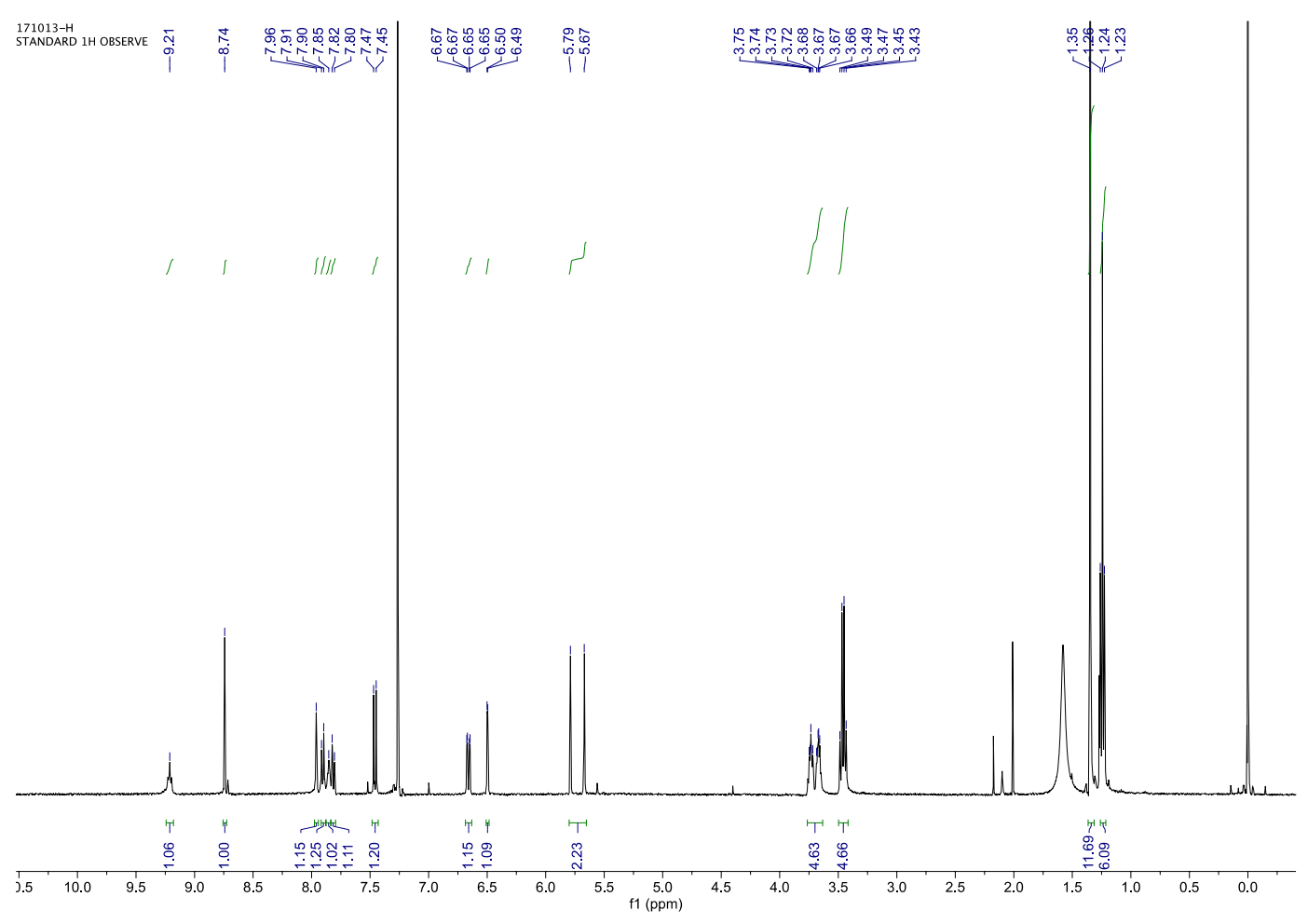

Supplementary Fig. $33{ }^{1} \mathrm{H}$ NMR of compound Hyp-L-1. 


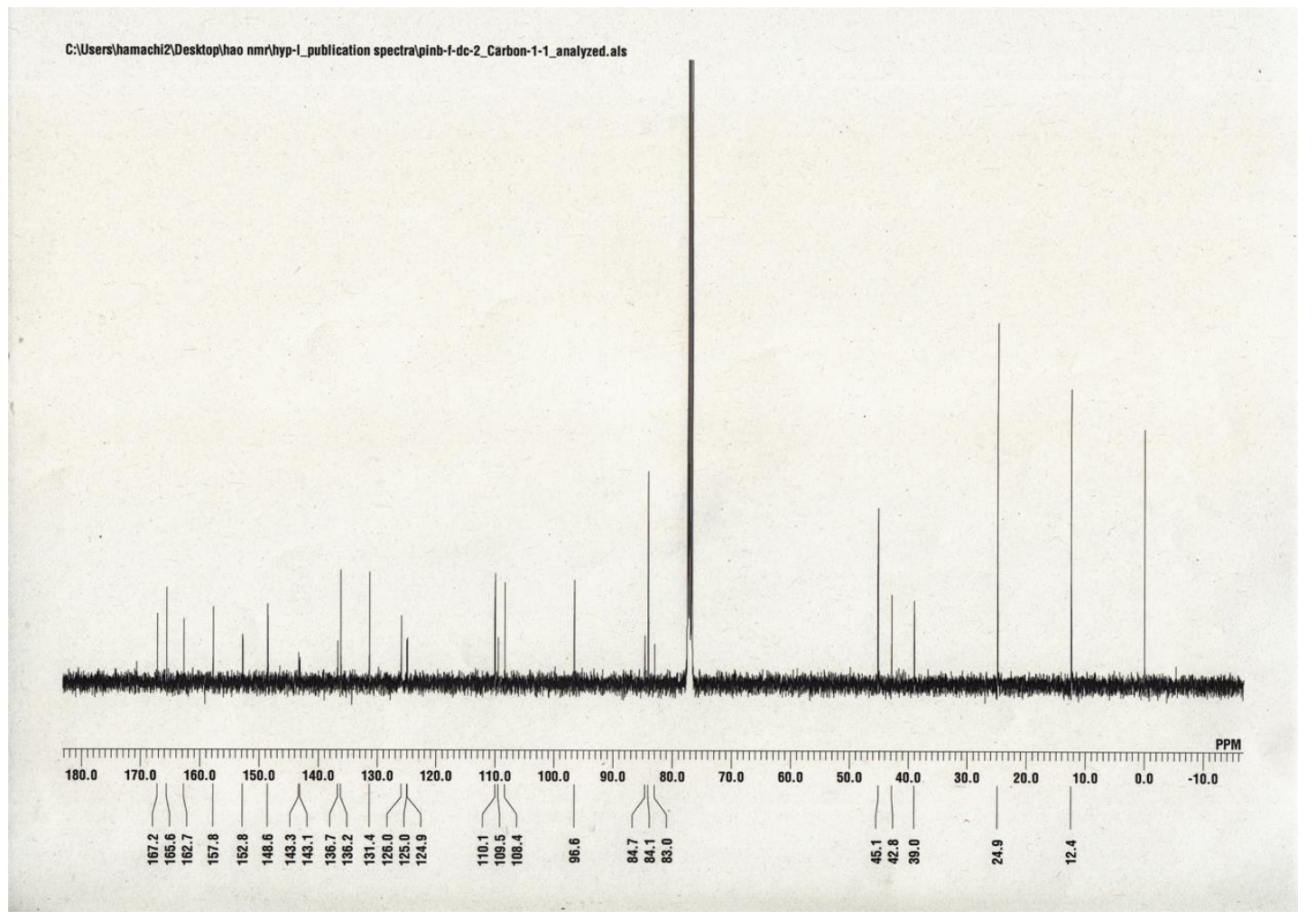

Supplementary Fig. $34{ }^{13} \mathrm{C}$ NMR of compound Hyp-L-1.

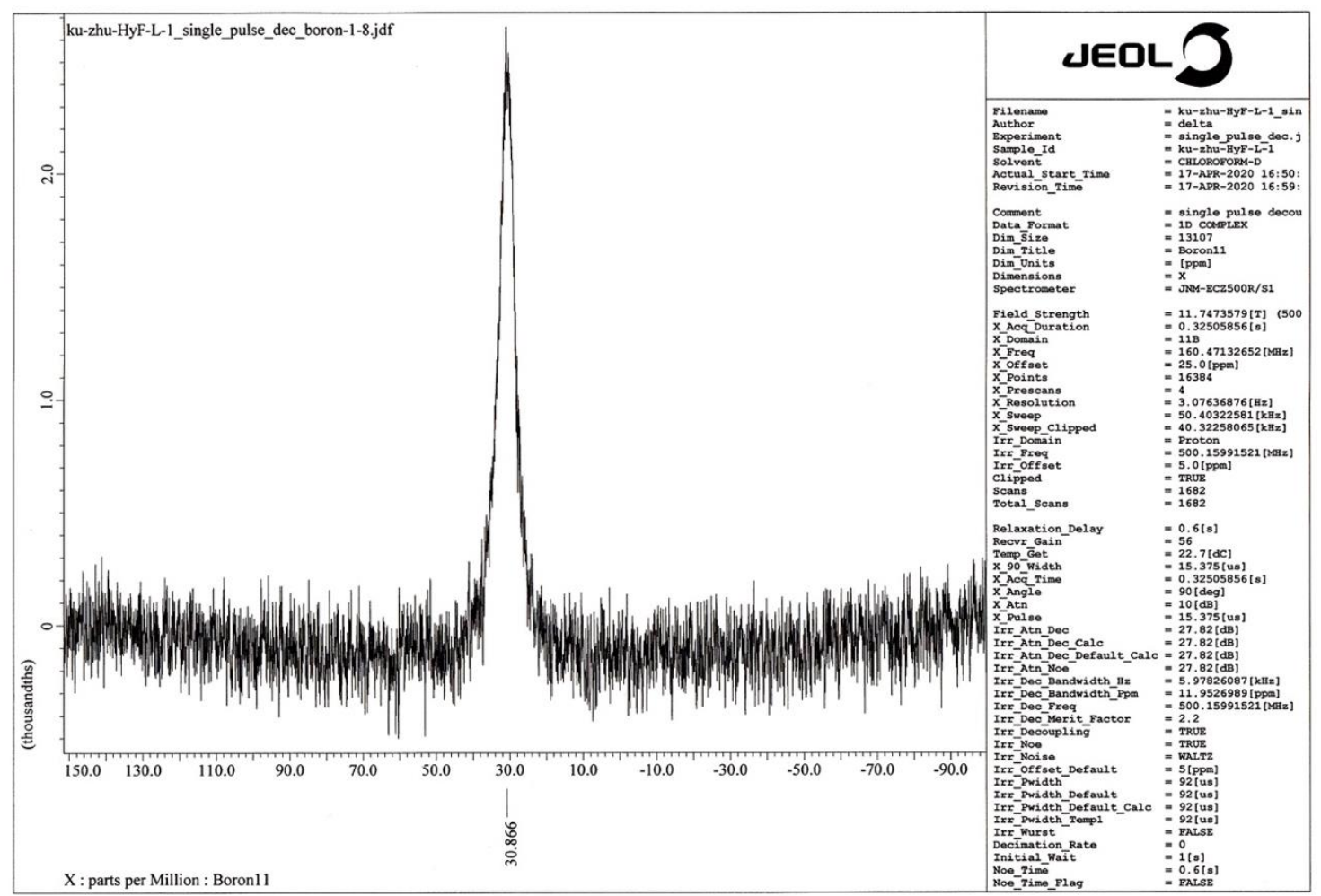

Supplementary Fig. $35{ }^{11}$ B NMR of compound Hyp-L-1. 


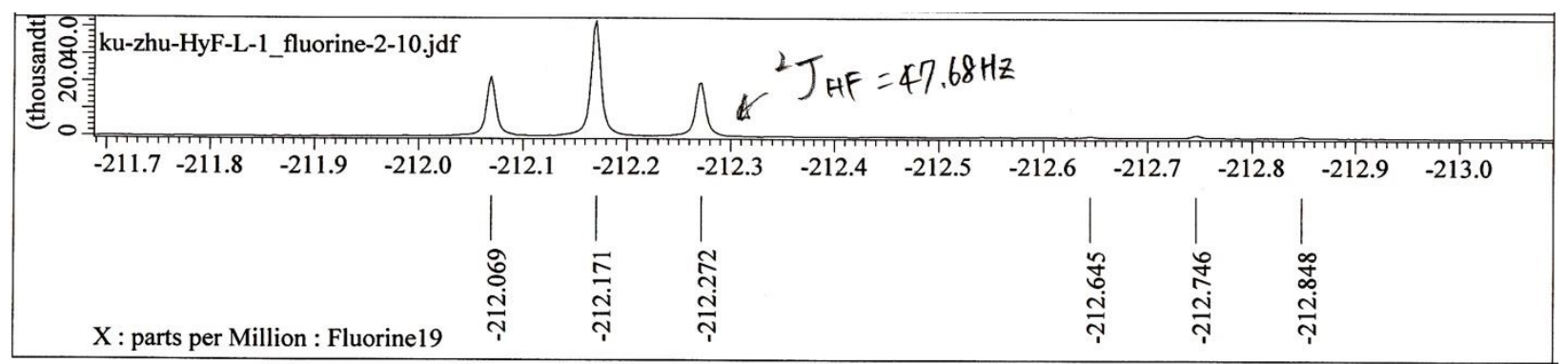

Supplementary Fig. $36{ }^{19}$ F NMR of compound Hyp-L-1.

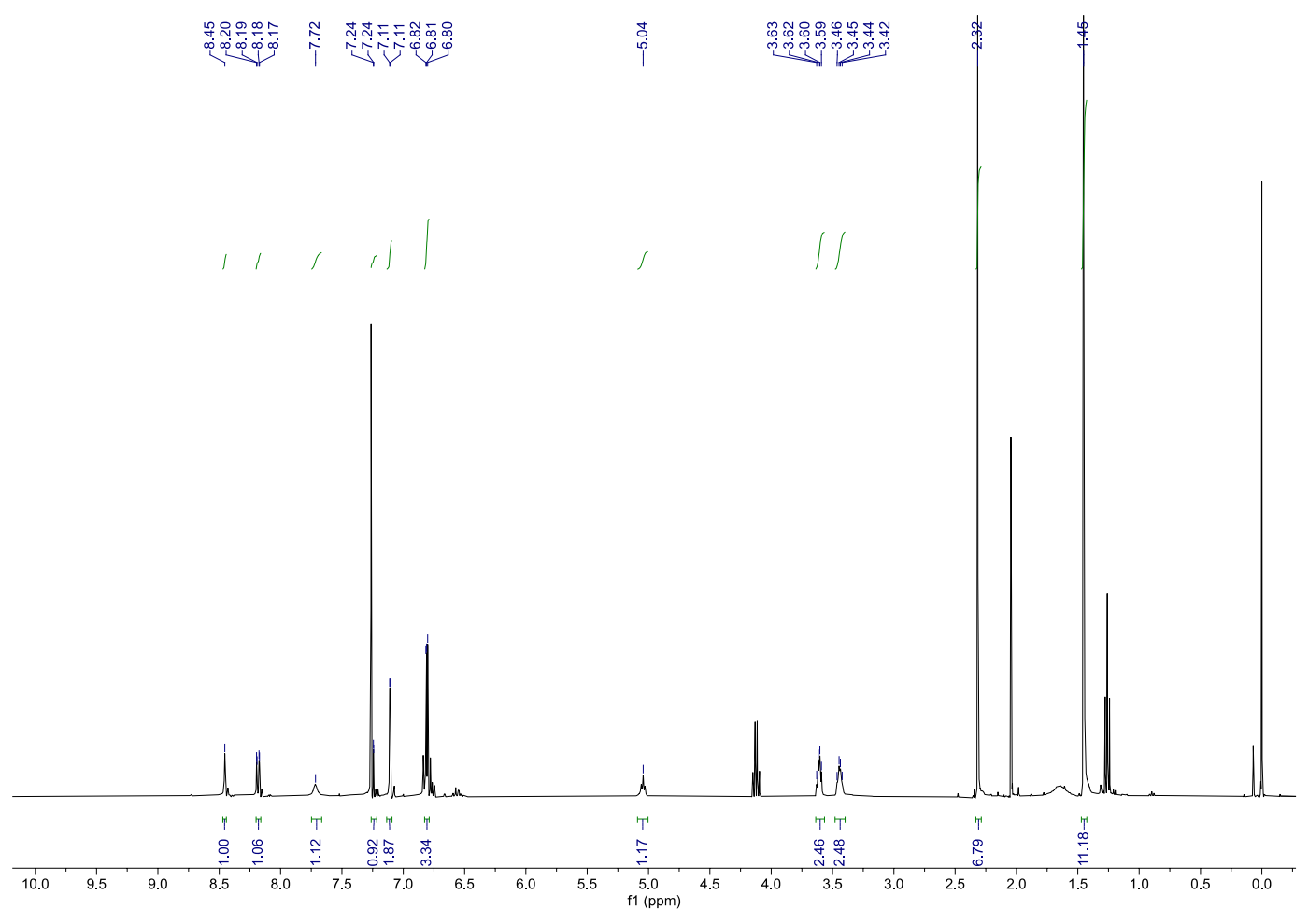

Supplementary Fig. $37^{1} \mathrm{H}$ NMR of compound 7. 


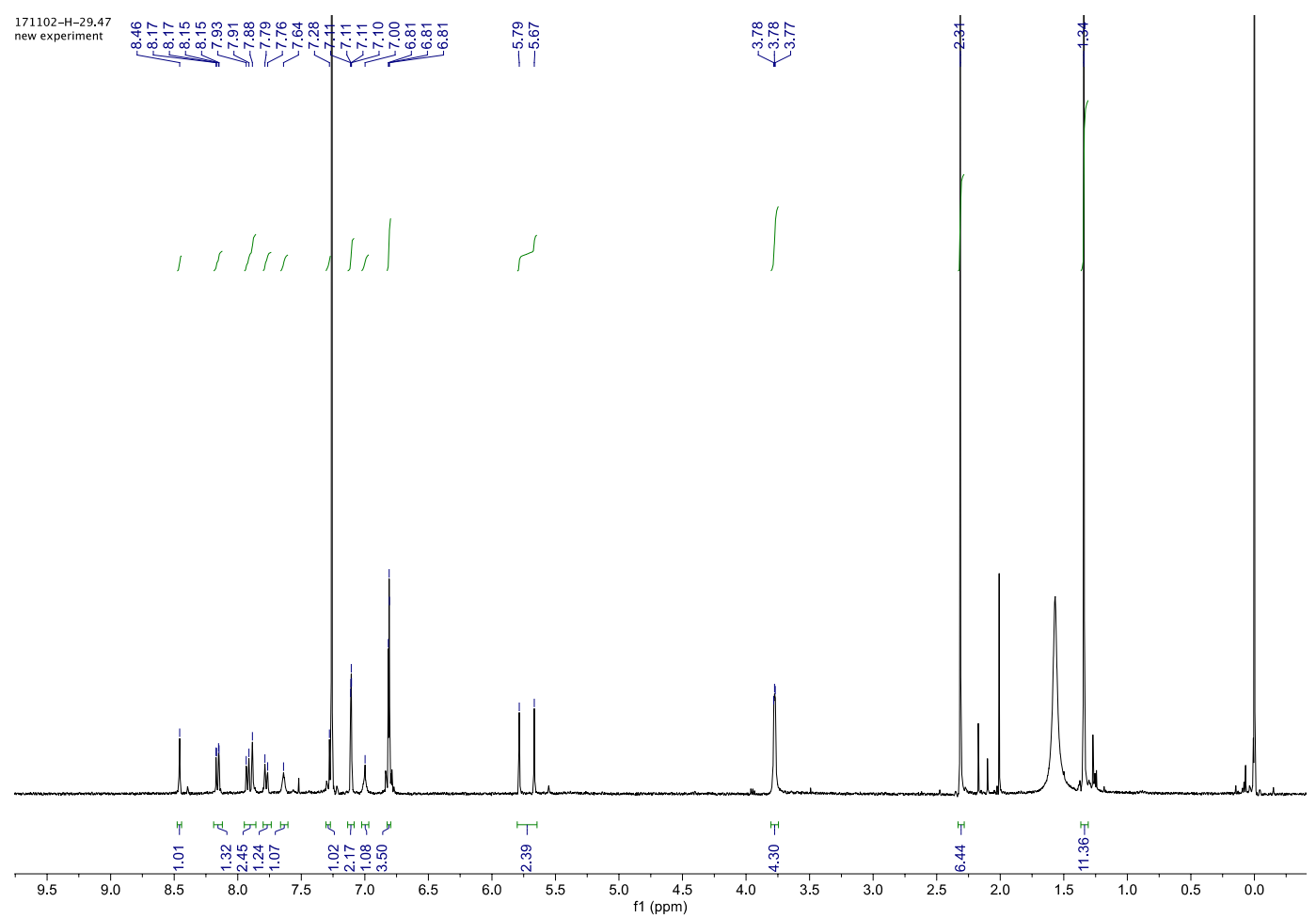

Supplementary Fig. $38{ }^{1} \mathrm{H}$ NMR of compound Hyp-L-2.

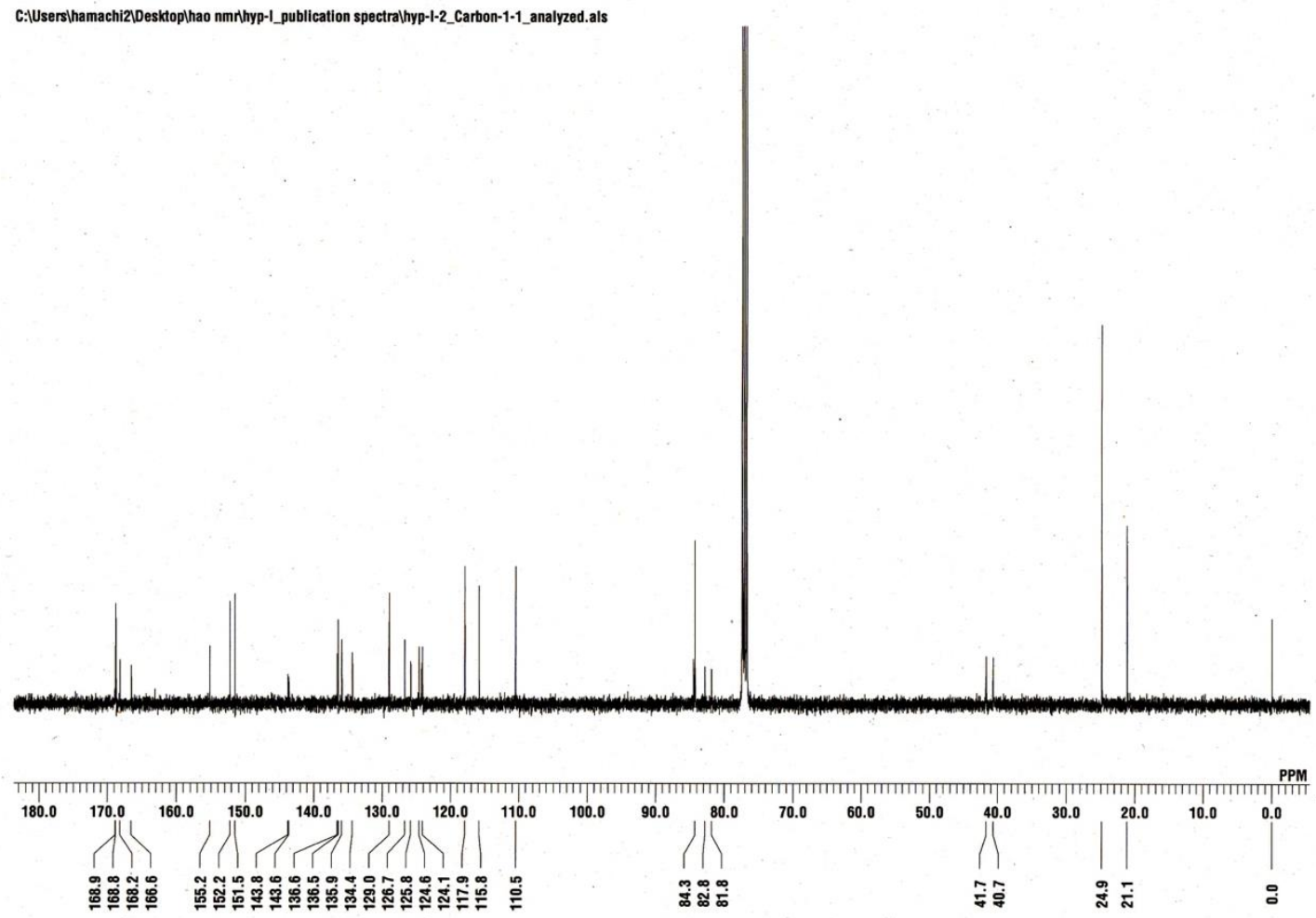

Supplementary Fig. $39{ }^{13} \mathrm{C}$ NMR of compound Hyp-L-2. 


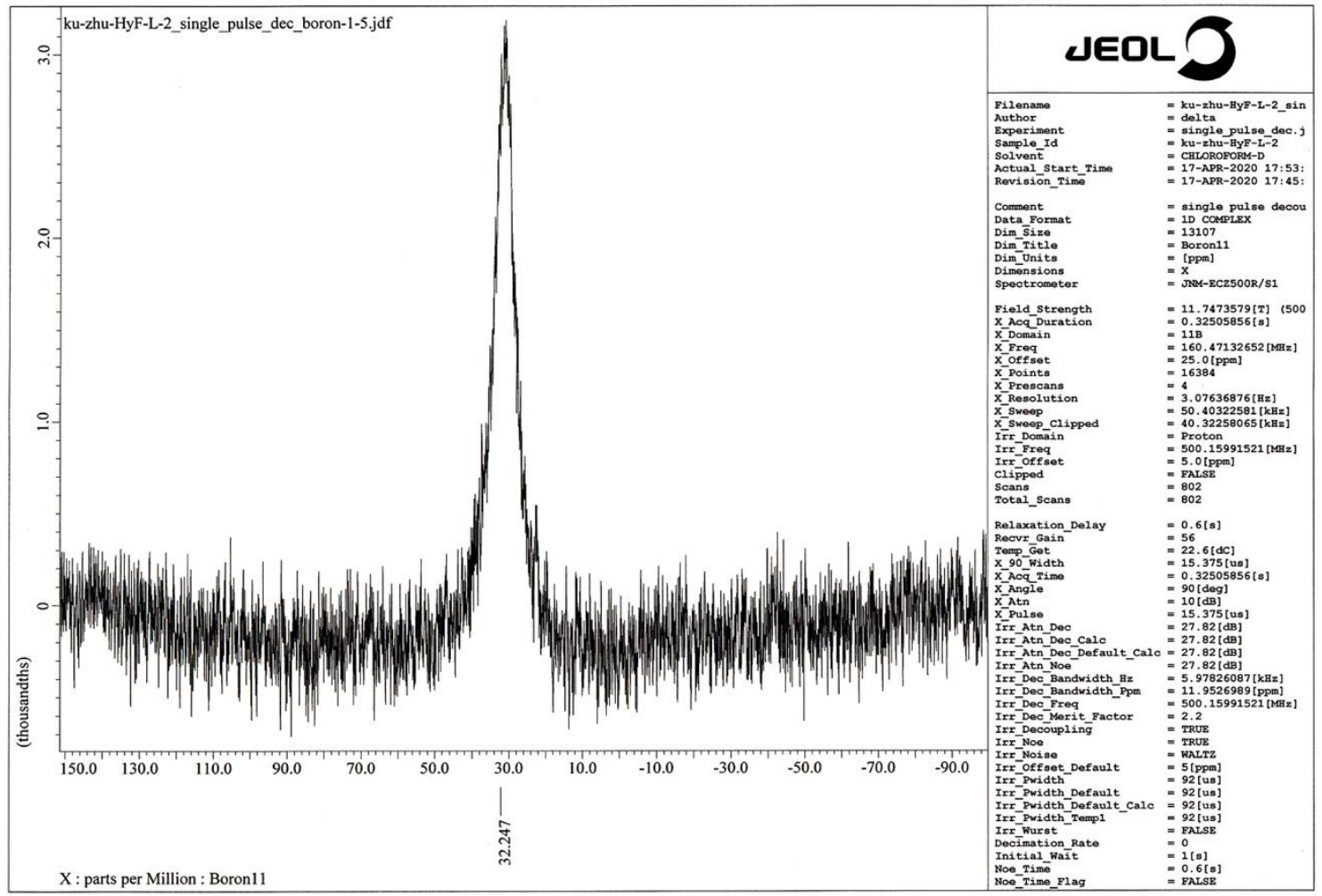

Supplementary Fig. $40{ }^{11}$ B NMR of compound Hyp-L-2.

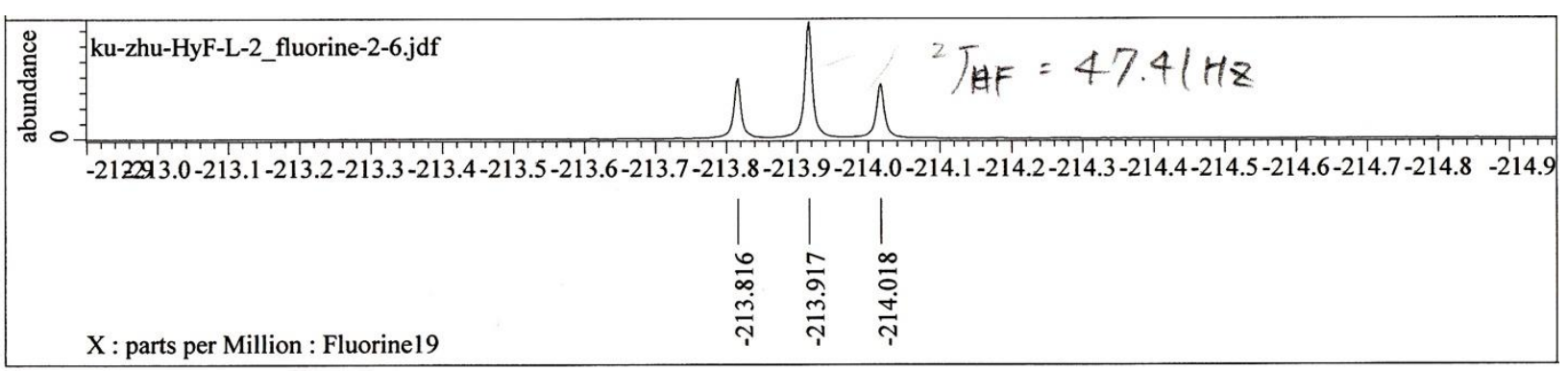

Supplementary Fig. $41{ }^{19}$ F NMR of compound Hyp-L-2. 


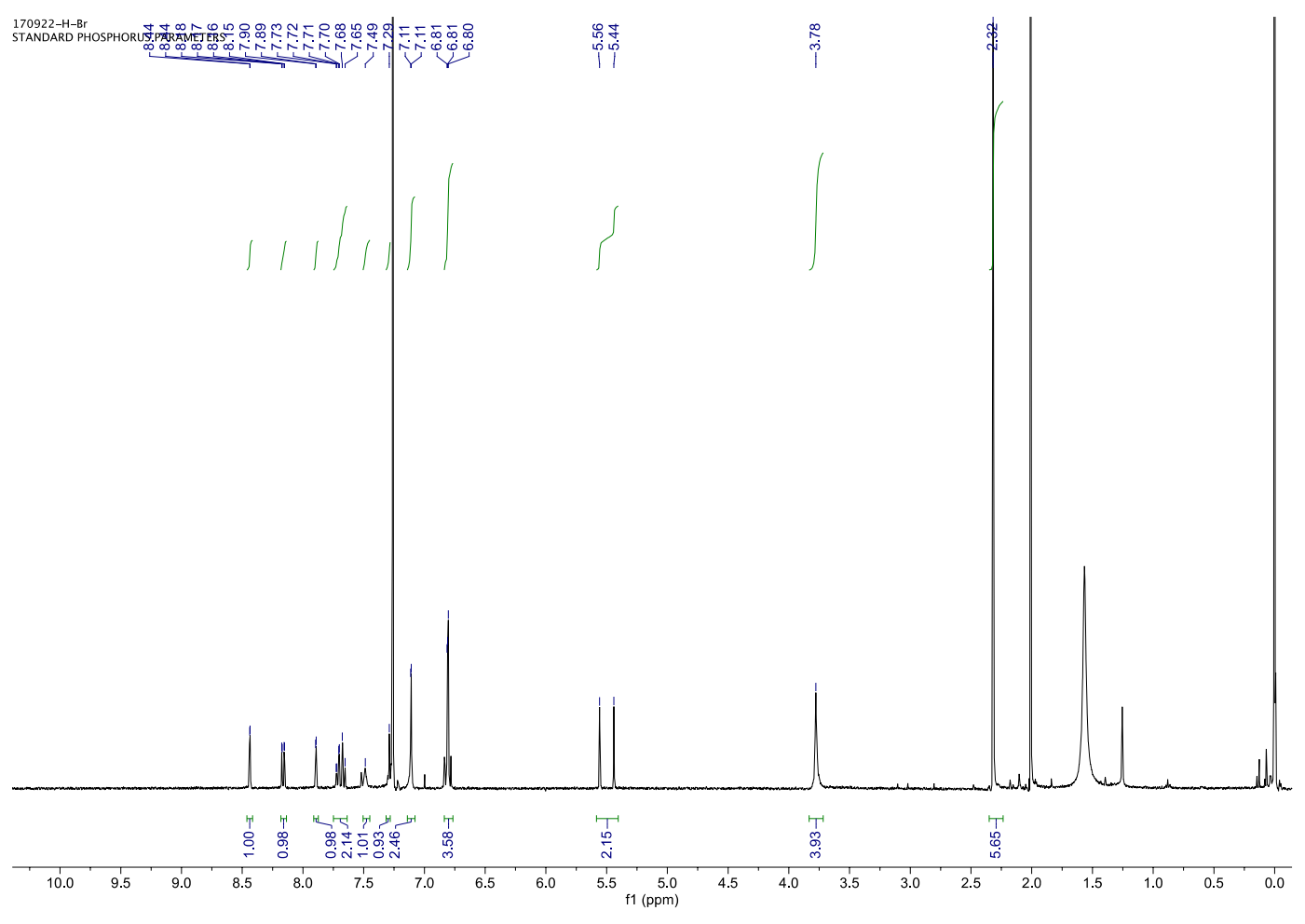

Supplementary Fig. $42{ }^{1} \mathrm{H}$ NMR of compound 8 . 


\section{References}

(S1) Lancaster, J. R. Diffusion of free nitric oxide. Method. Enzymol. 1996, 268, 31.

(S2) Winterbourn, C. C. Reconciling the chemistry and biology of reactive oxygen species. Nat. Chem. Biol., 2008, 4, 278.

(S3) Culbertson, C. T.; Jacobson, S. C.; Ramsey, J. M. Diffusion coefficient measurements in microfluidic devices. Talanta, 2002, 56, 365.

(S4) Weinert, E. E.; Dondi, R.; Colloredo-Melz, S.; Frankenfield, K. N.; Mitchell, C. H.; Freccero, M.; Rokita, S. E. Substituents on quinone methides strongly modulate formation and stability of their nucleophilic adducts. J. Am. Chem. Soc., 2006, 128, 11940.

(S5) Matsuo, K.; Nishikawa, Y.; Masuda, M.; Hamachi, I. Live-cell protein sulfonylation based on proximity-driven $N$-sulfonyl pyridone chemistry. Angew. Chem. Int. Ed. 2018, 57, 659.

(S6) Miki, T.; Fujishima, S.; Komatsu, K.; Kuwata, K.; Kiyonaka, S.; Hamachi, I. LDAI-based chemical labeling of intact membrane proteins and its pulse-chase analysis under live cell conditions. Chem. Biol. 2014, 21, 1013.

(S7) Tamura, T.; Ueda, T.; Goto, T.; Tsukidate, T.; Shapira, Y.; Nishikawa, Y.; Fujisawa, A.; Hamachi, I. Rapid labeling and covalent inhibition of intracellular native proteins using liganddirected $N$-acyl- $N$-alkyl sulfonamide. Nat. Commun. 2018, 9, 1870.

(S8) Miki, T.; Awa, M.; Nishikawa, Y.; Kiyonaka, S.; Wakabayashi, M.; Ishihama, Y.; Hamachi, I. A conditional proteomics approach to identify proteins involved in zinc homeostasis. Nat. Methods 2016, 13, 931.

(S9) Jin, S.; Wang, J.; Li, M.; Wang, B. Synthesis, evaluation, and computational studies of naphthalimide-based long-wavelength fluorescent boronic acid reporters. Chem. Eur. J. 2008, 14, 2795.

(S10) Chen, B.; Wang, P.; Jin, Q.; Tang, X. Chemosselective reduction and self-immolation based FRET probes for detecting hydrogen sulfide in solution and in cells. Org. Biomol. Chem. 2014, 12, 5629.

(S11) Jiang, J.; Zeng, D.; Li, S. Photogenerated quinone methides as protein affinity labeling reagents. ChemBioChem 2009, 10, 635.

(S12) Ni, A.; France, J. E.; Davies, H. M. L. Diversity synthesis using the complementary reactivity of rhodium (II)- and palladium (II)-catalyzed reactions. J. Org. Chem. 2006, 71, 5594. 
(S13) Brunet, A.; Aslam, T.; Bradley, M. Separating the isomers-efficient synthesis of the $\mathrm{N}$ hydroxysuccinimide esters of 5 and 6-carboxyfluorescein diacetate and 5 and 6-carboxyrhodamine B. Bioorg. Med. Chem. Lett. 2014, 24, 3186. 